RUNNING HEAD: Workplace Accommodations and Stigma

\title{
The Impact of Job Accommodations on Mental Health-Related Stigma
}

\author{
by \\ Christine Tulk
}

A thesis submitted to the Faculty of Graduate and Postdoctoral

Affairs in partial fulfillment of the requirements

for the degree of

Master of Arts

in

Psychology

\author{
Carleton University \\ Ottawa, Ontario
}

(C)2019

Christine Tulk 


\begin{abstract}
The current research examined the impact of accommodations for depression or anxiety (Study 1) and educational information (Study 2) on mental health-related stigma in the workplace. Participants read a scenario about a fictitious coworker returning to work following a leave of absence and answered items on negative stereotypes, unfairness, and emotional and behavioural responses. Scenarios varied the reason for leave [depression, anxiety, surgery] and accommodation [yes, no]. In Study 2, half of participants also read information about the employer's duty to accommodate. The results provided no evidence that accommodations or educational information influenced stigma. Rather, the results suggested that stigma towards accommodations for depression or anxiety may be the result of disclosing these mental health problems. Moreover, there was solid evidence that participants who endorsed negative stereotypes were more likely to believe that making changes for coworkers with health problems is unfair and to respond with negative emotions and behaviours.
\end{abstract}

Keywords: job accommodations, stigma, depression, anxiety 


\section{Acknowledgements}

I would first like to thank my thesis supervisor, Janet Mantler, for her support and guidance. I am very grateful to her for all the time she has dedicated to advising me and to providing constructive feedback that helped me progress through each stage of my thesis research. I am looking forward to continuing to learn under her supervision as I pursue my doctoral studies.

I would also like to extend my sincere thanks to my committee members: Kate Dupré, Merridee Bujaki, and Julie Blais. I am grateful for their time and insightful comments and for making my defense meeting such a positive experience.

Finally, I would like to express my gratitude to my family. Losing my father to cancer earlier this year has made it a particularly difficult time and their support and encouragement have helped me to persevere. My son, Jeremy, puts a smile on my face even at the most stressful of times, and my husband, Henry, inspires me to believe anything is possible. I am so grateful for their love and patience. 


\section{Table of Contents}

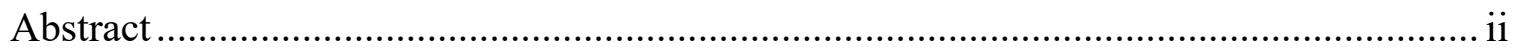

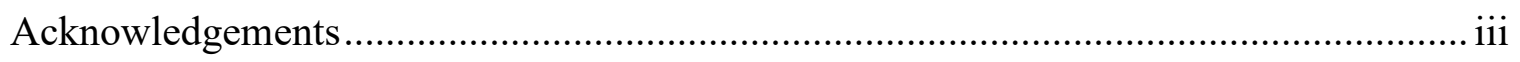

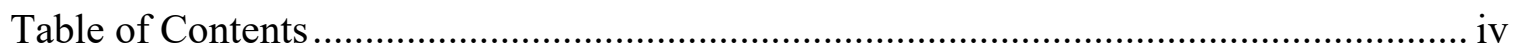

List of Tables ................................................................................................... vii

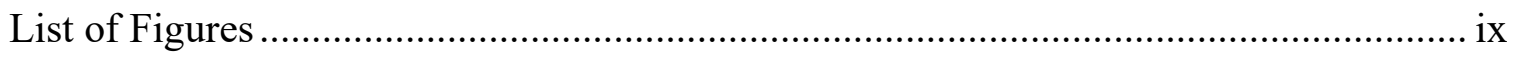

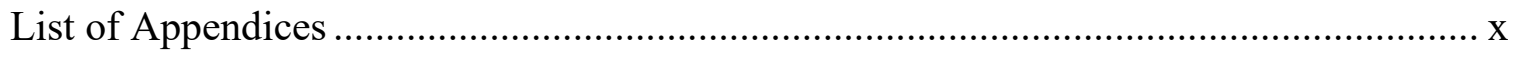

The Impact of Job Accommodations on Mental Health-Related Stigma ......................... 1

Depression and Anxiety in the Workplace ............................................................. 4

Accommodations ............................................................................................. 8

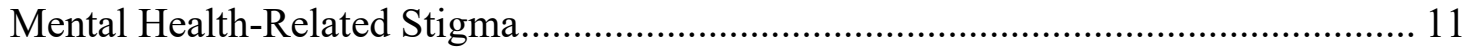

Negative Stereotypes in the Workplace ............................................................... 14

Perceived Unfairness from the Coworker Perspective ........................................ 18

Emotional Responses to Stereotypes and Unfairness ......................................... 20

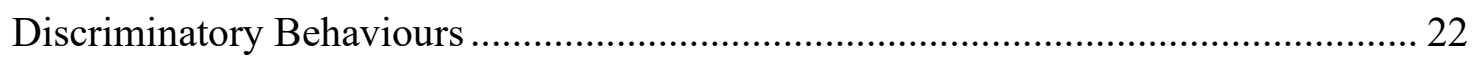

Reducing Stigma Through Education............................................................... 24

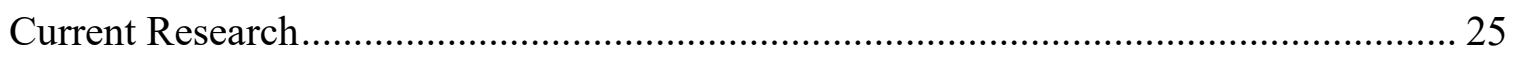

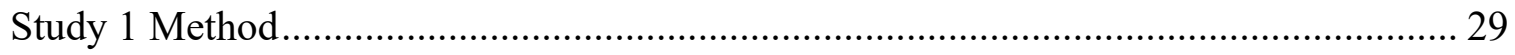

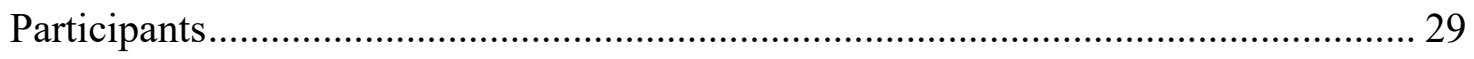

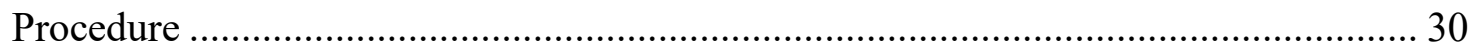

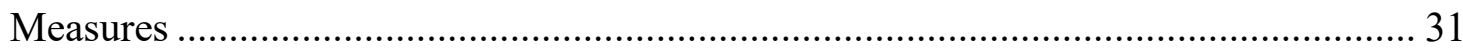

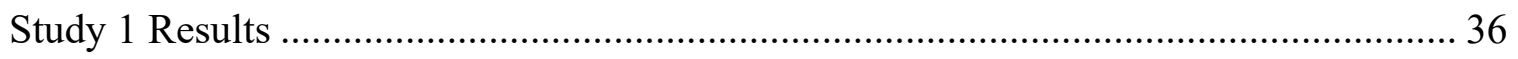

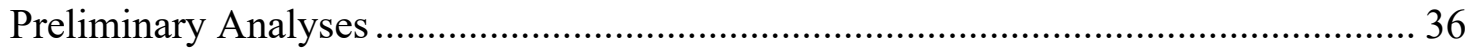


Impact of Accommodations on Negative Stereotypes................................................ 39

Mediation of Stereotypes and Emotional Responses by Perceived Unfairness............ 42

Impact of Emotions on Behavioural Outcomes ......................................................... 47

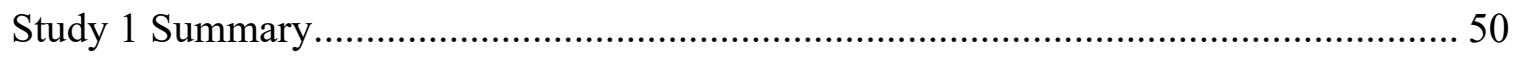

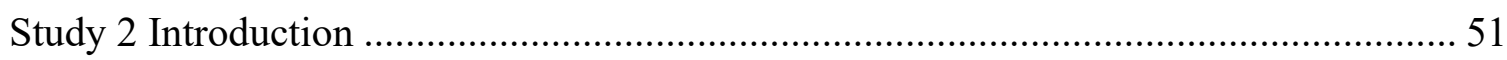

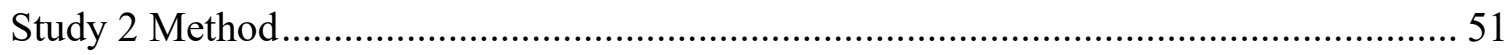

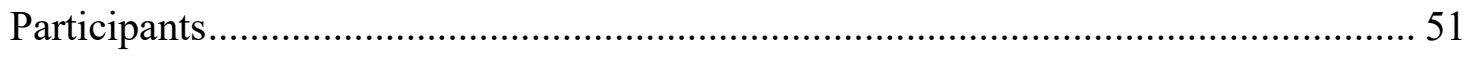

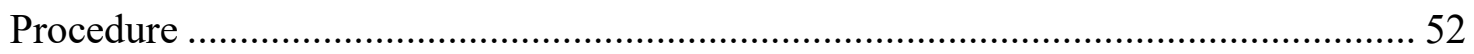

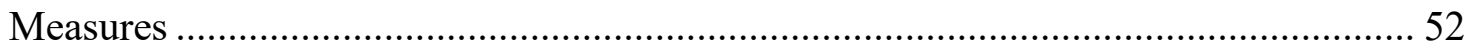

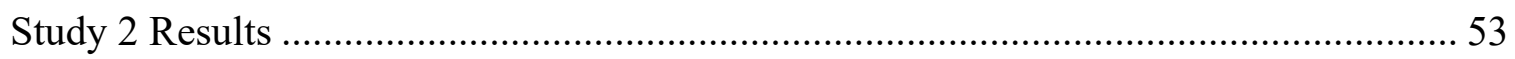

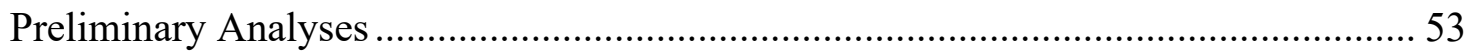

Impact of Accommodations and Info on Negative Stereotypes ................................... 56

Mediation of Stereotypes and Emotional Responses by Perceived Unfairness............ 61

Impact of Emotions on Behavioural Outcomes ........................................................... 65

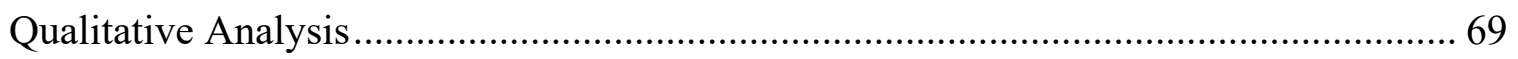

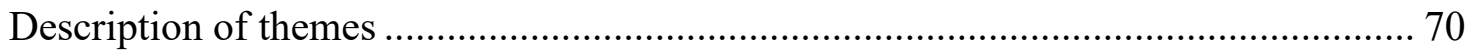

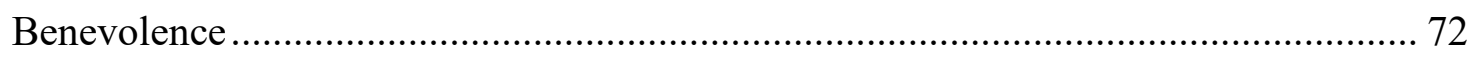

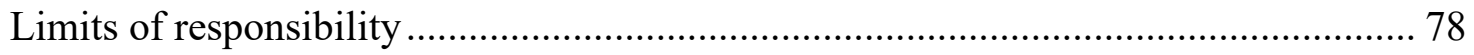

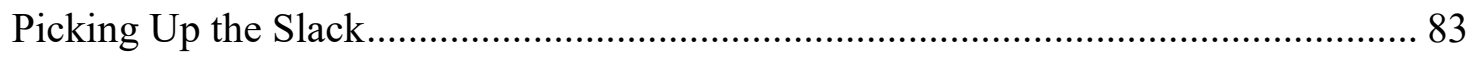

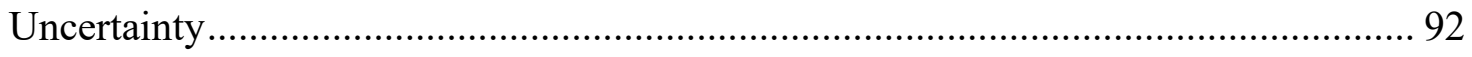

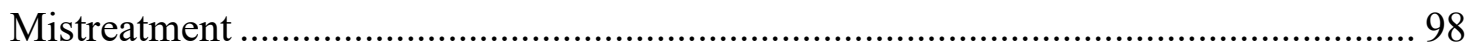

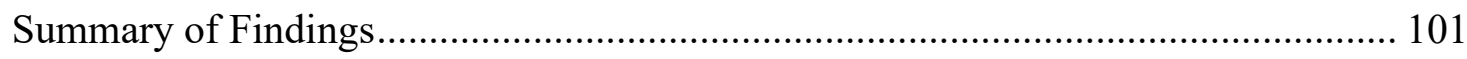

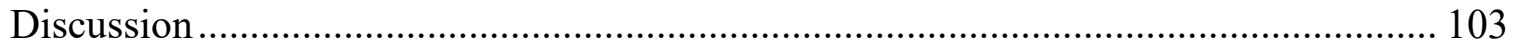




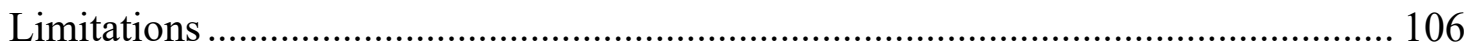

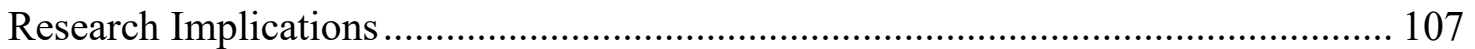

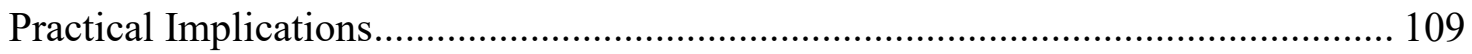

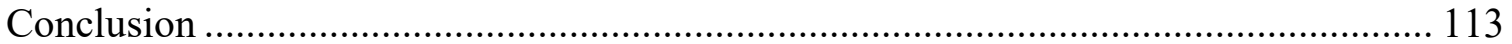




\section{List of Tables}

Table 1. Items for negative stereotypes and perceived unfairness................................ 34

Table 2. Means, Standard Deviations, and Correlations for Key Variables (Study 1) ..... 38

Table 3. Distribution of Males and Females according to Supervisor Status (Study 1)... 38

Table 4. Two-Way Analysis of Variance for Gender and Supervisor Status (Study 1) ... 38

Table 5. Regression Analysis for Malingering and Ability (Study 1) .......................... 41

Table 6. Regression Analysis for Blameworthy and Dangerous (Study 1) .................... 42

Table 7. Moderated Mediation Analyses using Malingering as Antecedent (Study 1) .... 45

Table 8. Moderated Mediation Analyses using Ability as Antecedent (Study 1) ........... 45

Table 9. Moderated Mediation Analyses using Blameworthy as Antecedent (Study 1).. 46

Table 10. Moderated Mediation Analyses using Dangerous as Antecedent (Study 1) .... 46

Table 11. Indirect Effects of Stereotypes on Anger, Fear, and Sympathy (Study 1)....... 47

Table 12. Regression Results for Willingness to Socialize (Study 1) .......................... 49

Table 13. Regression Results for Willingness to Give a Recommendation (Study 1) ..... 49

Table 14. Means, Standard Deviations, and Correlations for Key Variables (Study 2) ... 55

Table 15. Distribution of Males and Females according to Supervisor Status (Study 2). 56

Table 16. Regression Analysis for Malingering and Ability (Study 2) ......................... 58

Table 17. Regression Analysis for Blameworthy and Dangerous (Study 2) ................... 59

Table 18. Mediation Analyses using Malingering as Antecedent (Study 2) ................... 63

Table 19. Mediation Analyses using Ability as Antecedent (Study 2) .......................... 63

Table 20. Mediation Analyses using Blameworthy as Antecedent (Study 2) ................. 64

Table 21. Mediation Analyses using Dangerous as Antecedent (Study 2)..................... 64

Table 22. Indirect Effects of Stereotypes on Anger, Fear, and Sympathy (Study 2)....... 65 
Table 23. Regression Results for Willingness to Socialize (Study 2) ........................... 68

Table 24. Regression Results for Willingness to Give a Recommendation (Study 2) ..... 68

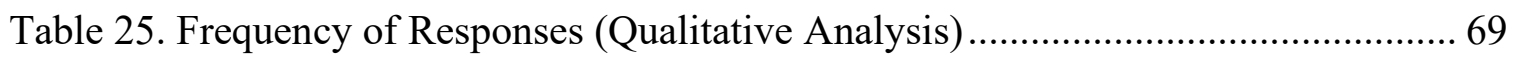




\section{List of Figures}

Figure 1. Proposed Moderation Model for Negative Stereotypes .................................. 27

Figure 2. Proposed Mediated Moderation Model for Emotional Responses..................... 28

Figure 3. Proposed Model for Behavioural Responses.................................................... 28

Figure 4. Interaction between Reason for Leave and Accommodation for Ability ........... 60

Figure 5. Thematic Map for Qualitative Analysis ........................................................... 71 


\section{List of Appendices}

Appendix A. Study 1 Recruitment Notice ………………..................................... 128

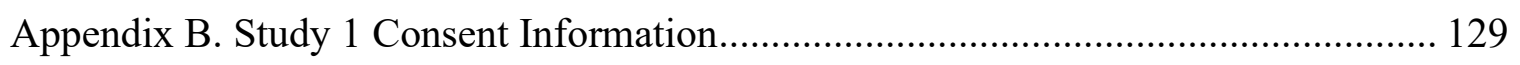

Appendix C. Study 1 and Study 2 Questionnaire ……………………....................... 131

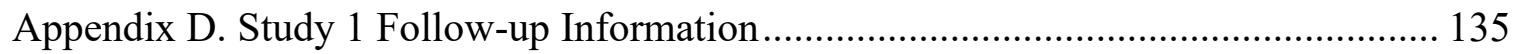

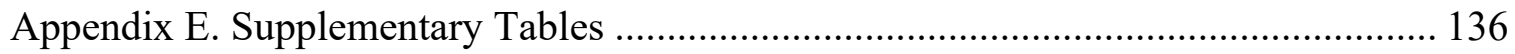

Appendix F. Study 2 Recruitment Notice................................................................ 141

Appendix G. Study 2 Consent Information ............................................................ 142

Appendix H. Study 2 Follow-up Information.............................................................. 144 


\section{The Impact of Job Accommodations on Mental Health-Related Stigma}

According to the World Health Organization (2016), common mental health

disorders such as anxiety and depression are the leading cause of disability and lost work productivity in higher income countries such as Canada. Although workplace prevalence rates are difficult to determine because individuals frequently avoid disclosing mental health problems, population-level data suggests that depression and anxiety are quite prevalent amongst working age Canadians (Canadian Medical Association, 2008; Dewa et al., 2004) and Americans (Center for Behavioral Health Statistics and Quality, 2017). Major depressive disorder is the leading reason for mental health-related disability leave in Canada (Dewa, Goering, Lin, \& Paterson, 2002), and anxiety disorders are believed to have comparable negative impacts on work (Lim, Sanderson, \& Andrews, 2000). Depression and anxiety result in both emotional and financial distress for individuals and their families, as well as high costs to organizations and the Canadian economy (Dewa \& McDaid, 2011; Mental Health Commission of Canada, 2017), making it crucial to better understand how to improve work-related outcomes for individuals with these mental health problems.

Although prevention and intervention efforts to reduce the occurrence and severity of workplace mental health problems have been the focus of an increasing amount of research in the field of occupational health psychology, less attention has focused on the process of job accommodations for such issues (Kelloway, 2017), which involve reasonable modifications to the job or workplace for the purpose of diminishing barriers to employment (Chow, Cichocki, \& Croft, 2014). This is surprising given that legislation has been enacted in many countries such as Canada (Canadian Human Rights 
Act, 1985) and the United States (Americans with Disabilities Act, 1990) to promote accommodations as a means of providing equal opportunities for those with mental and physical disabilities. Examples of accommodations meant to address the deficits in cognitive, emotional, or social functioning associated with anxiety and depression include technology aids to enhance memory, more structured supervision, being paired with a coworker for social support, using dividers to reduce noise and visual distractions, and reduced workload or hours (Peer \& Tenhula, 2011). These types of modifications are intended to help individuals on disability leave return to work by overcoming specific functional limitations until the individual can return to full regular duties (Schultz, Duplassie, Hanson, \& Winter, 2011).

Although there has been limited research studying the impact of accommodations, there is some evidence to suggest positive outcomes including improved interpersonal relationships with colleagues and supervisors (Shultz et al., 2011), reduction in symptoms, and successfully returning to work following disability leave (Chow et al., 2014; Peer \& Tenhula, 2011). In addition, the Job Accommodation Network, an American agency intended to assist employers with the implementation of accommodations, has reported benefits to employers such as reduced employee turnover and increased profitability (Job Accommodation Network, 2017). There is also evidence to suggest, however, that accommodations can lead to negative outcomes such as mistreatment by coworkers and supervisors (Kensbock, Boehm, \& Bourovoi, 2017), which rehabilitation professionals and academics (Schultz et al., 2011) attribute to stigma. 
Individuals with mental health problems are often stigmatized as less capable, personally weak, and dangerous (Krupa, Kirsh, Cockburn, \& Gewurtz, 2009), and there is a perception that disorders with less visible symptoms like anxiety and depression are illegitimate illnesses that can be faked for preferential treatment at work (Krupa et al., 2009; Parliament of Canada, 2006). Stigma theory (Goffman, 1963; Link \& Phelan, 2001) suggests that accommodations would likely increase perceptions of difference, resulting in increased stereotyping and stronger negative emotional and behavioural responses. Moreover, it is likely that some colleagues perceive accommodations to be unfair because they perceive this to be a form of special treatment (Colella et al., 2001) and because they have little input into accommodation processes (Colella, Paetzold, \& Belliveau, 2004). Hence, accommodations are likely to have benefits for both employees and organizations, but may also have unintended consequences such as increased stigma.

There has been very little research on stigma associated with accommodations for mental health problems, and no research to my knowledge examining whether accommodations increase stigma beyond the level experienced as a result of disclosing depression or anxiety. To address this knowledge gap, my research examined differences in perceived malingering, work ability, dangerousness, and blameworthiness for a fictitious colleague who either received a job accommodation or returned to normal work duties following a leave of absence for surgery, depression, or anxiety. I also examined whether endorsement of these negative stereotypes was associated with perceived unfairness, emotional responses, and willingness to socialize with or recommend the colleague for a job. Finally, considering the potential benefits of successful accommodations for both individuals and organizations, I investigated whether providing 
educational information to participants regarding legal obligations of employers and the purpose of accommodations would improve attitudes towards job accommodations.

\section{Depression and Anxiety in the Workplace}

Prevalence in the working population. According to psychiatric research on mental disorders (Everett, 2004), there are two broad categories of people with mental disorders to consider in the context of employment: those who have worked very little or not at all and those who are in the workforce attempting to avoid negative employmentrelated consequences. The first category tends to include individuals with earlier onset disorders (e.g., schizophrenia, autism), which can result in complete exclusion from the workforce because of disruptions in training and highly visible symptoms. The second category tends to include those with less severe, less visible disorders (e.g., depressive disorders, anxiety disorders) who are in the workforce but struggling, with or without the knowledge of their employers (Parliament of Canada, 2004). Whereas the primary concern for the first category is how to gain entry to the workforce, the primary concern for the second category is how to remain part of, or return to, the workforce (Everett, 2004).

Although a substantial portion of employed individuals with mental disorders are likely to have a depressive or anxiety disorder, exact prevalence rates are unclear (Dewa et al, 2004). In 2002 (Statistics Canada, 2004), 5\% of 15 to 64 year olds reported having major depressive disorder and 6\% reported having an anxiety disorder $(3.4 \%$ social phobia, $0.8 \%$ agoraphobia, $1.8 \%$ panic disorder) in the preceding 12 months. In 2012 (Statistics Canada, 2013), 5\% of 25 to 64 year olds reported having major depressive disorder and 3.0\% reported having generalized anxiety disorder in the preceding 12 
months. However, individuals do not always disclose diagnosed or suspected mental disorders (Dewa et al., 2004) because of stigma (MacDonald-Wilson et al., 2011), particularly amongst certain cultural groups (Augsberger, Yeung, Dougher, \& Hahm, 2015). Moreover, statistics specific to employment may not include individuals who have retired rather than claim disability or individuals counted as being on disability for a physical illness that is comorbid with depression or anxiety (Harvey \& Henderson, 2009).

Impact on work performance. Although considered less severe than other mental disorders such as schizophrenia, both depression and anxiety can be debilitating. The Diagnostic and Statistical Manual of Mental Disorders (5th ed.; DSM-5; American Psychiatric Association, 2013) includes a range of disorders featuring depressed mood (i.e., bipolar and related disorders, depressive disorders) or excessive fear and anxiety (i.e., anxiety disorders, obsessive-compulsive and related disorders, and trauma- and stressor-related disorders). One common criterion across all disorders, however, is that symptoms result in significant impairment in an important area of life such as work (e.g., not going to work, impaired work function).

The impact of reduced work functioning for individuals with depression and anxiety is reflected in rates of presenteeism (i.e. attending work but producing less or underperforming) more so than absenteeism (i.e., not attending work), with comorbid depression and anxiety being the most detrimental. For example, Lim et al. (2000) found that, over the previous 28 days, individuals with depressive disorders lost an average of 1.6 days of work and reduced productivity on 5.3 days. Individuals with anxiety disorders lost an average of 0.6 days and reduced productivity on 2.7 days. Finally, individuals with comorbid depressive and anxiety disorders had the most detrimental impact on work 
functioning, contributing to an average of 5.7 lost work days and 7.2 reduced productivity days. In another study, Dewa and Lin (2000) analyzed disability data collected from 9,953 randomly selected households from across Ontario and found that, compared to respondents with no chronic physical or mental health problems in the last 30 days, respondents with depressive or anxiety disorders were more likely to indicate an increase in the number of work days requiring an extreme amount of effort to function normally but not an increase in the number of partial or lost work days. Similar to other studies (e.g., Lim et al., 2000), Dewa and Lin also found that presenteeism and extra effort were greatest for respondents with more than one mental health disorder.

There is limited data on how symptoms of depression and anxiety impact work functioning; however, work attendance and productivity are likely affected by cognitive, emotional, and interpersonal limitations (Peer \& Tenhula, 2011), as well as difficulties with time management and coping with aspects of the physical work environment (Wald, 2011). For example, cognitive symptoms involving attention, memory, and verbal learning are consistently associated with reduced work functioning (e.g. McGurk \& Wykes, 2008) such as difficulty focusing on tasks (Wang et al., 2004). Reduced concentration, feeling easily distracted, fatigue, and trouble sleeping can be particularly hard on motivation and are strongly linked with presenteeism (Lerner et al., 2011). Furthermore, symptoms such as irritability and withdrawal from or avoidance of social interactions can result in interpersonal difficulties, which have been found to negatively impact work productivity (Gates \& Akabas, 2011). Moreover, for certain anxiety disorders, fears specific to the environment (e.g., elevators, enclosed spaces) may cause difficulty getting to and around the workplace (Wald, 2011). In short, there are numerous 
ways that symptoms of depression or anxiety can impact work performance.

When considering the impact of symptoms on work productivity, it is important to consider symptom severity for both depression (Lerner \& Henke, 2008) and anxiety (Erickson et al., 2009). Following their analysis of longitudinal data following youths into their adult employment years, Dooley, Prause, and Ham-Rowbottom (2000) concluded that more severe depressive symptoms at baseline predicted underemployment at subsequent time points. Moreover, Erickson et al. (2009) compared groups whose anxiety symptoms measured by the Beck Anxiety Inventory were classified as either minimal/mild or moderate/severe and found that work performance was impaired on a range of instruments (e.g., Work Limitations Questionnaire, Work Performance Scale) and that self-perceived potential for job advancement was greater for the minimal $/ \mathrm{mild}$ group. Given that severity of symptoms for both depression and anxiety can fluctuate, with some individuals experiencing varying levels of symptom severity over time and some individuals experiencing only one episode of impairment before returning to normal work functioning (Rogers \& MacDonald-Wilson, 2011), it can be difficult to predict when and for how long work performance will be affected.

To summarize, both depression and anxiety appear to be fairly common amongst the working population, and are both debilitating and costly to individuals and organizations alike. Reduced work productivity is an important concern for symptomatic employees who manage to attend work but experience functional limitations that interfere with work productivity. In addition, the wide variation in symptom severity experienced by those with depression or anxiety, the episodic nature of symptoms, and the potential for delayed improvement of work functioning following symptom improvement make it 
difficult to predict the timing of impaired work function. This knowledge becomes especially important when considering individuals whose symptoms are severe enough to require a leave of absence, because once symptoms have improved sufficiently, those individuals who attempt to return to work are likely to still be experiencing at least some level of reduced work function (Adler et al., 2006, Bender \& Farvolden, 2008). It is, therefore, important to better understand potential ways to help individuals overcome their limitations in order to prevent distress and additional leaves of absences.

\section{Accommodations}

The role of job accommodations. Research to improve workplace mental health has been described has having three main categories of activities: prevention, intervention, and accommodation (Kelloway, 2017). Prevention focuses on creating a work environment that promotes optimal health to keep employees from developing mental health problems. Interventions are activities or programs designed with the knowledge that, despite best efforts in prevention, mental health problems will continue to be present in the workplace because factors outside of work can contribute. Similar to the implementation of programs in schools where many school-aged children can be targeted, programs in workplaces can target many working-aged adults by providing information and services to reach those who may be struggling with a mental health problem.

In contrast to prevention and intervention, accommodation focuses on changes in the workplace at the individual-level and are tailored to meet the needs of each individual (Shultz et al., 2011). Defined by Chow et al. (2014) as "an adjustment in the work environment that enables an individual with a disability to participate fully in an 
employment setting," (p. 1126) accommodation is about recovery and rehabilitation with the primary goal of helping individuals return to full regular duties (Schultz et al, 2011). Although accommodation has received far less attention than prevention and intervention in the field of psychology (Kelloway, 2017), occupational rehabilitation researchers and practitioners (Schultz et al., 2011) view accommodations as an important means of helping individuals with residual symptoms return to work following leaves of absence for mental health problems and to stay at work during episodes of increased symptom severity.

Types of accommodations. In general, accommodations can be categorized as changes to the work environment, changes to job tasks or work requirements, social support and facilitated communications, or using technology aids (Schultz et al., 2011). The type and number of accommodations that are most useful, however, depends on the functional limitations (e.g. cognitive, social, or motivational) that the individual might be experiencing and the type of changes that are possible in a particular work environment. According to Peer and Tenhula (2011), examples of accommodations for individuals with cognitive symptoms such as poor concentration or ineffective time management include giving more time for tasks requiring attention to detail, relocating the individual to a quieter workspace, providing dividers to reduce distractions, or breaking complex tasks into smaller steps. In contrast, individuals experiencing interpersonal limitations as a result of social withdrawal or irritability can benefit from accommodations such as increased job structure, closer supervision, or job coaches. Finally, increasing breaks, providing supportive feedback, and adjusting work schedules are examples of accommodations that can be considered for individuals experiencing motivational 
limitations associated with symptoms such as low energy and psychomotor agitation.

One particular accommodation used to help employees return to work following leaves of absence for depression or anxiety is graded activity. Peer and Tenhula (2011) describe graded activity as introducing the returning employee back to the workplace with reduced hours and workload in combination with other job accommodations so that the employee is able to return to work while symptomatic. They also summarize evidence from studies by van der Klink, Blonk, Schene, and van Dijk (2003) and Blonk, Brenninkmeijer, Lagerveld, and Houtman (2006) showing that a combination of cognitive behavioural therapy and graded activity resulted in shorter return-to-work times and reduced sick days. This is considered important because, once an individual has been on leave for an extended period of time, the likelihood of ever returning to work decreases substantially (Blank, Peters, Pickvance, Wilford, \& MacDonald, 2008) and unemployment is associated with a lower quality of life (Center, 2011).

Benefits of accommodations. There are limited studies demonstrating effectiveness of accommodations for mental health problems; however, existing evidence suggests benefits for both individuals and employers. Vocational rehabilitation counsellors report that interpersonal difficulties with coworkers and supervisors often improve during the accommodation process as a result of increased understanding that performance difficulties attributed to incompetence were in fact related to exacerbated symptoms of depression (Schultz et al., 2011). In addition, the Job Accommodations Network, a service provided by the U.S. Department of Labor, reports that employers who have accommodated employees with disabilities have reported benefits including retaining valued employees, increasing productivity, reducing costs associated with 
employee turnover, savings on insurance costs, increased workplace safety, increased profitability, and increased customer base (Job Accommodation Network, 2017); however, considering that the function of the Job Accommodation Network is to assist employers with implementation of accommodations, it is perhaps not surprising that they highlight the benefits of accommodations.

Despite the potential to help individuals function more fully at work, there is also evidence that requesting and receiving an accommodation can have negative consequences. Although evidence is scant, experts with experience in occupational rehabilitation point to stigma experienced by individuals who receive accommodations as a barrier to successful implementation of accommodations (Shultz et al., 2011). Kensbock et al. (2017) conducted 15 focus group interviews with 73 employees from a large German manufacturing company who were part of the company's accommodation program, which had been established in response to an increased number of mental and physical health problems perceived as reducing work performance. Participants were asked to write about any positive or negative aspects of the accommodation process and then discuss these aspects as a group. Approximately $24 \%$ of codes generated for the template analysis referenced discrimination, bullying, and mistreatment from both coworkers and supervisors as a perceived consequence of their accommodation, leading to affective reactions including uncertainty, stress, and strain. The study did not, however, examine whether participants believed this mistreatment was a reaction to their accommodation or to the health problem that led to their accommodation.

\section{Mental Health-Related Stigma}

Although there is variation across domains of study (Link \& Phelan, 2001), 
psychology literature most frequently defines stigma as "an attribute or characteristic that conveys a social identity that is devalued in a particular social context" (Crocker, Major, \& Steele, 1998, p. 505). This definition is based on Goffman's (1963) seminal work on stigma, which proposed that individuals with "blemishes of individual character" (p. 2), such as mental illness, are quickly categorized as different and then associated with a range of negative stereotypes, leading to status loss and discrimination.

Research on stigma is generally undertaken from the perspective of either the stigmatized or the stigmatizer. From the perspective of the stigmatized, stigma encompasses experiences such as being rejected, treated as incompetent, or generally being viewed unfavourably (Wahl, 1999), as well as discrimination in educational and work contexts (King, 2007; Link, 1987). Further, when stigmatized individuals internalize dominant cultural beliefs, they can self-stigmatize, which leads to feelings of shame and lowered self-esteem (Corrigan et al., 2015). From the perspective of the stigmatizer, stigmatized individuals are associated with undesirable characteristics. For example, stigma associated with depression is conceptualized as perceptions that depression results from personal weakness rather than illness and that depressed individuals are unpredictable, dangerous, and unsuitable as employees and leaders (Griffiths et al., 2004). Because the primary goal of the present research was to examine whether stigma towards coworkers with depression or anxiety impacts the success of job accommodations, I chose to focus on the perspective of the stigmatizer in order to determine whether coworkers who are accommodated are likely to experience stigma beyond what would be expected following disclosure of these mental health problems.

To examine how mental health-related stigma functions in the context of job 
accommodations, the present research proposes a model of workplace stigma that is broadly based on Frijda's (1986) appraisal theory of emotions. According to this theory, appraisals of the meaning of a situation with respect to our own personal concerns elicit particular emotional responses, which encompass not only our subjective feeling of emotions (e.g., feeling angry) but also motivational components and action tendencies that guide our behaviour. Appraisals are made on a number of dimensions (Frijda, Kuipers, \& ter Schure, 1989), such as whether the situation or event is conducive to goals or unfair, and the output of these appraisals are emotional responses.

Applying these concepts to workplace mental health-related stigma, an event such an individual returning to work following a leave of absence for depression or anxiety triggers an appraisal of what this means for our goals and well-being. Endorsement of negative stereotypes (e.g., dangerousness) is likely to lead to an appraisal that having the individual with depression or anxiety as part of the work environment is not goalconducive or fair to the self or the team. Moreover, whereas appraisal that the situation is beyond our control is likely to elicit fear (e.g., uneasiness about the possibility of an increased workload), appraisal that someone else is responsible (e.g., the individual with depression) is likely to elicit anger (e.g., irritation at having to deal with this person) (Frijda et al., 1989). Finally, emotional responses such as anger and fear also involve the action tendencies to reject or to distance oneself from the individual (Frijda et al., 1989) and, therefore, can lead to behaviours like avoiding the individual in social situations.

Because accommodations are typically visible to others in the workplace and are likely to draw attention and increased scrutiny towards the individual being accommodated, differences are more salient, which is likely to increase stereotyping 
(Goffman, 1963; Link \& Phelan, 2001); consequently, appraisals of job accommodations may be more negative. Despite the possibility that accommodations may increase experiences of stigma for employees with mental health problems, however, there is no existing research to my knowledge that compares stigma towards coworkers who have or have not received a job accommodation for mental health reasons. In practice, the need for disclosure and the increased likelihood that coworkers deduce or speculate the reason for accommodation to be for a mental health problem is confounded with receiving the accommodation. As a consequence, there is a gap in the research regarding whether experiences of stigma are a result of receiving an accommodation or of disclosure.

To summarize, seminal work by Goffman (1963) proposed that stereotyping is the basis for stigma and ensuing research has generally agreed with this argument. According to Frijda's (1986) appraisal theory of emotions, appraisals of the situational meaning and relevance for our own goals elicit emotional responses, which include tendencies toward action that shape our behaviour. Based on this theory, I propose that negative stereotypes contribute to appraisals that having an individual with depression and anxiety as a coworker is not goal-conducive and, importantly, is unfair to the self or the team. These appraisals then trigger negative emotional responses (e.g., anger, fear), which include tendencies to avoid and to reject the individual.

\section{Negative Stereotypes in the Workplace}

There are four negative stereotypes associated with depression and anxiety that can have important consequences for stigma in the workplace. Similar to other life domains, individuals with depression and, to a lesser extent, anxiety are considered to be more dangerous than the average individual. Further, both depression and anxiety are 
associated with the stereotype that individuals with these mental health problems have a weak character and are to blame for their situation. More specific to the workplace, individuals with depression or anxiety are stereotyped as being less able to perform their work tasks and as malingering in order to get out of work (Krupa et al., 2009).

Dangerous. Although the stereotype of dangerousness is most frequently applied to people with schizophrenia, those with depressive disorders (Angermeyer et al., 2014) and to a lesser extent anxiety disorders (Curcio \& Corboy, 2019) are also believed to be dangerous. Despite the fact that mass shootings account for a small percentage (e.g., less than $1 \%$ in the United States) of gun-related homicides, there is frequent and dramatic media coverage of mass shootings in schools and workplaces that often focuses on depression as the cause of violence (Knoll \& Annas, 2016), and exposure to media depictions of individuals with mental disorders as violent is associated with increased beliefs in dangerousness (Jorm, Reavley, \& Ross, 2012).

Indeed, Romer and Bock (2008) found that $62.3 \%$ of participants believed a person with untreated depression was more likely to be violent compared to other people, and $28.1 \%$ believed a person with depression was more likely to be violent even after receiving treatment. Moreover, a vignette study conducted in Alberta found that $22 \%$ of 3,047 participants between the ages of 18 and 74 believed that the individual described as depressed would be dangerous (Cook \& Wang, 2010). In comparison, less than 5\% of 617 respondents to a vignette survey believed that a fictitious character with generalized anxiety disorder was a danger to others (Griffiths, Batterham, Barney, \& Parsons, 2011).

Consequently, coworkers who know that an individual has depression or anxiety may be speculating as to whether that individual is likely to be dangerous, and decisions 
may be influenced by whether or not the individual has been treated. Because accommodations are meant to help employees whose symptoms are contributing to functional limitations, it is possible that accommodations may signal to coworkers that the individual's treatment has not been entirely successful and, therefore, strengthen fears that the individual might harm them or other colleagues.

Blameworthy. The idea that individuals are to blame for their mental health problems because of weak character or irresponsible behaviour is one of the more persistent stereotypes associated with both depression and anxiety. Population-level studies generally find that the public blames individuals with depression or anxiety more than they blame individuals with disorders like schizophrenia (e.g., Wood, Birtel, Alsawy, Pyle, \& Morrison, 2014), possibly because depression and anxiety are viewed as personal weakness rather than as a mental health problem (Curcio \& Corboy, 2019; Jorm $\&$ Wright, 2008). Moreover, certain anxiety disorders like social anxiety disorder are particularly likely to be viewed as weakness (Curcio \& Corboy, 2019; Jorm \& Wright, 2008), possibly because of confusion with character traits like shyness (Davidson, 2005).

Although the findings on blame are primarily from population-level studies, it is reasonable to believe that the stereotype of blameworthiness also applies to the workplace. Furthermore, individuals who are stereotyped as having character weaknesses (e.g., can't handle pressure, too shy) may be particularly disadvantaged in an achievement context such as work where strength of character and good social skills are valued attributes. It is, therefore, important to understand whether needing support in the form of job accommodations might be viewed as further confirmation of personal weakness and hence strengthen the stereotype that individuals with depression or anxiety are to blame. 
Work ability. A workplace is a unique social context wherein people's skills and abilities are depended upon for team and organizational success. As such, individuals who are perceived as less capable or who cannot be relied upon to complete their work may be perceived to threaten team and organizational success and may consequently be perceived as a hindrance. There is a consistent trend within previous research to suggest that many people erroneously believe that mental disorders necessarily result in reduced competence (Ipsos Reid, 2007; Krupa et al., 2009; Schulze \& Angermeyer, 2003) or confuse mental disorders with intellectual disability (Schultz et al., 2011). In addition, false beliefs that individuals with mental health problems such as depression or anxiety are unable to handle the stress of employment (Krupa et al, 2009) and cannot adapt to today's changing work environments (Schultz et al., 2011) may contribute to perceptions that employees with depression or anxiety are unreliable.

Given the importance of ability in the workplace, the stereotype that individuals with depression or anxiety are less capable and reliable may be particularly harmful. This is further complicated by symptoms of depression and anxiety, such as difficulty concentrating and decision-making (Lerner et al., 2011; Wang et al., 2004), which may be perceived by others as inability to perform (Krupa et al., 2009). Because accommodations often result in workplace changes to address symptoms limiting work performance (Peer \& Tenhula, 2011), it is important to understand whether coworkers view accommodations as further proof that individuals with depression or anxiety are less capable and reliable, thereby strengthening the stereotype of reduced ability.

Malingering. Although symptoms of severe mental disorders are often quite visible, symptoms of depression and anxiety can be intermittent and less visible (Peer \& 
Tenhula, 2011; Wald, 2011). This can raise questions of legitimacy around a person's claim of mental illness, and people can be seen as faking in order to obtain benefits such as a lighter workload, time off work, and other workplace accommodations (Parliament of Canada, 2006; Krupa et al., 2009). For example, 60\% of Canadian workers sampled in an Ipsos Reid (2007) survey on depression in the workplace believed that "there needs to be a way to verify someone is actually suffering from depression before they are given any special consideration at work" (p. 14). Furthermore, the Canadian Medical Association Annual Report Card on Health Care (Canadian Medical Association, 2008) found that $46 \%$ of Canadians thought people "use the term mental illness as an excuse for bad behaviour," confirming that people do indeed believe that coworkers can use depression to receive preferential treatment or excuse behaviour at work.

\section{Perceived Unfairness from the Coworker Perspective}

Research on stigma has not typically examined the role that perceived unfairness plays in negative responses to individuals with mental health problems; however, considering that employees with depression or anxiety are negatively stereotyped as dangerous, blameworthy, less able, and malingering, it is perhaps not surprising that some coworkers would perceive it unfair to themselves or other team members to have these individuals as coworkers. Indeed, Krupa et al. (2009) found unfairness to be a common theme for co-workers and supervisors who believed that employees with mental health problems impeded progress towards goals, took up valuable positions that could be occupied by more competent workers, and in some cases endangered the safety of others.

Given that some individuals may perceive it to be unfair, in general, to deal with a coworker who has depression or anxiety, it is also perhaps not surprising that 
accommodations for depression or anxiety might worsen these perceptions. Colella (2001) explains that from the co-worker perspective, an accommodation represents different treatment for employees with disabilities and has the potential to be viewed as distributive injustice when those employees are perceived as receiving a valued perk. Her model of factors that influence distributive fairness judgments of this different treatment highlights the many factors that can result in a judgment of unfairness including degree of direct impact to coworkers, equity comparisons (e.g., the accommodation awards a coveted reward), and perception of need (e.g., less need perceived for less visible disorders). This model is relatively untested; however, qualitative interviews (Shultz et al., 2011) and focus groups (Kensbock et al,,2017) support the idea that accommodations can be perceived as unfair, and Paetzold et al. (2008) found that providing an accommodation to a physically disabled individual was only considered fair until their performance exceeded that of an individual without a disability.

In short, it is likely that some employees perceive it as unfair to have individuals with depression or anxiety as coworkers and this perception may increase when these individuals receive job accommodations. This can have important consequences for both individuals and organizations because being treated unfairly is associated with a range of negative outcomes such as lower job satisfaction, retaliatory behaviours (e.g., theft), and reduced organizational commitment (Colquitt et al., 2001). According to a meta-analysis of organizational justice research (Colquitt et al., 2013), which concluded that the association between unfair treatment and performance outcomes was mediated by positive and negative affect, negative emotional responses offer one possible explanation for negative reactions to individuals with depression or anxiety. 


\section{Emotional Responses to Stereotypes and Unfairness}

According to Frijda's (1986) appraisal theory of emotions, appraisals of situations and events elicit emotional responses that prepare us for action. Appraisals can be complex, involving assessments on multiple dimensions such as whether a situation helps or hinders goals, is fair or unfair, or was intentionally caused by someone else (Frijda et al., 1989). Whereas believing a negative stereotype about a coworker with depression or anxiety is likely to lead to negative appraisals that the situation is unfair and will hinder goals, not believing these negative stereotypes is likely to lead to positive appraisals that the situation is fair and will not hinder goals (and will perhaps help if helping others is a personal goal). These positive or negative appraisals then elicit positive (e.g., sympathy, compassion) or negative (e.g., anger, irritation, fear) emotional responses.

Research specifically examining emotional responses to individuals with mental health problems is, however, scant. In studies of the German public, Angermeyer and Matschinger $(1997,2003)$ categorized emotional reactions to vignettes of individuals with schizophrenia or depression as anger, fear, or pity, with schizophrenia eliciting stronger responses than depression. Angermeyer, Holzinger, and Matschinger's (2010) literature review of emotional reactions to mental illness expanded the pity category to include positive emotions like desire to help, compassion, and empathy, and concluded that the public's emotional reactions to major depression is mixed, including both positive emotions (e.g., compassion because individuals are struggling) and negative emotions (e.g., fear because individuals are believed to be dangerous). In the workplace, Krupa et al. (2009) established that co-workers and supervisors can be irritated by depressive symptoms like poor concentration, as well as angry or afraid when an employee who is 
believed dangerous is permitted to continue working. Employers can also be frustrated that they are expected to demonstrate social responsibility by employing individuals with mental health problems who they believe to be poor employees.

Similarly, although there has been research demonstrating that injustice can impact health and health behaviours (e.g., smoking, alcohol use) by contributing to negative outcomes such as burnout, perceived stress, and strain (Robbins, Ford, \& Tetrick, 2012), I could find no research examining whether perceived unfairness impacts emotional or behavioural responses to individuals with mental health problems. Similar to Frijda's (1986) appraisal theory of emotions, affect-based perspectives on organizational justice outcomes theorize that injustice triggers a primary appraisal that the situation is harmful to goals, leading to negative emotional states that explain outcomes such as counterproductive work behaviours and task performance (e.g., Barclay, Skarlicki, \& Pugh, 2005). These affect-based theories of organizational justice are supported by results of a recent meta-analysis (Colquitt et al., 2013), which concluded that justice and injustice were both moderately associated with positive and negative emotional states, respectively.

Negative emotional responses of coworkers can have deleterious effects on stigmatized individuals. Humans are particularly attuned to negative emotions during interpersonal interactions (Major \& Eccleston, 2005) and may in turn react with their own negative emotions, confirming stereotypes that individuals with mental health problems are unstable (Angermeyer \& Holzinger, 2010). Moreover, perceptions that coworkers are angry, irritated, or uneasy can strengthen self-stigma, resulting in feelings of shame and inadequacy (Link et al., 2004) and a reduced sense of belonging (Major \& O'Brien, 
2005). This is particularly important because a lowered sense of belonging is implicated in worsening of depressive symptoms (Steger \& Kashdan, 2009) and increased risk of suicide (Fisher, Overholser, Ridley, Braden, \& Rosoff, 2015). Clearly, as Link et al. (2004) contend in their review of measures of general stigma outcomes, more research on emotional responses is important to our overall understanding of workplace stigma.

\section{Discriminatory Behaviours}

One of the most studied concepts in stigma research is social distance, which is the inclination to put distance between oneself and a stigmatized individual in social settings (Link et al., 2004). Based on Bogardus' (1925) seminal research on racial stigma, social distance is frequently used as a measure of stigma associated with mental illness (Pescosolido, 2013), particularly schizophrenia (e.g., Angermeyer \& Matschinger, 1996; Angermeyer \& Matschinger, 2003; Schomerus, Van der Auwera, Matschinger, Baumeister, \& Angermeyer, 2015). Participants are typically asked to read a scenario or think of an individual with a mental problem and then indicate how willing they would be to socialize with that individual. This exclusion can threaten a stigmatized individual's basic needs for social attachments (Major \& Eccleston, 2005) and on a practical level can have negative consequences such as unemployment or underemployment (Stuart, 2004).

Although recent anti-stigma campaigns have increased knowledge and awareness of mental health problems (Jorm et al., 2012), desire for social distance appears relatively unchanged. For example, analyses of population data collected between 1990 and 2004 from Europe, the United States, and Australia showed that the number of people who would accept a co-worker with depression remained unchanged at 55\% (Schomerus et al., 2012). Furthermore, vignette studies of attitudes towards psychiatric illness reveal that 
participants are more likely to believe that most other people desire social distance (e.g., would not want to have the person as a friend or employee) from a person with major depressive disorder (Angermeyer, Matschinger, Carta, \& Schomerus, 2014). In addition, although effects are generally found to be stronger for schizophrenia, desire for social distance from depressed and anxious individuals continues to be prominent (Anderson, Jeon, Blenner, Wiener, \& Hope, 2015) and appears to increase with participant age (Schomerus et al., 2015). Finally, qualitative research focused on the experience of stigma reveals that people with depressive disorders commonly report losing friends, family, and coworkers who do not believe the illness is real (Krupa et al., 2009) or who fear violent and dangerous behaviour (Parliament of Canada, 2006). In short, people with depression and anxiety disorders are quite likely to experience rejection, exclusion, and avoidance in the workplace related to stigmatizing attitudes towards mental disorders.

To summarize, stigma towards depression and anxiety in the workplace is multifaceted. Across a range of life domains, individuals with mental health problems are frequently stereotyped as dangerous and are blamed for their mental health problems. Specific to the workplace, these individuals can be stereotyped as malingering to receive special treatment at work and less able to work because of incompetence and unreliability. Because accommodations are highly visible and likely to make differences more salient, it is possible that negative stereotypes towards depression and anxiety increases stereotyping. In turn, endorsement of negative stereotypes is likely to lead to appraisals that having a coworker with depression or anxiety is not fair and will hinder goals, resulting in increased anger and fear and reduced sympathy. 


\section{Reducing Stigma Through Education}

There is evidence that, in general, education about mental health problems can help to improve public perception and reduce stigma. Educational approaches to stigma reduction typically provide information that challenges myths and negative stereotypes about mental health problems (Corrigan \& Fong, 2014) and decrease stigma by increasing knowledge of certain disorders (Grant, Bruce, \& Batterham, 2016). Although there is evidence that contact approaches (i.e., having individuals targeted for attitude change spend time with individuals who are experiencing mental health problems) can have larger effects sizes (Corrigan et al., 2012), educational approaches can be designed to more easily reach a large number of individuals. For example, during the period that Australia's beyondblue social media campaign was active, there were increases in awareness and understanding of depression at a population level across Australia, as well as increases in beliefs that treatments such as anti-depressants and counselling could be helpful (Jorm, Christensen, \& Griffiths, 2004). Hence, an educational approach to reducing stigma in the workplace might be the most practical means of reaching employees.

A small amount of research on job accommodations points to education as a useful tool in reducing stigma. In qualitative research on job accommodations (Shultz et al., 2011), a sample of 41 academics and vocational rehabilitation experts identified workplace education and awareness as key to reducing stigma associated with accommodations for mental health conditions. Gates (2000) used an education intervention (i.e., an explanation of the Americans with Disabilities Act, an overview of the limitations experienced by accommodated employees, and discussions of 
accommodation strategies with the workgroup) to address misconceptions of work group members and to increase understanding of accommodations in order to improve returnto-work experiences of employees following leaves of absence for mental health reasons. Colella, Paetzold, and Belliveau (2004) advocate education (e.g., information on legal obligations of employers, the purpose of job accommodations, and commonly used accommodations) as a mean of improving perceptions of fairness for accommodations for mental health reasons.

Finally, research on the impact of anti-stigma campaigns demonstrates that it is important to understand whether educational messages have the intended effect. Corrigan and Fong (2014) identified several well-intentioned attempts at education that have had unintended consequences. For example, messages in the 1990s framing depression as a brain disorder had the intended effect of reducing blame but also unintentionally decreased beliefs that depression could be treated. In addition, educational messages on anti-depressants, intending to increase perceptions that depression is treatable, had differing effects depending on whether participants identified themselves as "mentally ill" (increased stigma) or not (decreased stigma). Hence, providing educational information about mental health and job accommodations may be an important mechanism for reducing stigma, but it is important to test the impact of educational messages on a range of stigma outcomes in order to understand if the message has the intended effects.

\section{Current Research}

Given the prevalence of depression and anxiety and the potential for job accommodations to help individuals experiencing symptoms of these disorders to overcome functional limitations at work, it is important to better understand workplace 
attitudes towards these mental health problems and job accommodations. Stigma associated with mental health problems can be debilitating and is one of the most frequently cited reasons for difficulties implementing accommodations (Shultz et al., 2011). Individuals who receive accommodations for mental health problems report negative reactions and mistreatment from co-workers and perceive these reactions to be the result of stigma (e.g. Kensbock et al., 2017). To my knowledge, however, there has been no research to examine if negative reactions are stronger for those who receive accommodation compared to those who disclose depression or anxiety but do not request accommodation. Moreover, despite recommendations by rehabilitation experts to educate colleagues about accommodations as a means of reducing stigma (Shultz et al., 2011), there has been no research to examine the impact of providing such information. The current research addressed this knowledge gap by testing the models shown in Figure 1, Figure 2, and Figure 3.

The model shown in Figure 1 was used to test the following three research questions. For a coworker returning to work following a leave of absence:

1. Would depression or anxiety be associated with perceived malingering, ability, blameworthiness, and dangerousness compared to a physical health problem?

2. Would receiving an accommodation moderate the association of depression or anxiety with perceived malingering, ability, blameworthiness, and dangerousness compared to a physical health problem?

3. Would providing information on accommodations moderate the association between receiving an accommodation and the associations of depression and anxiety with perceived malingering, ability, blameworthiness, and dangerousness? 


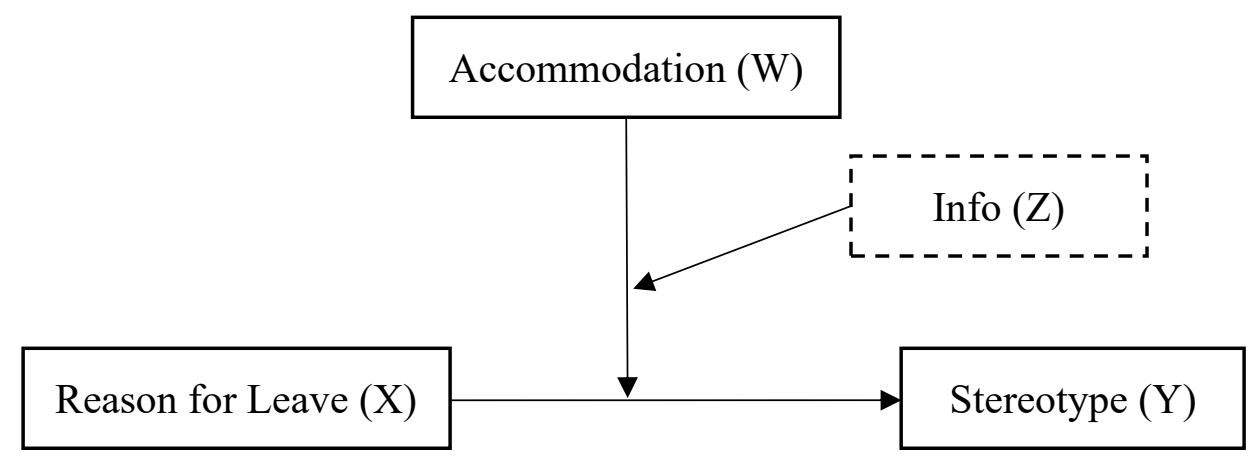

Figure 1. Proposed moderation model for the effect of reason for leave (surgery, depression, anxiety) on endorsement of stereotypes (malingering, ability, blameworthy, dangerous). The effect of depression and anxiety compared to surgery is moderated by whether the coworker receives accommodation (yes, no) and whether the participant reads educational information (yes, no) on the employer's duty to accommodate. Dashed lines indicate the variable was included in Study 2 but not Study 1 .

The model shown in Figure 2 was used to test the next three research questions.

For a coworker returning to work following a leave of absence:

4. Would receiving an accommodation moderate the associations of perceiving malingering, ability, blameworthiness, and dangerousness with perceived unfairness?

5. Would providing information on accommodations moderate the association between receiving an accommodation and the associations of perceived malingering, ability, blameworthiness, and dangerousness with perceived unfairness?

6. Would perceived unfairness mediate the association of perceived malingering, ability, blameworthiness, and dangerousness with anger, fear, and sympathy?

Finally, the model shown in Figure 3 was used to test the last two research questions. For a coworker returning to work following a leave of absence:

7. Would anger, fear, and sympathy predict willingness to socialize with the coworker?

8. Would anger, fear, and sympathy predict willingness to give a job recommendation for the coworker? 


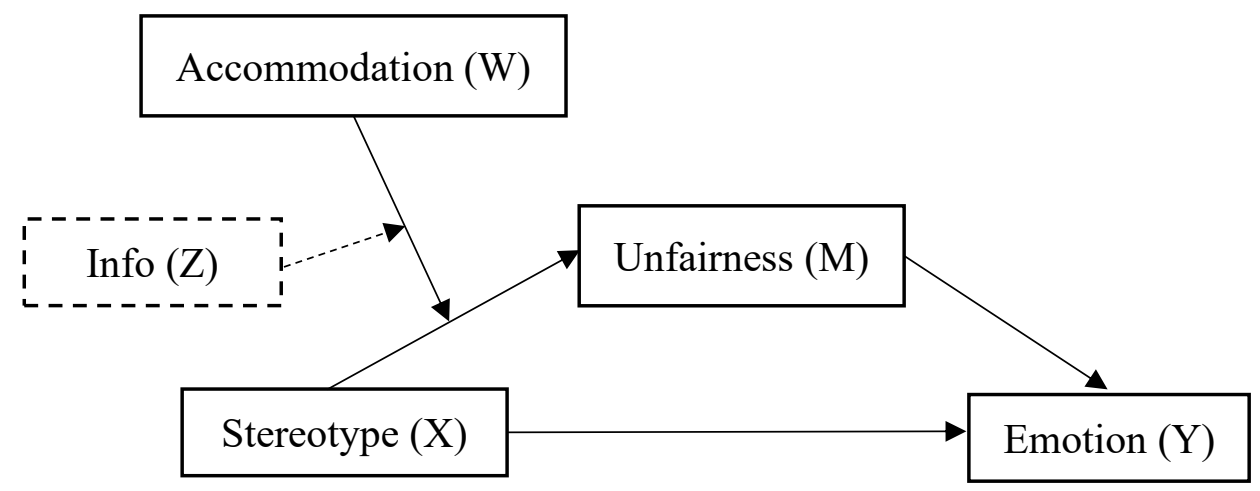

Figure 2. Proposed moderated mediation model for effect of stereotypes on emotional responses. Unfairness mediates the association between each stereotype (malingering, ability, blameworthiness, dangerousness) and emotional responses (anger, fear, sympathy) conditional on accommodation (yes, no) and whether the participant reads educational information (yes, no) on the employer's duty to accommodate. Dashed lines indicate the variable was included in Study 2 but not Study 1.

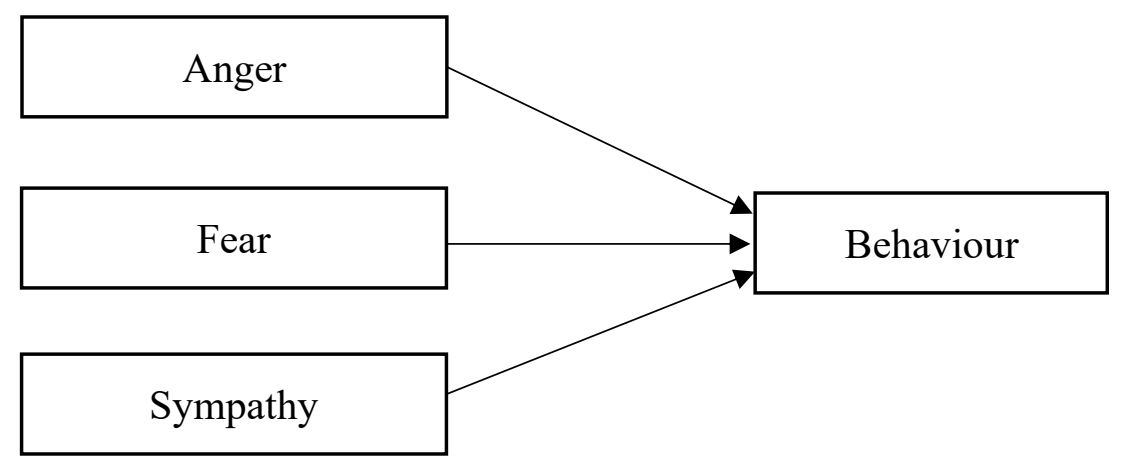

Figure 3. Model of emotional responses (anger, fear, sympathy) predicting behavioural outcomes (willingness to socialize, willingness to give a job recommendation)

To address these research questions, I conducted two studies using the experimental vignette survey method, which permits manipulation of predictor variables that would otherwise not be ethically or practically possible by presenting participants with a realistic scenario (Aguinis \& Bradley, 2014). Atzmuller and Steiner (2010) recommend using small vignette experiments such as this to examine main and interaction effects common to the kinds of judgments and beliefs being considered by this 
research. Study 1 was conducted using a sample of working adults using Amazon's Mechanical Turk online web platform to recruit participants from the United States and Canada. Participants were randomly assigned to read one of six scenarios describing a colleague who would be receiving a job accommodation or returning to normal duties following a period of leave for surgery, depression, or anxiety. Study 2 was conducted using a Canadian sample of adults working for a large department of the federal government. Participants were randomly assigned to read one of the same six scenarios from Study 1; however, half of the participants in Study 2 also read educational information on the employer's duty to accommodate in Canada. Participants in both studies then answered the same items on stereotypes, perceived unfairness, emotional responses, and behavioural outcomes, as well as an open-ended item on their experiences with coworkers with mental and physical health problems. In short, Study 2 was a replication of Study 1 but added an educational information condition and used a sample from within one Canadian organization rather than a population-based sample from the United States and Canada.

\section{Study 1 Method}

\section{Participants}

Participants were recruited using Amazon Mechanical Turk's web platform, an online crowd-sourcing service where requesters post tasks called Human Intelligence Tasks (HITs) and registered workers can complete the tasks for a fee. The initial sample comprised 669 individuals from the United States (99\%) and Canada (1\%). Participants who declined consent $(n=2)$, accepted consent but then quit $(n=23)$, viewed the scenario but then quit $(n=10)$, or quit before answering manipulation checks $(n=7)$ 
were removed. A further 238 cases were removed for failing manipulation checks.

Finally, participants who did not respond to demographics $(n=9)$ and participants who preferred not to specify gender $(n=3)$ were excluded from the analyses. The final sample $(N=362)$ included 177 male and 185 female participants with a mean age of 37.59 years $(S D=12.18$ years $)$ and a mean of 16.28 years $(S D=1.53$ years $)$ experience in the paid workforce. Of these participants, $70.3 \%$ worked full-time, $38.5 \%$ were supervisors, and the majority were well-educated (23.0\% high school, $16.2 \%$ college diploma, $42.5 \%$ bachelor's degree, $14.8 \%$ graduate degree, $2.3 \%$ professional designation, $1.1 \%$ other).

\section{Procedure}

The recruitment notice (see Appendix A) was posted on Amazon's Mechanical Turk website for workers located in either the United States or Canada who had a minimum of a $95 \%$ approval rating. Clicking the link in the recruitment notice redirected participants to the study hosted on the Qualtrics online survey platform. After consenting to participate (see Appendix B), participants were randomly assigned to read one of six vignettes written for the present research describing a fictitious colleague returning to work following a leave of absence for health reasons. The vignettes varied the health reason for leave [surgery vs depression vs anxiety] and whether or not the colleague would be receiving a job accommodation [extra time for detailed work and one afternoon a week off for medical appointments vs returning to regular schedule and duties].

After reading the vignette, participants responded to items (see Appendix C) on 1) negative stereotypes including perceived malingering, reduced work ability, blame, and dangerousness 2) perceived unfairness of the situation for others at work 3) emotional responses including anger, fear, and sympathy 4) willingness to socialize with or give a 
job recommendation for the fictitious colleague and 5) manipulation checks. Participants were then asked to answer an open-ended item on their experiences with coworkers returning to work after a leave of absence for mental or physical health reasons followed by demographics including age, gender, education level, occupation, years in the paid workforce, employment status, and supervisory status. Finally, participants were presented with follow-up information (see Appendix D) including websites where they could find more information on job accommodations. The mean completion time for the questionnaire was 8.05 minutes.

\section{Measures}

Vignettes. Vignettes began by asking participants to imagine themselves in a scenario wherein their supervisor advises them that a co-worker who has been on leave for either surgery, depression, or anxiety will soon be returning to work. The vignette described the fictitious co-worker as either returning to normal duties and schedule or as receiving an accommodation consisting of 1) extra time for certain tasks that depend on ability to concentrate and 2) leaving early one afternoon a week for treatment appointments. Five graduate students reviewed the vignettes to check for face validity and clarity and to verify that the manipulations were noticeable. Revisions were also made following consultation with a human resources advisor with experience handling accommodation requests for the federal government. The complete text of the vignettes was as follows:

Please read the scenario and information that follows. Try to imagine yourself and the people in this scenario as if it were really happening to you.

One of your colleagues has been on leave [after surgery to repair a broken leg | for depression | for anxiety]. You learn that they will be returning to work next week. Your colleague has been deemed fit to return to work but they can still have 
problems with tiredness and concentration. [To accommodate these problems, your colleague will be given extra time to complete detailed tasks and will leave early one afternoon each week for appointments $\mid$ Despite these problems, your colleague will be resuming their regular duties and schedule]. Your supervisor asks that you support your colleague as they adjust to being back at work. Because you have the most experience on the team, you're asked to spend time bringing the person up to speed.

Negative Stereotypes. Stigma research using a vignette design frequently asks participants whether the individual described in the vignette possesses characteristics based on negative stereotypes associated with mental health problems. Qualitative research on accommodations and, more generally, mental health problems in the workplace, highlights two common workplace-specific beliefs about coworkers with mental health problems that are not captured by existing quantitative measures: reduced work ability and perceived malingering. The four items created for the present research to assess these two stereotypes (see Table 1) were based on interviews of employees with mental health problems (Gates, 2000; Krupa et al., 2009), interviews of rehabilitation professionals and academics (Schultz et al., 2011), and reports to the Standing Senate Committee studying mental illness in Canada (Parliament of Canada, 2006). Response options ranged from 1 (strongly disagree) to 5 (strongly agree) on a 5-point Likert-type scale. The mean of each two-item scale was used as the score for that scale. Higher scores indicated higher levels of perceived malingering and work ability.

For the general stereotypes of blameworthiness and dangerousness that are wellestablished across many life domains including the workplace, the present research used seven items (see Table 1) taken from Schomerus et al. (2016). There are three items for the dangerousness scale and four items for blameworthy scale. Responses ranged from 1 (strongly disagree) to 5 (strongly agree) on a 5-point Likert-type scale. The mean of 
items for each sub-scale was used as the score for that sub-scale. Higher scores indicate higher levels of blameworthiness and perceived dangerousness.

Perceived Unfairness. Although there is substantial research on fairness in organizations, there were no quantitative items available to measure judgments of unfairness for the style of vignettes created for this research. The two items shown in Table 1 were, therefore, created for the present research based on a theoretical review (Colella, 2001) of coworker judgments regarding fairness of workplace accommodations. Response options ranged from 1 (strongly disagree) to 5 (strongly agree) on a 5-point Likert-type scale. The mean of items was used as the score for unfairness. Higher scores indicated stronger beliefs that the situation in the vignette was unfair.

Emotional responses. Participants were asked to rate the extent to which they felt each of 10 different emotions while reading the vignette on a scale of 1 (not at all) to 5 (extremely). Eight of these emotions are from Angermeyer and Matschinger's (1996) scale designed to assess three emotional reactions to mental illness: anger (i.e., anger, irritation, disgust), fear (i.e., fear, uneasiness, anxiety), and pity (i.e. sympathy, desire to help). Also, because the majority of these items are negative emotions, two positive items, inspiration and enthusiasm, were added for the current research.

The means of the anger and fear items were used as the scores for anger and fear. Because one of the goals of my research was to test associations between emotional responses and behavioural intentions, I decided not to use the desire to help item, which is a behavioural intention rather than an emotional response. The score for the single sympathy item was, therefore, used as the score for sympathy. Higher scores indicated higher levels of anger, fear, and sympathy. 
Table 1.

Items for negative stereotypes and perceived unfairness

Work Ability ${ }^{1}$

1. This person would be a capable employee.

2. This person would be a reliable co-worker.

Malingering ${ }^{1}$

3. People often pretend to have health problems like this to get special treatment at work.

4. This person is probably using illness as an excuse to get out of doing their work.

Dangerousness ${ }^{2}$

5. This person is a danger to other people.

6. This person is unpredictable.

7. This person is a danger to themselves.

Blameworthy ${ }^{2}$

8. This person is to blame for their problems.

9. To some extent, it is this person's fault that they got into this situation.

10. This person only has to pull themselves together to get well.

11. This person's problems likely result from their weak character.

Perceived Unfairness ${ }^{1}$

12. This situation would be unfair to other people at work.

13. Making changes at work for this person would be unfair.

Notes. No items were reverse-scored.

${ }^{1}$ Items created for the present research. ${ }^{2}$ Items taken from Schomerus et al. (2016).

Willingness to socialize. In a review of measures used to study mental illness stigma, Link, Yang, Phelan, and Collins (2004) summarized the use of variants of Bogardus' (1925) social distance scale to study stigma associated with race and mental illness. They described social distance scales as including items that measure how willing participants are to socialize with another individual. For the current research, items for willingness to socialize were taken from two scales based on the Bogardus (1925) social 
distance scale. Two items (i.e. have this person move next door and have this person start working closely with you) were taken directly from research on mental health stigma in general community settings by Schomerus et al., (2016). Three items from their scale were modified to be specific to the work context (i.e. spend an evening socializing with this person at a work event, make friends with this person outside of work, and make friends with this person at work) and one further item was modified to be more current (i.e. have this person meet your family instead of have this person marry into your family). In addition to items based on previous research, three items were created for the current research (i.e., work in the area next to this person, have this person become your supervisor, and take a coffee break with this person). These items were included to represent a broader range of social situations common to the workplace. Response options ranged from 1 (definitely not willing) to 5 (definitely willing) on a 5-point Likerttype scale. The mean of all items was used as an overall score for willingness to socialize. Willingness to give a job recommendation. One additional item (i.e. recommend this person for a job), taken from research by Norman, Sorrentino, Windell, and Manchanda (2008), was included to assess a second behavioural intention regarding the fictitious coworker described in the vignette. Response options ranged from 1 (definitely not willing) to 5 (definitely willing) on a 5-point Likert-type scale. The score for the single item was used as the score for willingness to give a job recommendation.

Manipulation checks. Two items were included to assess whether participants read and understood the vignette. One item asked whether the fictitious co-worker from the vignette was returning to work following leave for surgery, following leave for depression, or following leave for anxiety. A second item asked whether the co-worker 
was returning to their normal duties and schedule or would be given extra time for tasks and one afternoon a week for medical appointments. Participants who did not answer manipulation check items correctly were excluded from analyses.

Experience with health problems. One open-ended item was included asking participants to describe their experiences with colleagues or other people outside of work who have returned to work following a leave of absence for mental or physical health problems. The goal of including this item was to better understand thoughts and feelings associated with stigma and to explore any differences between reactions to mental and physical health problems. The item read as follows: Could you describe any experiences you may have had with colleagues or other people outside of work who have returned to work following a leave of absence for mental or physical health conditions? What did you think and feel when that colleague returned to work? Please remember not to identify any individual co-workers or yourself in your answer.

Demographics and employment information. Participants were asked to answer items on demographics and employment status including age, gender, level of education, occupation, full-time or part-time status, years in the paid workforce, and current supervisor status.

\section{Study 1 Results}

\section{Preliminary Analyses}

Descriptive statistics. Means, standard deviations, and correlations for key study variables are shown in Table 2. At the group level, the means indicated low endorsement of negative stereotypes (i.e., malingering, ability, blameworthiness, and dangerousness), positive emotional responses (i.e., low anger and fear, moderately high sympathy), and 
willingness to socialize. Correlations between the negative stereotypes and the perceived unfairness variables were moderately high and followed a similar pattern as correlations between the negative stereotypes and emotion variables. Perceiving malingering, reduced work ability, blameworthiness, and dangerousness were all positively associated with anger and fear and negatively associated with sympathy. Gender and supervisor status were correlated with several variables and were, therefore, included as control variables in the main regression analyses.

Cronbach's alphas for each of the scales are included on the diagonal. Scale items taken from previous research (i.e., blameworthy, dangerous, anger, fear, socialize) demonstrated strong internal consistency, similar to results of previous research (e.g., Schomerus et al., 2016). Scale items created for the present research (i.e., malingering, ability, and unfairness) also demonstrated good internal consistency. It is, therefore, reasonable to assume that the scales used for the present research provided measurements that would be consistent with other population-level samples.

Analysis of participant gender and supervisor status. Because of similar correlation patterns for supervisor status and gender, I conducted a chi-square test of independence for gender and supervisor status to determine whether male and female participants were evenly distributed as supervisors and non-supervisors. The results in Table 3 showed that males and females were in fact not evenly distributed according to supervisor status, $\chi^{2}(1,362)=8.02, p=.01$, with higher percentages of male supervisors and female non-supervisors. I, therefore, conducted a series of two-way ANOVAs (see Table 4), which showed no significant interactions between participant gender and supervisor status. 
Table 2.

Means, Standard Deviations, and Correlations for Key Variables (Study 1)

\begin{tabular}{|c|c|c|c|c|c|c|c|c|c|c|c|c|c|c|}
\hline & $M$ & $S D$ & 1 & 2 & 3 & 4 & 5 & 6 & 7 & 8 & 9 & 10 & 11 & 12 \\
\hline 1. Malingering & 2.06 & 0.91 & $(.81)$ & & & & & & & & & & & \\
\hline 2. Ability & 3.65 & 0.77 & $-.41^{* * *}$ & $(.83)$ & & & & & & & & & & \\
\hline 3. Blameworthy & 2.15 & 0.92 & $.66^{* * *}$ & $-.45^{* * *}$ & $(.88)$ & & & & & & & & & \\
\hline 4. Dangerous & 2.08 & 0.83 & $.62^{* * *}$ & $-.51^{* * *}$ & $.73^{* * *}$ & $(.86)$ & & & & & & & & \\
\hline 5. Unfairness & 2.31 & 0.92 & $.69^{* * *}$ & $-.55^{* * *}$ & $.60^{* * *}$ & $.60^{* * *}$ & $(.77)$ & & & & & & & \\
\hline 6. Anger & 1.37 & 0.70 & $.52^{* * *}$ & $-.34^{* * *}$ & $.53^{* * *}$ & $.49^{* * *}$ & $.59^{* * *}$ & $(.85)$ & & & & & & \\
\hline 7. Fear & 1.56 & 0.72 & $.32^{* * *}$ & $-.20^{* * *}$ & $.33^{* * *}$ & $.40^{* * *}$ & $.42^{* * *}$ & $.71^{* * *}$ & $(.80)$ & & & & & \\
\hline 8. Sympathy & 3.85 & 0.96 & $-.40^{* * *}$ & $.48^{* * *}$ & $-.38^{* * *}$ & $-.34^{* * *}$ & $-.46^{* * *}$ & $-.30^{* * *}$ & -.09 & - & & & & \\
\hline 9. Recommend & 3.47 & 0.99 & $-.29^{* * *}$ & $.61^{* * *}$ & $-.39^{* * *}$ & $-.34^{* * *}$ & $-.41^{* * *}$ & $-.26^{* * *}$ & $-.13^{* *}$ & $.51^{* * *}$ & - & & & \\
\hline 10. Socialize & 3.85 & 0.80 & $-.45^{* * *}$ & $.62^{* * *}$ & $-.50^{* * *}$ & $-.43^{* * *}$ & $-.52^{* * *}$ & $-.38^{* * *}$ & $-.27^{* * *}$ & $.60^{* * *}$ & $.70^{* * *}$ & $(.93)$ & & \\
\hline 11. Gender ${ }^{\mathrm{a}}$ & - & - & $-.17^{* *}$ & .01 & $-.26^{* * *}$ & $-.13^{* *}$ & $-.11^{*}$ & -.11 & -.01 & $.11^{*}$ & .05 & .07 & - & \\
\hline 12. Supervisor ${ }^{\mathrm{b}}$ & - & - & $.22^{* * *}$ & .01 & $.21^{* * *}$ & $.14^{*}$ & $.14^{*}$ & $.12^{*}$ & .06 & -.02 & .01 & -.00 & $-.13^{* *}$ & - \\
\hline 13. Age & 37.56 & 12.19 & -.05 & -.01 & -.05 & -.03 & -.06 & -.08 & -.07 & -.05 & .00 & .06 & .00 & .05 \\
\hline
\end{tabular}

Notes. $N=362$. Cronbach's alphas are listed on the diagonal in parentheses.

${ }^{\mathrm{a}}$ Male coded as 0 ; Female coded as $1 .{ }^{\mathrm{b}}$ Non-supervisor coded as 0 ; Supervisor coded as 1.

$* p<.05 . * * p<.01 . * * * p<.001$. 
Table 3.

Distribution of Males and Females according to Supervisor Status (Study 1)

\begin{tabular}{lcccccccc}
\hline & \multicolumn{3}{c}{ Non-supervisors } & & \multicolumn{3}{c}{ Supervisors } \\
\cline { 2 - 4 } \cline { 6 - 8 } & Observed & Expected & \%Gender & & Observed & Expected & \%Gender \\
\hline Males & 96 & 108 & 54.2 & & 81 & 69 & 45.8 \\
Females & 124 & 112 & 67.0 & & 61 & 73 & 33.0 \\
\hline
\end{tabular}

Note. $\chi^{2}(1,362)=8.02, p=.01$

Table 4.

Two-Way Analysis of Variance for Gender and Supervisor Status (Study 1)

\begin{tabular}{|c|c|c|c|c|c|c|c|c|c|}
\hline & \multicolumn{3}{|c|}{ Gender $(\mathrm{G})^{\mathrm{a}}$} & \multicolumn{3}{|c|}{ Supervisor $(\mathrm{S})^{\mathrm{b}}$} & \multicolumn{3}{|c|}{$\mathrm{G}^{\mathrm{N}} \mathrm{S}^{\mathrm{c}}$} \\
\hline & $F$ & $p$ & $\eta_{p}^{2}$ & $F$ & $p$ & $\eta_{p}^{2}$ & $F$ & $p$ & $\eta_{p}^{2}$ \\
\hline Malingering & 7.24 & .01 & 0.02 & 15.60 & $<.001$ & 0.04 & 0.01 & .92 & 0.00 \\
\hline Ability & 0.30 & .59 & 0.00 & 0.08 & .78 & 0.00 & 1.85 & .17 & 0.01 \\
\hline Blameworthy & 21.21 & $<.001$ & 0.06 & 12.51 & $<.001$ & 0.03 & 0.11 & .74 & 0.00 \\
\hline Dangerous & 4.87 & .03 & 0.01 & 5.15 & .02 & 0.01 & 0.23 & .64 & 0.00 \\
\hline Unfairness & 3.23 & .07 & 0.01 & 5.82 & .02 & 0.02 & 0.10 & .75 & 0.00 \\
\hline Anger & 2.92 & .09 & 0.01 & 4.40 & .04 & 0.01 & 0.01 & .93 & 0.00 \\
\hline Fear & 0.01 & .92 & 0.00 & 1.26 & .26 & 0.00 & 0.04 & .83 & 0.00 \\
\hline Sympathy & 3.65 & .06 & 0.01 & 0.49 & .48 & 0.00 & 0.29 & .59 & 0.00 \\
\hline Recommend & 1.09 & .30 & 0.00 & 0.12 & .73 & 0.00 & 0.10 & .75 & 0.00 \\
\hline Socialize & 0.98 & .32 & 0.00 & 0.04 & .84 & 0.00 & 1.12 & .29 & 0.00 \\
\hline
\end{tabular}

Note. $\eta_{p}{ }^{2}=$ partial eta-squared.

${ }^{\text {a}}$ Male coded as 0 ; Female coded as $1 . d f=1,358 .{ }^{\text {b } N o n-s u p e r v i s o r ~ c o d e d ~ a s ~} 0$; Supervisor coded as $1 . d f=1,358 .{ }^{c} d f=1,358$. 
Outliers. The data were examined for univariate outliers using boxplots for perceived unfairness, each of the stereotype variables (i.e., malingering, ability, blameworthy, dangerous), emotion variables (i.e., anger, fear, pity), and behaviour variables (i.e., willingness to socialize, recommend for job). There were 24 extreme outliers for the anger variable and 6 extreme outliers for the fear variable. An examination of multivariate outliers revealed that, although Mahalanobis' distance was high for several cases, the studentized deleted residuals were not significant. Hence, all cases were retained for analyses.

Missing data. Of the 362 cases in the dataset, 18 (4.9\%) had missing data; 17 of these cases were missing data on one item and one of these cases was missing data on two items. Little's MCAR test was non-significant, $\chi^{2}(532)=500.50, p=.83$, indicating that all data were missing completely at random. Therefore, all cases were retained for the subsequent regression analyses.

Assumption testing. Finally, tests of assumptions of ordinary least squares regression were also conducted. Plots of zpred vs zresid were created to test assumptions of linearity and homoscedasticity. Normal Q-Q plots and boxplots were generated, and Ztests of skew and kurtosis were conducted to test the assumption of normality. Assumptions of linearity, homoscedasticity, and normality for regression were met.

\section{Impact of Accommodations on Negative Stereotypes}

The first set of research questions represented by the moderation model in Figure 1 examined the impact of accommodations on endorsement of negative stereotypes for depression and anxiety compared to a physical health problem. To test these research questions, I conducted hierarchical multiple regression analyses using each of the 
stereotype variables (i.e., perceived malingering, ability, blameworthy, and dangerousness) as outcomes. Means and standard deviations for each outcome variable by reason for leave and accommodation are included as supplementary tables in Appendix E.

For the regression analyses, one dichotomous variable was created to represent the manipulation of accommodation [yes=extra time for tasks and time off work for appointments, no=returning to regular duties and schedule] in the vignette. Two dummycoded variables, depression $\left(D_{1}\right)$ and anxiety $\left(D_{2}\right)$, were created to represent the three levels of reasons for leave (i.e., surgery, depression, anxiety) varied in the vignette. Surgery was used as the reference category, meaning that the regression coefficients for depression $\left(D_{1}\right)$ and anxiety $\left(D_{2}\right)$ represent comparisons to surgery. Two-way interaction terms were created by multiplying the values of depression $\left(\mathrm{D}_{1}\right)$ and accommodation $(\mathrm{W})$ and the values of anxiety $\left(\mathrm{D}_{2}\right)$ and accommodation $(\mathrm{W})$.

The regression analyses were run four times to test whether the effects of depression $\left(\mathrm{D}_{1}\right)$ and anxiety $\left(\mathrm{D}_{2}\right)$ on malingering $\left(\mathrm{Y}_{1}\right)$, ability $\left(\mathrm{Y}_{2}\right)$, blameworthy $\left(\mathrm{Y}_{3}\right)$, and dangerous $\left(\mathrm{Y}_{4}\right)$ were moderated by accommodation $(\mathrm{W})$. As shown in Table 5 and Table 6 , the accommodation manipulation had no impact in this study. There were no significant interactions between either depression or anxiety and the accommodation condition, and there were no main effects of accommodation. Hence, receiving an accommodation did not moderate the association of depression or anxiety with perceived malingering, ability, blameworthiness, or dangerousness compared to a physical health problem. Neither did receiving an accommodation have an impact across all reasons for leave. 
Table 5 .

Hierarchical Regression Analysis for Malingering and Ability (Study 1)

\begin{tabular}{|c|c|c|c|c|c|c|c|c|}
\hline & \multicolumn{4}{|c|}{ Malingering } & \multicolumn{4}{|c|}{ Ability } \\
\hline & $\Delta R^{2}$ & $B$ & $S E$ & $\beta$ & $\Delta R^{2}$ & $B$ & $S E$ & $\beta$ \\
\hline Step 1 & $.08^{* * *}$ & & & & .03 & & & \\
\hline Gender & & $-0.26^{* *}$ & 0.09 & -0.14 & & 0.01 & 0.08 & 0.01 \\
\hline Supervisor & & $0.38^{* * *}$ & 0.10 & 0.21 & & 0.00 & 0.08 & 0.00 \\
\hline Depression & & 0.10 & 0.11 & 0.05 & & $-0.18^{*}$ & 0.10 & -0.11 \\
\hline Anxiety & & -0.02 & 0.11 & -0.01 & & $-0.28^{* *}$ & 0.10 & -0.17 \\
\hline Accommodation & & 0.11 & 0.09 & 0.06 & & 0.00 & 0.08 & 0.00 \\
\hline Step 2 & .003 & & & & .001 & & & \\
\hline $\begin{array}{l}\text { Depression } \mathrm{x} \\
\text { Accommodation }\end{array}$ & & 0.22 & 0.23 & 0.09 & & -0.11 & 0.20 & -0.05 \\
\hline $\begin{array}{l}\text { Anxiety } \mathrm{x} \\
\text { Accommodation }\end{array}$ & & 0.05 & 0.23 & 0.02 & & -0.03 & 0.20 & -0.01 \\
\hline
\end{tabular}

Notes. Gender coded $0=$ male, $1=$ female. Supervisor coded $0=$ no, $1=$ yes. Depression and anxiety dummy-coded with surgery as reference. Accommodation coded $0=$ no, $1=$ yes. $* p<.05 . * * p<.01 . * * * p<.001$.

Examining the main effects of depression and anxiety, malingering was not associated with either depression or anxiety. In contrast, ability was negatively associated with both depression and anxiety, with lower perceived ability for depression compared to surgery and for anxiety compared to surgery. Further, blameworthy was positively associated with anxiety but not depression, with participants indicating increased blame for anxiety compared to surgery. Finally, dangerous was positively associated with both depression and anxiety, with higher perceived dangerousness for depression compared to surgery and anxiety compared to surgery.

To summarize, there was no support for the moderation model in Figure 1. Whether or not the colleague described in the vignette received an accommodation had no influence on participants' endorsement of negative stereotypes. Interestingly, there were also no main effects of depression or anxiety for perceived malingering, indicating 
that participants did not believe the colleague with depression or anxiety was more likely to be malingering compared to the colleague recovering from surgery.

Table 6.

Hierarchical Regression Analysis for Blameworthy and Dangerous (Study 1)

\begin{tabular}{|c|c|c|c|c|c|c|c|}
\hline & \multicolumn{3}{|c|}{ Blameworthy } & \multicolumn{4}{|c|}{ Dangerous } \\
\hline & $\Delta R^{2}$ & $S E$ & $\beta$ & $\Delta R^{2}$ & $B$ & $S E$ & $\beta$ \\
\hline Step 1 & $.11^{* * *}$ & & & $.10^{* * *}$ & & & \\
\hline Gender & $-0.43^{* * *}$ & 0.09 & -0.23 & & $-0.16^{*}$ & 0.08 & -0.10 \\
\hline Supervisor & $0.35^{* * *}$ & 0.10 & 0.19 & & $0.24^{* *}$ & 0.09 & 0.14 \\
\hline Depression & 0.10 & 0.11 & 0.05 & & $0.47^{* * *}$ & 0.10 & 0.27 \\
\hline Anxiety & $0.25^{*}$ & 0.11 & 0.12 & & $0.45^{* * *}$ & 0.10 & 0.25 \\
\hline Accommodation & -0.10 & 0.09 & -0.05 & & -0.02 & 0.08 & -0.01 \\
\hline Step 2 & .002 & & & .00 & & & \\
\hline $\begin{array}{l}\text { Depression } \mathrm{x} \\
\text { Accommodation }\end{array}$ & 0.03 & 0.22 & 0.01 & & 0.01 & 0.20 & 0.01 \\
\hline $\begin{array}{l}\text { Anxiety } \mathrm{x} \\
\text { Accommodation }\end{array}$ & -0.18 & 0.23 & -0.07 & & -0.05 & 0.20 & -0.02 \\
\hline
\end{tabular}

Notes. Gender coded $0=$ male, $1=$ female. Supervisor coded $0=$ no, $1=$ yes. Depression and anxiety dummy-coded with surgery as reference. Accommodation coded $0=$ no, $1=$ yes. $* p<.05 . * * p<.01$. *** $p<.001$.

\section{Mediation of Stereotypes and Emotional Responses by Perceived Unfairness}

The second set of research questions represented by the moderated mediation model in Figure 2 examined whether accommodations moderated the effects of negative stereotypes on emotional response variables. To test these research questions, I conducted moderated mediation analyses using model 7 of Hayes' (2018) PROCESS macro using each stereotype, malingering $\left(\mathrm{X}_{1}\right)$, ability $\left(\mathrm{X}_{2}\right)$, blameworthy $\left(\mathrm{X}_{3}\right)$, and dangerous $\left(\mathrm{X}_{4}\right)$, as the antecedent and each emotional response, anger $\left(\mathrm{Y}_{1}\right)$, fear $\left(\mathrm{Y}_{2}\right)$, and sympathy $\left(\mathrm{Y}_{3}\right)$, as the consequent. Each of the analyses included unfairness (M) as the mediator and accommodation (W) as the moderator. The regression results for malingering, ability, 
blameworthy, and dangerous are shown in Table 7, Table 8, Table 9, and Table 10, respectively. Indirect effects are shown in Table 11.

Perceived Unfairness. Overall, there was no evidence that the accommodation manipulation had any impact on how unfair participants perceived the situation to be for themselves or other team members. There were no significant interactions between accommodation and any of the negative stereotypes, indicating that the associations of perceived malingering, ability, blameworthiness, and dangerousness with perceived unfairness were not moderated by the accommodation condition. Perceived unfairness was, however, positively associated with malingering, blameworthy, and dangerous and negatively associated with ability, indicating that stereotypes did impact how unfair participants perceived the situation described in the vignette. In addition, unfairness was positively associated with anger and fear but negatively associated with sympathy, indicating that perceived unfairness was associated with more anger and fear but less sympathy.

Indirect effects on anger, fear, and sympathy. All indirect effects of the negative stereotypes on emotional responses were significant. Increases in malingering, blameworthy, and dangerous were associated with increases in anger and fear and decreases in sympathy through perceived unfairness. Moreover, increases in ability were associated with decreases in anger and fear and increases in sympathy through perceived unfairness. These indirect effects were not, however, influenced by the accommodation manipulation. Although there were slight differences in the size of the indirect effects between the accommodation and no accommodation conditions, contrast comparisons indicated that these differences were not significant. 
Direct effects on anger, fear, and sympathy. Examining the direct effects of negative stereotypes on emotional responses reveals that some stereotypes had an impact on emotional responses even after accounting for indirect effects through unfairness. For anger, the direct effects of malingering, blameworthy, and dangerous were significant. For fear, the direct effects of blameworthy and dangerous were significant. For sympathy, all direct effects remained significant. These results suggest that negative stereotypes influenced emotional responses directly, as well as indirectly through perceived unfairness.

To summarize the results of the analyses for the model in Figure 2, there was strong evidence that perceived unfairness mediated the association between negative stereotypes and emotional responses; however, this mediation was not moderated by the accommodation condition. Whether or not the colleague described in the vignette received an accommodation had no impact on the associations of negative stereotypes with perceived unfairness. In short, endorsing negative stereotypes was associated with perceptions that having a coworker with health problems was unfair to participants and their team members. In turn, perceiving the situation to be unfair was associated with increased anger and fear and decreased sympathy. 
Table 7.

Moderated Mediation Analyses using Malingering as the Antecedent

\begin{tabular}{|c|c|c|c|c|c|c|c|c|c|c|c|c|c|c|c|c|}
\hline \multirow[b]{3}{*}{ Antecedent } & \multicolumn{16}{|c|}{ Consequent } \\
\hline & \multicolumn{4}{|c|}{ Unfairness } & \multicolumn{4}{|c|}{ Anger } & \multicolumn{4}{|c|}{ Fear } & \multicolumn{4}{|c|}{ Sympathy } \\
\hline & $B$ & $S E$ & $L L$ & $U L$ & $B$ & $S E$ & $L L$ & $U L$ & $B$ & $S E$ & $L L$ & $U L$ & $B$ & $S E$ & $L L$ & $\overline{U L}$ \\
\hline Gender & 0.02 & 0.07 & -0.13 & 0.16 & -0.03 & 0.06 & -0.15 & 0.09 & 0.06 & 0.07 & -0.08 & 0.20 & 0.12 & 0.11 & -0.08 & 0.33 \\
\hline Supervisor & -0.04 & 0.07 & -0.18 & 0.11 & 0.02 & 0.06 & -0.11 & 0.14 & -0.01 & 0.07 & -0.14 & 0.14 & 0.09 & 0.11 & -0.12 & 0.31 \\
\hline Unfairness (M) & & & & & $0.33^{* * *}$ & 0.04 & 0.24 & 0.41 & $0.30^{* * *}$ & 0.05 & 0.20 & 0.41 & $-0.43^{* * *}$ & 0.08 & -0.58 & -0.27 \\
\hline Malinger (X) & $0.70^{* * *}$ & 0.05 & 0.59 & 0.81 & $0.17^{* * *}$ & 0.05 & 0.08 & 0.26 & 0.04 & 0.05 & -0.06 & 0.15 & $-0.19^{*}$ & 0.08 & -0.35 & -0.03 \\
\hline Accommodation (W) & -0.20 & 0.17 & -0.54 & 0.15 & & & & & & & & & & & & \\
\hline \multirow[t]{2}{*}{$\mathrm{X} \times \mathrm{W}$} & 0.02 & 0.07 & -0.13 & 0.17 & & & & & \multirow{2}{*}{\multicolumn{4}{|c|}{$\begin{array}{c}R^{2}=.18 \\
F(4 \quad 357)=1966^{* * *}\end{array}$}} & \multicolumn{4}{|c|}{$R^{2}=23$} \\
\hline & \multicolumn{4}{|c|}{$\begin{aligned} R^{2} & =.48 \\
F(5 \quad 356) & =6633^{* * *}\end{aligned}$} & \multicolumn{4}{|c|}{$\begin{array}{c}R^{2}=.37 \\
F(4 \quad 357)=5234\end{array}$} & & & & & \multicolumn{4}{|c|}{$F(4,357)=26.09^{* * *}$} \\
\hline
\end{tabular}

$* p<.05 .{ }^{* *} p<.01 . * * * p<.001$

$F(4,357)=52.34^{* * *}$

$F(4,357)=19.66^{* *}$

Table 8 .

Moderated Mediation Analyses using Ability as the Antecedent

\begin{tabular}{|c|c|c|c|c|c|c|c|c|c|c|c|c|c|c|c|c|}
\hline \multirow[b]{3}{*}{ Antecedent } & \multicolumn{16}{|c|}{ Consequent } \\
\hline & \multicolumn{4}{|c|}{ Unfairness } & \multicolumn{4}{|c|}{ Anger } & \multicolumn{4}{|c|}{ Fear } & \multicolumn{4}{|c|}{ Sympathy } \\
\hline & $B$ & $S E$ & $L L$ & $U L$ & $B$ & $S E$ & $L L$ & $U L$ & $B$ & $S E$ & $L L$ & $U L$ & $B$ & $S E$ & $L L$ & $U L$ \\
\hline Gender & -0.15 & 0.08 & -0.31 & 0.01 & -0.06 & 0.06 & -0.18 & 0.06 & 0.06 & 0.07 & -0.08 & 0.19 & $0.18^{\dagger}$ & 0.10 & -0.02 & 0.38 \\
\hline Supervisor & $0.25^{* *}$ & 0.08 & 0.09 & 0.41 & 0.06 & 0.06 & -0.07 & 0.18 & 0.002 & 0.07 & -0.14 & 0.14 & -0.01 & 0.10 & -0.22 & 0.19 \\
\hline Unfairness (M) & & & & & $0.42^{* * *}$ & 0.04 & 0.34 & 0.50 & $0.36^{* * *}$ & 0.05 & 0.27 & 0.45 & $-0.32^{* * *}$ & 0.07 & -0.45 & -0.19 \\
\hline Ability (X) & $-0.57^{* * *}$ & 0.08 & -0.73 & -0.42 & -0.04 & 0.05 & -0.13 & 0.05 & 0.05 & 0.05 & -0.06 & 0.16 & $0.48^{* * *}$ & 0.08 & 0.33 & 0.64 \\
\hline Accommodation (W) & 0.44 & 0.39 & -0.33 & 1.21 & & & & & & & & & & & & \\
\hline \multirow[t]{2}{*}{$\mathrm{X} \times \mathrm{W}$} & -0.14 & 0.10 & -0.35 & 0.07 & & & & & \multirow{2}{*}{\multicolumn{4}{|c|}{$R^{2}=.18$}} & \multirow{2}{*}{\multicolumn{4}{|c|}{$\begin{array}{c}R^{2}=.29 \\
F(4,357)=36.80^{*}\end{array}$}} \\
\hline & \multicolumn{4}{|c|}{$R^{2}=.33$} & \multicolumn{4}{|c|}{$\begin{aligned} R^{2} & =.35\end{aligned}$} & & & & & & & & \\
\hline
\end{tabular}

$* p<.05 . * * p<.01 .{ }^{* * *} p<.001$. 
Table 9.

Moderated Mediation Analyses using Blameworthy as the Antecedent

\begin{tabular}{|c|c|c|c|c|c|c|c|c|c|c|c|c|c|c|c|c|}
\hline \multirow[b]{3}{*}{ Antecedent } & \multicolumn{16}{|c|}{ Consequent } \\
\hline & \multicolumn{4}{|c|}{ Unfairness } & \multicolumn{4}{|c|}{ Anger } & \multicolumn{4}{|c|}{ Fear } & \multicolumn{4}{|c|}{ Sympathy } \\
\hline & $B$ & $S E$ & $L L$ & $U L$ & $B$ & $S E$ & $L L$ & $U L$ & $B$ & $S E$ & $L L$ & $U L$ & $B$ & $S E$ & $L L$ & $\overline{U L}$ \\
\hline Gender & 0.08 & 0.08 & -0.07 & 0.25 & 0.02 & 0.06 & -0.10 & 0.13 & 0.09 & 0.07 & -0.05 & 0.23 & 0.08 & 0.11 & -0.13 & 0.30 \\
\hline Supervisor & 0.04 & 0.08 & -0.12 & 0.20 & 0.01 & 0.06 & -0.11 & 0.13 & -0.01 & 0.07 & -0.16 & 0.13 & 0.09 & 0.11 & -0.12 & 0.30 \\
\hline Unfairness (M) & & & & & $0.32^{* * *}$ & 0.04 & 0.24 & 0.39 & $0.27^{* * *}$ & 0.05 & 0.18 & 0.36 & $-0.44^{* * *}$ & 0.07 & -0.58 & -0.30 \\
\hline Blameworthy (X) & $0.57^{* * *}$ & 0.06 & 0.45 & 0.69 & $0.21^{* * *}$ & 0.04 & 0.14 & 0.29 & $0.11^{*}$ & 0.05 & 0.02 & 0.21 & $-0.19^{* *}$ & 0.07 & -0.34 & -0.05 \\
\hline Accommodation (W) & -0.18 & 0.20 & -0.57 & 0.21 & & & & & & & & & & & & \\
\hline \multirow[t]{2}{*}{$\mathrm{X} \times \mathrm{W}$} & 0.08 & 0.09 & -0.09 & 0.25 & \multirow{2}{*}{\multicolumn{4}{|c|}{$\begin{aligned} R^{2} & =.39 \\
F(4,357) & =57.75\end{aligned}$}} & \multirow{2}{*}{\multicolumn{4}{|c|}{$\begin{array}{c}R^{2}=.19 \\
357)=2118\end{array}$}} & \multirow{2}{*}{\multicolumn{4}{|c|}{$\begin{array}{c}R^{2}=.23 \\
F(4,357)=26.64\end{array}$}} \\
\hline & \multicolumn{4}{|c|}{$\begin{array}{c}R^{2}=.36 \\
F(5-356)=4037\end{array}$} & & & & & & & & & & & & \\
\hline
\end{tabular}

${ }^{*} p<.05 .{ }^{* *} p<.01 .{ }^{* * *} p<.001$

Table 10.

Moderated Mediation Analyses using Dangerous as the Antecedent

\begin{tabular}{|c|c|c|c|c|c|c|c|c|c|c|c|c|c|c|c|c|}
\hline \multirow[b]{3}{*}{ Antecedent } & \multicolumn{16}{|c|}{ Consequent } \\
\hline & \multicolumn{4}{|c|}{ Unfairness } & \multicolumn{4}{|c|}{ Anger } & \multicolumn{4}{|c|}{ Fear } & \multicolumn{4}{|c|}{ Sympathy } \\
\hline & $B$ & $S E$ & $L L$ & $U L$ & $B$ & $S E$ & $L L$ & $U L$ & $B$ & $S E$ & $L L$ & $U L$ & $B$ & $S E$ & $L L$ & $U L$ \\
\hline Gender & -0.05 & 0.08 & -0.20 & 0.11 & -0.04 & 0.06 & -0.16 & 0.08 & 0.07 & 0.07 & -0.06 & 0.21 & 0.14 & 0.11 & -0.07 & 0.35 \\
\hline Supervisor & 0.10 & 0.08 & -0.05 & 0.26 & 0.04 & 0.06 & -0.08 & 0.16 & -0.01 & 0.07 & -0.15 & 0.13 & 0.06 & 0.11 & -0.15 & 0.27 \\
\hline Unfairness (M) & & & & & $0.35^{* * *}$ & 0.04 & 0.27 & 0.43 & $0.23^{* * *}$ & 0.05 & 0.14 & 0.32 & $-0.48^{* * *}$ & 0.07 & -0.62 & -0.34 \\
\hline Dangerous (X) & $0.64^{* * *}$ & 0.07 & 0.51 & 0.77 & $0.17^{* * *}$ & 0.04 & 0.08 & 0.26 & $0.20^{* * *}$ & 0.05 & 0.10 & 0.30 & -0.13 & 0.08 & -0.28 & 0.03 \\
\hline Accommodation (W) & -0.11 & 0.21 & -0.53 & 0.30 & & & & & & & & & & & & \\
\hline \multirow[t]{2}{*}{$\mathrm{XxW}$} & 0.03 & 0.09 & -0.15 & 0.22 & \multirow{2}{*}{\multicolumn{4}{|c|}{$\begin{array}{c}R^{2}=.37 \\
F(4,357)=52.73\end{array}$}} & \multirow{2}{*}{\multicolumn{4}{|c|}{$\begin{aligned} R^{2} & =.21 \\
F(4,357) & =24.05^{*}\end{aligned}$}} & \multirow{2}{*}{\multicolumn{4}{|c|}{$\begin{array}{c}R^{2}=.22 \\
F(4,357)=25.24^{* * *}\end{array}$}} \\
\hline & \multicolumn{4}{|c|}{$\begin{aligned} R^{2} & =.37 \\
F(5,356) & =4141^{*}\end{aligned}$} & & & & & & & & & & & & \\
\hline
\end{tabular}

${ }^{*} p<.05 .{ }^{* *} p<.01 .{ }^{* * *} p<.001$

$$
\begin{aligned}
R^{2} & =.37 \\
F(5,356) & =41.41^{* * *}
\end{aligned}
$$$$
F(4,357)=52.73^{* * *}
$$$$
F(4,357)=24.05^{* * *}
$$ 
Table 11.

Indirect Effects of Stereotypes on Anger, Fear, and Sympathy (Study 1)

\begin{tabular}{|c|c|c|c|c|c|c|c|c|}
\hline \multirow[b]{2}{*}{ Path of Indirect Effect } & \multicolumn{4}{|c|}{ No Accommodation } & \multicolumn{4}{|c|}{ Accommodation } \\
\hline & $B$ & $\begin{array}{c}\text { Boot } \\
\text { SE }\end{array}$ & $\begin{array}{c}\text { Boot } \\
\text { LL }\end{array}$ & $\begin{array}{c}\text { Boot } \\
\text { UL }\end{array}$ & $B$ & $\begin{array}{c}\text { Boot } \\
\text { SE }\end{array}$ & $\begin{array}{c}\text { Boot } \\
\text { LL }\end{array}$ & $\begin{array}{c}\text { Boot } \\
U L\end{array}$ \\
\hline \multicolumn{9}{|l|}{ Anger } \\
\hline Malingering - Unfair - Anger & 0.23 & 0.04 & 0.15 & 0.32 & 0.24 & 0.05 & 0.15 & 0.34 \\
\hline Ability - Unfair - Anger & -0.24 & 0.05 & -0.34 & -0.15 & -0.30 & -0.05 & -0.40 & -0.20 \\
\hline Blameworthy - Unfair - Anger & 0.18 & 0.03 & 0.12 & 0.25 & 0.20 & 0.04 & 0.13 & 0.29 \\
\hline Dangerous - Unfair - Anger & 0.22 & 0.04 & 0.14 & 0.31 & 0.23 & 0.05 & 0.15 & 0.33 \\
\hline \multicolumn{9}{|l|}{ Fear } \\
\hline Malingering - Unfair — Fear & 0.21 & 0.05 & 0.12 & 0.32 & 0.22 & 0.06 & 0.12 & 0.34 \\
\hline Ability — Unfair — Fear & -0.20 & 0.04 & -0.29 & -0.12 & -0.25 & 0.05 & -0.35 & -0.16 \\
\hline Blameworthy - Unfair — Fear & 0.15 & 0.03 & 0.09 & 0.22 & 0.17 & 0.04 & 0.10 & 0.26 \\
\hline Dangerous - Unfair - Fear & 0.14 & 0.04 & 0.08 & 0.22 & 0.15 & 0.04 & 0.08 & 0.24 \\
\hline \multicolumn{9}{|l|}{ Sympathy } \\
\hline Malingering - Unfair — Sympathy & -0.30 & 0.06 & -0.42 & -0.17 & -0.31 & 0.07 & -0.44 & -0.18 \\
\hline Ability - Unfair — Sympathy & 0.18 & 0.05 & 0.10 & 0.29 & 0.23 & 0.05 & 0.13 & 0.34 \\
\hline Blameworthy — Unfair — Sympathy & -0.25 & 0.05 & -0.35 & -0.16 & -0.28 & 0.06 & -0.41 & -0.18 \\
\hline Dangerous - Unfair — Sympathy & -0.31 & 0.06 & -0.43 & -0.20 & -0.32 & 0.06 & -0.45 & -0.20 \\
\hline
\end{tabular}

Notes. Boot $\mathrm{SE}=$ bootstrap standard error, Boot LL = bootstrap lower limit of $95 \%$ confidence interval, Boot UL = bootstrap upper limit of $95 \%$ confidence interval. Confidence intervals not including zero represent a significant indirect effect. Bootstrap estimates for standard errors and confidence intervals were generated using 5000 bootstrap samples.

\section{Impact of Emotions on Behavioural Outcomes}

The third set of research questions represented by the model in Figure 3 examined whether emotional responses to the vignettes were associated with behavioural outcomes. Specifically, these questions addressed whether anger, fear, and sympathy predicted willingness to socialize with or give a job recommendation for the colleague described in the vignettes. Because of the high correlation between anger and fear $(r=.71)$, the behavioural outcomes were first regressed separately on anger, fear, and sympathy in 
order to examine the unique impact of each emotion and then again with anger, fear, and sympathy entered simultaneously to examine the total variance explained by all three emotions together. Results for willingness to socialize with and willingness to give a job recommendation are shown in Table 12 and Table 13, respectively.

Examining the separate regressions of willingness to socialize on anger, fear, and sympathy, willingness to socialize was negatively associated with anger and fear and positively associated with sympathy, separately explaining $15 \%, 8 \%$, and $27 \%$ of the total variance, respectively. When anger, fear, and sympathy were simultaneously included in the regression, all three emotions explained $33 \%$ of the total variance in willingness to socialize.

Examining the separate regressions for willingness to give a job recommendation on anger, fear, and sympathy, willingness to recommend was also negatively associated with anger and fear and positively associated with sympathy. When anger, fear, and sympathy were simultaneously included in the regression, all three emotions explained $19 \%$ of the total variance in willingness to recommend.

In sum, there was strong evidence to support the model proposed in Figure 3. Separately, sympathy explained more of the variance in both willingness to socialize with and give a job recommendation, followed by anger and fear, respectively. Together all three emotions explained more variance than each did separately. Hence, feeling less sympathetic, angrier, and more afraid in response to the vignette was associated with a greater likelihood of discriminatory behaviours. 
Table 12.

Regression Results for Willingness to Socialize (Study 1)

\begin{tabular}{|c|c|c|c|c|c|c|c|c|c|c|c|c|c|c|c|c|}
\hline \multirow[b]{2}{*}{ Antecedent } & \multicolumn{16}{|c|}{ Willingness to Socialize } \\
\hline & $B$ & $S E$ & $L L$ & $U L$ & $B$ & $S E$ & $L L$ & $U L$ & $B$ & $S E$ & $L L$ & $U L$ & $B$ & $S E$ & $L L$ & $U L$ \\
\hline Gender & 0.05 & 0.08 & -0.11 & 0.20 & 0.10 & 0.08 & -0.06 & 0.26 & 0.02 & 0.07 & -0.13 & 0.16 & 0.00 & 0.07 & -0.14 & 0.14 \\
\hline Supervisor & 0.09 & 0.08 & -0.07 & 0.25 & 0.05 & 0.08 & -0.12 & 0.21 & 0.05 & 0.07 & -0.09 & 0.20 & 0.09 & 0.07 & -0.05 & 0.23 \\
\hline Anger & $-0.44^{* * *}$ & 0.06 & -0.55 & -0.33 & & & & & & & & & $-0.20^{* *}$ & 0.07 & -0.35 & -0.05 \\
\hline Fear & & & & & $-0.30^{* * *}$ & 0.06 & -0.41 & -0.19 & & & & & -0.12 & 0.07 & -0.26 & 0.01 \\
\hline \multirow{2}{*}{ Sympathy } & \multirow{2}{*}{\multicolumn{4}{|c|}{$\begin{array}{c}R^{2}=.15 \\
F(3,358)=20.96^{* *}\end{array}$}} & & & & & $0.37^{* * *}$ & 0.03 & 0.31 & 0.43 & $0.33^{* * *}$ & 0.03 & 0.26 & 0.39 \\
\hline & & & & & & $\begin{array}{r}R^{2}= \\
358)=\end{array}$ & $\begin{array}{l}.08 \\
=10.14\end{array}$ & & \multicolumn{4}{|c|}{$\begin{array}{c}R^{2}=.27 \\
F(3,358)=43.8^{* * *}\end{array}$} & \multicolumn{4}{|c|}{$\begin{array}{c}R^{2}=.33 \\
F(5,356)=35.72^{* * *}\end{array}$} \\
\hline
\end{tabular}

Table 13.

Regression Results for Willingness to Give a Job Recommendation (Study 1)

\begin{tabular}{|c|c|c|c|c|c|c|c|c|c|c|c|c|c|c|c|c|}
\hline \multirow[b]{2}{*}{ Antecedent } & \multicolumn{16}{|c|}{ Willingness to Recommend } \\
\hline & $B$ & $S E$ & $L L$ & $U L$ & $B$ & $S E$ & $L L$ & $U L$ & $B$ & $S E$ & $L L$ & $U L$ & $B$ & $S E$ & $L L$ & $U L$ \\
\hline Gender & 0.05 & 0.10 & -0.15 & 0.26 & 0.10 & 0.11 & -0.10 & 0.31 & 0.02 & 0.10 & -0.17 & 0.21 & 0.00 & 0.10 & -0.19 & 0.19 \\
\hline Supervisor & 0.09 & 0.11 & -0.12 & 0.30 & 0.05 & 0.11 & -0.16 & 0.26 & 0.06 & 0.10 & -0.13 & 0.26 & 0.09 & 0.10 & -0.10 & 0.29 \\
\hline Anger & $-0.37^{* * *}$ & 0.07 & -0.51 & -0.22 & & & & & & & & & $-0.23^{*}$ & 0.10 & -0.43 & -0.03 \\
\hline Fear & & & & & $-0.18^{*}$ & 0.07 & -0.32 & -0.04 & & & & & 0.02 & 0.09 & -0.17 & 0.20 \\
\hline Sympathy & & & & & & & & & $0.37^{* * *}$ & 0.04 & 0.28 & 0.45 & $0.33^{* * *}$ & 0.05 & 0.24 & 0.42 \\
\hline & $F(3$ & $\begin{array}{c}R^{2}= \\
356)\end{array}$ & $\begin{array}{l}.07 \\
=8.67\end{array}$ & & & $\begin{array}{r}R^{2}= \\
3,356)\end{array}$ & $\begin{array}{l}.02 \\
=2.44\end{array}$ & & & $\begin{array}{c}R^{2}= \\
356)\end{array}$ & $\begin{array}{l}.17 \\
=24.68\end{array}$ & & $F(5$, & $\begin{array}{c}R^{2}= \\
354)=\end{array}$ & $\begin{array}{l}.19 \\
=16.90\end{array}$ & \\
\hline
\end{tabular}

$* p<.05 .{ }^{*} p<.01 . * * * p<.001$. 


\section{Study 1 Summary}

The objective of Study 1 was to investigate whether accommodations increase stigma towards depression and anxiety. First, I examined how levels of perceived malingering, ability, blameworthiness, and dangerousness for depression and anxiety compared to surgery were influenced by accommodations. Second, I examined whether perceived unfairness mediated the associations between each of these negative stereotypes and emotional responses. Third, I examined whether these emotional reactions were in turn associated with behavioural intentions to socialize or give a job recommendation.

Counter to expectations, receiving an accommodation had no effect on endorsement of negative stereotypes for either depression or anxiety compared to surgery. Moreover, overall endorsement of stereotypes was surprisingly low, suggesting that, as a group, the participants in this sample held fairly positive attitudes towards coworkers with both mental and physical health problems. This does not mean, however, that stigma does not exist. Rather, the proportion of participants in this sample who held negative attitudes was small compared to those who held positive attitudes. In addition, the results suggest that coworkers with depression or anxiety are viewed as somewhat more dangerous and less able compared to coworkers recovering from surgery. Given that there was strong evidence that participants who endorsed negative stereotypes were more likely to react negatively, it is important to understand whether these results are generalizable to work environments where employees may be more likely to disclose mental health problems and to request accommodations. 


\section{Study 2 Introduction}

There were two main goals for Study 2. The first goal was to evaluate generalizability of the findings from Study 1 through replication with a sample from the Canadian public service, a unionized work environment that promotes employee rights to accommodations for mental health problems (Public Service Alliance of Canada, n.d.). The second goal was to assess the influence of providing educational information describing the employer's duty to accommodate and the purpose of job accommodations. I, therefore, used the same vignettes and measures from Study 1 in a sample of working adults employed by a department of the federal government of Canada. In addition to being randomly assigned to read one of six vignettes, participants in Study 2 were also randomly assigned to the information condition. Despite the accommodation condition having no impact in Study 1, I anticipated that adding the information condition would be beneficial for at least two reasons. First, accommodations might be viewed differently in an organizational sample from the Canadian public service compared to a population sample primarily from the United States. Second, the information condition should generally improve perceptions of accommodations.

\section{Study 2 Method}

\section{Participants}

Participants were recruited from a large department of the Canadian federal government. The initial sample comprised 329 individuals. Participants who declined consent ( $n=12)$, accepted consent but then quit $(n=8)$, viewed the scenario but then quit ( $n=21)$, or quit before answering manipulation checks $(n=17)$ were removed. A further 56 responses were excluded for failing manipulation checks. Finally, participants who did 
not respond to demographics $(n=7)$ were excluded from the analyses. The final sample $(N=207)$ included 53 male and 154 female participants with a mean age of 43.02 years $(S D=10.95$ years $)$ and a mean of 22.59 years $(S D=10.76$ years $)$ experience in the paid workforce. Of these participants, 95.6\% worked full-time, $29.0 \%$ were supervisors, and the majority were well-educated (8.2\% high school, $28.0 \%$ college diploma, $44.4 \%$ bachelor's degree, $11.6 \%$ graduate degree, $4.3 \%$ professional designation, $3.4 \%$ other).

\section{Procedure}

The recruitment notice (see Appendix F) was sent out as part of a weekly enewsletter about the department to all employees. Clicking the link in the recruitment notice took participants to the study hosted on the Qualtrics online survey platform. The study began with consent information (see Appendix G), which ended with an item asking participants if they voluntarily agree to participate. For those participants who consented, the procedure then followed the same steps as Study 1 with the addition of the information manipulation. After reading one of the six vignettes varying reason for leave (surgery vs depression vs anxiety), half of the participants read information on the employer's duty to accommodate and the purpose of job accommodations. The follow-up information (see Appendix H) was also changed to include only Canadian resources.

\section{Measures}

All measures from Study 1 including vignettes were used for Study 2. In addition, half of the participants were presented with educational information about job accommodations including information on human rights legislation, employers' duty to accommodate employees with mental and physical health conditions, and limitations on 
the duty to accommodate. The complete text of the educational information was as follows:

Employees with mental and physical health disabilities are protected from discrimination under the Canadian Human Rights Act. When an employee has a mental or physical health condition that results in a limitation of skills or abilities, employers have a duty to accommodate. This can mean changes to rules or practices that prevent these employees from fully participating in the workplace. This does not mean that an employer is obligated to employ a person who cannot perform essential job functions. This also does not mean lowering standards of qualifications for a particular job.

\section{Study 2 Results}

\section{Preliminary Analyses}

Descriptive statistics. Means, standard deviations, and correlations for all study variables are shown in Table 14. At the group level, the means indicated low endorsement of negative stereotypes (i.e., malingering, ability, blameworthiness, and dangerousness), positive emotional responses (i.e., low anger, low fear, high sympathy), and willingness to socialize. Participants also tended to disagree that the situation described in the vignette would be unfair to themselves or others at work. There were small correlations between the stereotype variables and anger, but only the dangerous stereotype was associated with fear. Of the three emotion variables, sympathy was most strongly correlated with all negative stereotypes. Although participant gender and supervisor status were not correlated with other study variables, they were included in the main regression analyses as control variables to allow for comparisons with Study 1 results and because prior research suggests these variables can impact stigma outcomes.

Cronbach's alphas for each of the scales are included on the diagonal. Internal consistency for the blameworthy and dangerous items was similar to past research (e.g., 
Schomerus et al, 2016). In comparison, internal consistency was lower for the anger and fear items used in past research and for the malinger, ability, and unfairness items created for the present research. This suggests that the sample for Study 2 differs in some way from a sample taken from the general population and that these scales have a higher degree of measurement error for this sample.

Participant gender and supervisor status. Although participant gender and supervisor status were not correlated with key study variables as in Study 1, I conducted a chi-square test on these two variables for comparison with Study 1 and to increase my understanding of sample characteristics. As shown in Table 15, the distribution of males and females into the supervisor and non-supervisor categories did not differ from expected, $\chi^{2}(1,207)=1.63, p=.20$, indicating no association between participant gender and supervisor status.

Outliers. The data were examined for univariate outliers using boxplots for unfairness, each of the stereotype variables (i.e., malingering, ability, blameworthy, dangerous), emotion variables (i.e., anger, fear, sympathy), and behaviour variables (i.e., willingness to socialize, recommend for job). There was 1 extreme outlier for the unfairness variable and 8 extreme outliers for the anger variable. An examination of scatterplots, studentized residuals, and Mahalanobis' distances, however, revealed no multivariate outliers. Therefore, all cases were retained for analyses. 
Table 14.

Means, Standard Deviations, and Correlations for Key Variables (Study 2)

\begin{tabular}{|c|c|c|c|c|c|c|c|c|c|c|c|c|c|c|}
\hline & $M$ & $S D$ & 1 & 2 & 3 & 4 & 5 & 6 & 7 & 8 & 9 & 10 & 11 & 12 \\
\hline 1. Malingering & 1.60 & 0.62 & $(.75)$ & & & & & & & & & & & \\
\hline 2. Ability & 3.78 & 0.66 & $-.35^{* * *}$ & $(.63)$ & & & & & & & & & & \\
\hline 3. Blameworthy & 1.50 & 0.65 & $.56^{* * *}$ & $-.34^{* * *}$ & $(.86)$ & & & & & & & & & \\
\hline 4. Dangerous & 1.71 & 0.65 & $.34^{* * *}$ & $-.37^{* * *}$ & $.68^{* * *}$ & $(.74)$ & & & & & & & & \\
\hline 5. Unfairness & 1.81 & 0.66 & $.53^{* * *}$ & $-.44^{* * *}$ & $.44^{* * *}$ & $.34^{* * *}$ & $(.60)$ & & & & & & & \\
\hline 6. Anger & 1.22 & 0.40 & .12 & $-.14^{* *}$ & $.19^{* *}$ & $.12^{*}$ & $.19^{* *}$ & $(.67)$ & & & & & & \\
\hline 7. Fear & 1.64 & 0.65 & .03 & -.05 & .03 & $.17^{*}$ & $.21^{* *}$ & $.42^{* * *}$ & $(.68)$ & & & & & \\
\hline 8. Sympathy & 3.98 & 0.80 & $-.39^{* * *}$ & $.37^{* * *}$ & $-.43^{* * *}$ & $-.30^{* * *}$ & $-.39^{* * *}$ & $-.19^{* *}$ & -.03 & - & & & & \\
\hline 9. Recommend & 3.71 & 0.86 & $-.21^{* *}$ & $.43^{* * *}$ & $-.36^{* * *}$ & $-.36^{* * *}$ & $-.34^{* * *}$ & $-.22^{* * *}$ & $-.17^{*}$ & $.32^{* * *}$ & - & & & \\
\hline 10. Socialize & 4.03 & 0.61 & $-.32^{* * *}$ & $.48^{* * *}$ & $-.48^{* * *}$ & $-.33^{* * *}$ & $-.34^{* * *}$ & $-.25^{* *}$ & -.12 & $.39^{* * *}$ & $.70^{* * *}$ & $(.89)$ & & \\
\hline 11. Gender ${ }^{\mathrm{a}}$ & - & - & .00 & .04 & -.01 & -.09 & .11 & .08 & -.03 & -.07 & .14 & .10 & - & \\
\hline 12. Supervisor ${ }^{\mathrm{b}}$ & - & - & -.11 & -.07 & -.00 & .06 & .10 & .00 & -.03 & -.11 & -.09 & -.03 & -.09 & - \\
\hline 13. Age & 43.02 & 10.95 & -.09 & .07 & -.05 & .07 & -.09 & -.03 & .02 & -.10 & .03 & .05 & -.09 & $.21^{* *}$ \\
\hline
\end{tabular}

Notes. $N=207$. Cronbach's alphas are listed on the diagonal in parentheses.

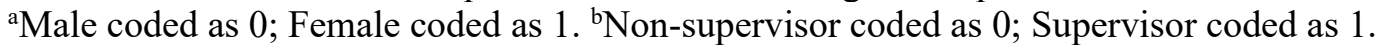

${ }^{*} p<.05 .{ }^{* *} p<.01 .{ }^{* * *} p<.001$. 
Table 15.

Distribution of Males and Females according to Supervisor Status (Study 2)

\begin{tabular}{lccccccc}
\hline & \multicolumn{3}{c}{ Non-supervisors } & & \multicolumn{3}{c}{ Supervisors } \\
\cline { 2 - 4 } \cline { 7 - 9 } \cline { 6 - 9 } & Observed & Expected & $\%$ Gender & & Observed & Expected & $\%$ Gender \\
\hline Males & 34 & 38 & $64.2 \%$ & & 19 & 15 & $35.8 \%$ \\
Females & 113 & 109 & $44.6 \%$ & & 41 & 45 & $26.6 \%$ \\
\hline
\end{tabular}

Note. $\chi^{2}(1,207)=1.63, p=.20$

Missing data. Of the 207 cases in the dataset, 12 (5.7\%) had missing data; 11 of these cases were missing data on one item and 1 of these cases was missing data on 9 items, which made up the scales for anger and fear. Little's MCAR test was nonsignificant, $\chi^{2}=297.87, d f=340, p=.95$, indicating that all data were missing completely at random. Therefore, all cases were retained for the subsequent regression analyses. The one case missing data for the anger and fear scales was excluded from all analyses that used these two variables.

Assumption testing. Finally, tests of assumptions of ordinary least squares regression were also conducted. Plots of zpred vs zresid were created to test assumptions of linearity and homoscedasticity. Normal Q-Q plots and boxplots were generated and Ztests of skew and kurtosis were conducted to test the assumption of normality.

Assumptions of linearity, homoscedasticity, and normality for regression were met.

\section{Impact of Accommodations and Info on Negative Stereotypes}

The first set of research questions represented by the moderation model in Figure 1 examined the impact of accommodations and educational information about accommodations on endorsement of negative stereotypes for depression and anxiety 
compared to a physical health problem. To test these research questions, I conducted hierarchical multiple regression analyses using each of the stereotype variables (i.e., perceived malingering, ability, blameworthiness, and dangerousness) as outcomes. Means and standard deviations for each outcome variable by reason for leave, accommodation, and educational information are included as supplementary tables in Appendix E.

For the regression analyses, the categorical variables created for Study 1 were again used for Study 2. This included one dichotomous variable to represent the manipulation of accommodation [yes=extra time for tasks and time off work for appointments, no=returning to regular duties and schedule], and two dummy-coded variables, depression $\left(D_{1}\right)$ and anxiety $\left(D_{2}\right)$, to represent the comparisons between depression and surgery and anxiety and surgery, respectively. A second dichotomous variable was created to represent whether or not participants were provided with educational info [yes, no] on accommodations. Two-way interaction terms were created by multiplying all combinations of the values of depression $\left(\mathrm{D}_{1}\right)$, accommodation $(\mathrm{W})$, and info $(Z)$ and all combination of the values of anxiety $\left(\mathrm{D}_{2}\right)$, accommodation $(\mathrm{W})$, and info $(Z)$. Three-way interaction terms were created by multiplying the values of depression $\left(\mathrm{D}_{1}\right)$, accommodation $(\mathrm{W})$, and info $(\mathrm{Z})$ and the values of anxiety $\left(\mathrm{D}_{2}\right)$, accommodation (W), and info (Z).

The regression analyses were run four times to test whether the effects of depression $\left(\mathrm{D}_{1}\right)$ and anxiety $\left(\mathrm{D}_{2}\right)$ on malingering $\left(\mathrm{Y}_{1}\right)$, ability $\left(\mathrm{Y}_{2}\right)$, blameworthy $\left(\mathrm{Y}_{3}\right)$, and dangerous $\left(\mathrm{Y}_{4}\right)$ were moderated by accommodation $(\mathrm{W})$ and info $(\mathrm{Z})$. As shown in Table 16 and Table 17, the accommodation and information manipulations had no impact on perceived malingering, blameworthy, or dangerous. There were no significant three- 
way interactions in Step 3 and no significant two-way interactions in Step 2. There were also no main effects in Step 1 for either accommodation or info for these outcomes.

Table 16.

Hierarchical Regression Analysis for Malingering and Ability (Study 2)

\begin{tabular}{|c|c|c|c|c|c|c|c|c|}
\hline & \multicolumn{4}{|c|}{ Malingering $\left(\mathrm{Y}_{1}\right)$} & \multicolumn{4}{|c|}{ Ability $\left(\mathrm{Y}_{2}\right)$} \\
\hline & $\overline{\Delta R^{2}}$ & $B$ & $S E$ & $\beta$ & $\overline{\Delta R^{2}}$ & $\bar{B}$ & $S E$ & $\beta$ \\
\hline Step 1 & .02 & & & & .01 & & & \\
\hline Gender & & -0.02 & 0.10 & -0.01 & & 0.05 & 0.11 & 0.03 \\
\hline Supervisor & & -0.15 & 0.10 & -0.11 & & -0.09 & 0.10 & -0.06 \\
\hline Depression & & -0.09 & 0.11 & -0.07 & & -0.03 & 0.11 & -0.02 \\
\hline Anxiety & & -0.01 & 0.11 & -0.01 & & -0.04 & 0.11 & -0.03 \\
\hline Accommodation & & 0.02 & 0.09 & 0.01 & & 0.07 & 0.09 & 0.05 \\
\hline Info & & 0.02 & 0.09 & 0.02 & & -0.02 & 0.09 & -0.01 \\
\hline Step 2 & .02 & & & & .05 & & & \\
\hline Info x Accommodation & & 0.00 & 0.18 & 0.00 & & -0.20 & 0.19 & -0.13 \\
\hline Info x Depression & & 0.19 & 0.21 & 0.11 & & 0.07 & 0.23 & 0.04 \\
\hline Info x Anxiety & & 0.41 & 0.22 & 0.24 & & -0.35 & 0.23 & -0.19 \\
\hline $\begin{array}{l}\text { Depression } \\
\text { x Accommodation }\end{array}$ & & 0.08 & 0.22 & 0.05 & & $-0.45^{*}$ & 0.23 & -0.27 \\
\hline $\begin{array}{l}\text { Anxiety } \\
\text { x Accommodation }\end{array}$ & & 0.10 & 0.22 & 0.06 & & $-0.40^{\dagger}$ & 0.23 & -0.23 \\
\hline Step 3 & .00 & & & & .00 & & & \\
\hline $\begin{array}{l}\text { Info x Depression } \\
\text { x Accommodation }\end{array}$ & & 0.10 & 0.43 & 0.05 & & -0.07 & 0.45 & -0.03 \\
\hline $\begin{array}{l}\text { Info x Anxiety } \\
\text { x Accommodation }\end{array}$ & & -0.26 & 0.44 & -0.12 & & -0.08 & 0.46 & -0.04 \\
\hline
\end{tabular}

Notes. Gender coded $0=$ male, $1=$ female. Supervisor coded $0=$ no, $1=$ yes. Depression and anxiety dummy-coded with surgery as reference. Accommodation coded $0=$ no, $1=$ yes. Info coded $0=$ no, $1=$ yes. $\dagger p<.10 . * p<.05 . * * p<.01 . * * * p<.001$.

Although there was no effect of the info manipulation on perceived ability, there was an unexpected effect of accommodation. As shown in Step 2 of the regression for ability in Table 16, there was a significant two-way interaction between depression and accommodation and a marginally significant two-way interaction between anxiety and accommodation. Further examination of these two-way interactions (see Figure 4) revealed that receiving an accommodation significantly predicted an increase in ability for surgery, $B=0.45, S E=0.19, \beta=0.34, t(195)=2.40, p=.02$, but not depression, $B=$ - 
$0.10, S E=0.16, \beta=-0.07, t(195)=-0.62, p=.53$, or anxiety, $B=-0.04, S E=0.16, \beta=-$ $0.03, t(195)=-0.27, p=.79$. Hence, rather than decreasing perceived ability for the mental health conditions, the accommodation resulted in a small increased in perceived ability for the surgery condition.

Table 17.

Hierarchical Regression Analysis for Blameworthy and Dangerous (Study 2)

\begin{tabular}{|c|c|c|c|c|c|c|c|c|}
\hline & \multicolumn{4}{|c|}{ Blameworthy $\left(\mathrm{Y}_{3}\right)$} & \multicolumn{4}{|c|}{ Dangerous $\left(\mathrm{Y}_{4}\right)$} \\
\hline & $\Delta R^{2}$ & $B$ & $S E$ & $\beta$ & $\Delta R^{2}$ & $B$ & $S E$ & $\beta$ \\
\hline Step 1 & .01 & & & & $.08^{* *}$ & & & \\
\hline Gender & & -0.03 & 0.11 & -0.02 & & -0.13 & 0.10 & -0.09 \\
\hline Supervisor & & -0.01 & 0.10 & -0.01 & & 0.06 & 0.10 & 0.04 \\
\hline Depression & & -0.05 & 0.11 & -0.04 & & $0.33^{* *}$ & 0.11 & 0.24 \\
\hline Anxiety & & 0.01 & 0.11 & 0.01 & & $0.39^{* * *}$ & 0.11 & 0.29 \\
\hline Accommodation & & 0.04 & 0.09 & 0.03 & & -0.04 & 0.09 & -0.03 \\
\hline Info & & 0.06 & 0.09 & 0.05 & & 0.06 & 0.09 & 0.04 \\
\hline Step 2 & .00 & & & & .01 & & & \\
\hline Info x Accommodation & & 0.05 & 0.19 & 0.03 & & 0.07 & 0.18 & 0.05 \\
\hline Info x Depression & & 0.08 & 0.23 & 0.04 & & -0.02 & 0.22 & -0.01 \\
\hline Info x Anxiety & & 0.00 & 0.23 & 0.00 & & -0.10 & 0.22 & -0.06 \\
\hline $\begin{array}{l}\text { Depression } \\
\text { x Accommodation }\end{array}$ & & 0.16 & 0.23 & 0.09 & & -0.07 & 0.22 & -0.04 \\
\hline $\begin{array}{l}\text { Anxiety } \\
\text { x Accommodation }\end{array}$ & & 0.03 & 0.23 & 0.02 & & -0.29 & 0.22 & -0.17 \\
\hline Step 3 & .03 & & & & .01 & & & \\
\hline $\begin{array}{l}\text { Info x Depression } \\
\text { x Accommodation }\end{array}$ & & 0.41 & 0.45 & 0.18 & & 0.29 & 0.44 & 0.13 \\
\hline $\begin{array}{l}\text { Info x Anxiety } \\
\text { x Accommodation }\end{array}$ & & -0.62 & 0.46 & -0.27 & & -0.42 & 0.44 & -0.18 \\
\hline
\end{tabular}




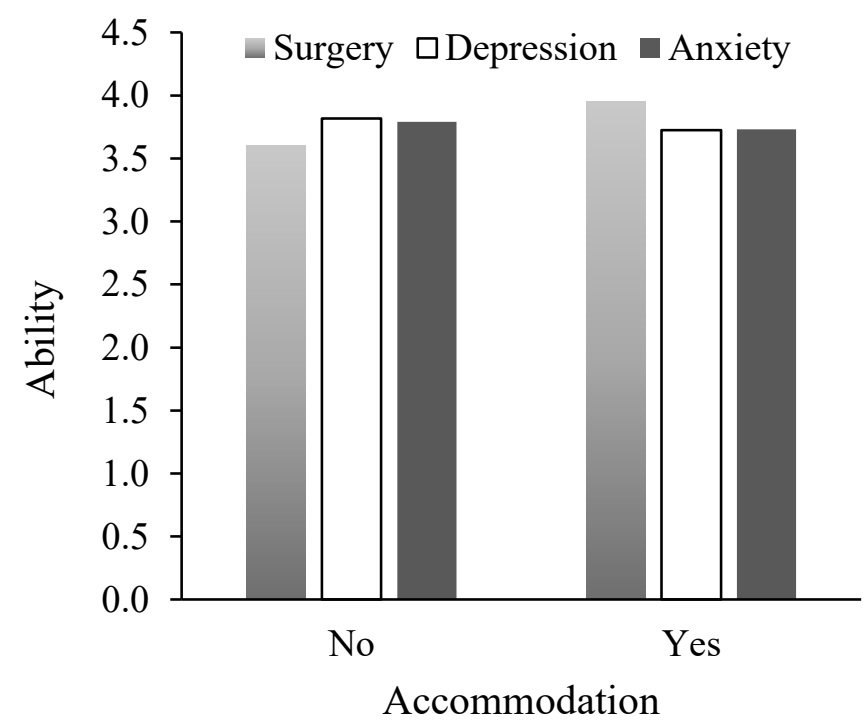

Figure 2. Plot of interaction between reason for leave and accommodation for perceived ability (Study 2)

Examining the main effects of depression and anxiety, only dangerous was significantly associated with depression or anxiety. Both depression and anxiety were associated with increased perceived dangerousness compared to surgery. Hence, there was little impact on negative stereotypes or perceived unfairness with the exception of perceived dangerousness.

To summarize the results for the research questions modelled in Figure 1, the information manipulation had no effect on any of the negative stereotypes or perceived unfairness. The accommodation manipulation interacted with depression and anxiety only in the regression for ability, with accommodation slightly increasing perceived ability for surgery. Finally, the only significant main effects in Step 1 of the regression analyses showed increased perceived dangerousness for both depression and anxiety compared to surgery. Hence, similar to Study 1, there was no evidence that the accommodation manipulation had any impact. Moreover, there was no evidence that providing 
educational information on accommodations reduced endorsement of negative stereotypes or perceived unfairness.

\section{Mediation of Stereotypes and Emotional Responses by Perceived Unfairness}

The second set of research questions represented by the moderated mediation model in Figure 2 examined 1) whether perceiving a situation to be unfair to oneself was a mediator of the association between negative stereotypes and emotional responses and 2) whether accommodations and information on accommodations moderated this proposed mediation. To test these research questions, I conducted moderated mediation analyses using model 11 of Hayes' (2018) PROCESS macro using malingering $\left(\mathrm{X}_{1}\right)$, ability $\left(\mathrm{X}_{2}\right)$, blameworthy $\left(\mathrm{X}_{3}\right)$, and dangerous $\left(\mathrm{X}_{4}\right)$ as the antecedent and angry $\left(\mathrm{Y}_{1}\right)$, afraid $\left(\mathrm{Y}_{2}\right)$, sympathy $\left(\mathrm{Y}_{3}\right)$, as the consequent. Each of the analyses included unfairness (M) as the mediator and both accommodation (W) and info (Z) as moderators.

Because there were no significant interactions with either moderator and no moderation of the indirect effects, I decided to simplify interpretation of the mediation analyses by dropping the moderator variables. I, therefore, repeated the analyses by conducting simple mediation analyses using Hayes' PROCESS macro (model 4) including unfairness $(\mathrm{M})$ as the mediator, malingering $\left(\mathrm{X}_{1}\right)$, ability $\left(\mathrm{X}_{2}\right)$, blameworthy $\left(\mathrm{X}_{3}\right)$, and dangerous $\left(\mathrm{X}_{4}\right)$ as antecedents, and anger $\left(\mathrm{Y}_{1}\right)$, fear $\left(\mathrm{Y}_{2}\right)$, and sympathy $\left(\mathrm{Y}_{3}\right)$ as consequents. Regression results for each mediation analysis are shown in Table 18, Table 19, Table 20, and Table 21. Indirect effects are shown in Table 22.

Results of the regressions showed that perceived unfairness was associated with all stereotype variables. Unfairness was positively associated with malingering, blameworthy, and dangerous and negatively associated with ability, suggesting that 
endorsing negative stereotypes increased how unfair participants perceived the situation described in the vignette to be for themselves. Unfairness was also positively associated with anger and fear but negatively associated with sympathy, indicating that perceiving the situation was more unfair to oneself was associated with more anger, more fear, and less sympathy.

Indirect effects. Examining the indirect effects of the negative stereotypes on emotional responses, the only significant indirect effect for anger was for danger, with perceived danger associated with increased anger through perceived unfairness. For fear, there were significant indirect effects for malinger, blame, and danger but not ability. Increases in malingering, blameworthy, and dangerous were all associated with increased fear through perceived unfairness. For sympathy, all indirect effects were significant; increases in malingering, blameworthy, and dangerous were associated with decreases in sympathy through perceived unfairness and increases in ability were associated with increases in sympathy through perceived unfairness.

Direct effects. Examining the direct effects of negative stereotypes on emotional responses, there were no significant effects of malingering, ability, blameworthy, or dangerous associated with anger. Moreover, there was only one marginally significant direct effect for fear, which was the negative association of fear with malingering. In contrast, all direct effects were significant for sympathy. Malingering, blameworthy, and dangerous were negatively associated with sympathy, and ability was positively associated with sympathy. 
Table 18.

Mediation Analyses using Malingering as the Antecedent (Study 2)

\begin{tabular}{|c|c|c|c|c|c|c|c|c|c|c|c|c|c|c|c|c|}
\hline \multirow[b]{3}{*}{ Antecedent } & \multicolumn{16}{|c|}{ Consequent } \\
\hline & \multicolumn{4}{|c|}{ Unfairness } & \multicolumn{4}{|c|}{ Anger } & \multicolumn{4}{|c|}{ Fear } & \multicolumn{4}{|c|}{ Sympathy } \\
\hline & $B$ & $S E$ & $L L$ & $U L$ & $B$ & $S E$ & $L L$ & $U L$ & $B$ & $S E$ & $L L$ & $U L$ & $B$ & $S E$ & $L L$ & $\overline{U L}$ \\
\hline Gender & $0.18^{*}$ & 0.09 & 0.01 & 0.36 & 0.06 & 0.06 & -0.07 & 0.19 & -0.10 & 0.10 & -0.31 & 0.10 & -0.04 & 0.14 & -0.31 & 0.23 \\
\hline Supervisor & $0.24^{* *}$ & 0.08 & 0.07 & 0.41 & -0.01 & 0.06 & -0.13 & 0.12 & -0.11 & 0.10 & -0.31 & 0.09 & -0.18 & 0.13 & -0.45 & 0.08 \\
\hline Unfairness (M) & & & & & $0.11^{*}$ & 0.05 & 0.01 & 0.21 & $0.29^{* * *}$ & 0.08 & 0.13 & 0.46 & $-0.33^{* *}$ & 0.11 & -0.54 & -0.11 \\
\hline \multirow[t]{2}{*}{ Malingering $(\mathrm{X})$} & $0.58^{* * *}$ & 0.06 & 0.46 & 0.70 & 0.01 & 0.05 & -0.09 & 0.12 & $-0.14^{\dagger}$ & 0.09 & -0.31 & 0.03 & $-0.42^{* * *}$ & 0.11 & -0.65 & -0.20 \\
\hline & \multicolumn{4}{|c|}{$\begin{array}{c}R^{2}=.32 \\
F(3,202)=3164\end{array}$} & \multicolumn{4}{|c|}{$R^{2}=.04$} & \multicolumn{4}{|c|}{$R^{2}=.06$} & \multicolumn{4}{|c|}{$\begin{array}{c}R^{2}=.21 \\
F(4,201)=13.13^{* * *}\end{array}$} \\
\hline
\end{tabular}

$* p<.05 . * * p<.01 . * * * p<.001$.

Table 19.

Mediation Analyses using Ability as the Antecedent (Study 2)

\begin{tabular}{|c|c|c|c|c|c|c|c|c|c|c|c|c|c|c|c|c|}
\hline \multirow[b]{3}{*}{ Antecedent } & \multicolumn{16}{|c|}{ Consequent } \\
\hline & \multicolumn{4}{|c|}{ Unfairness } & \multicolumn{4}{|c|}{ Anger } & \multicolumn{4}{|c|}{ Fear } & \multicolumn{4}{|c|}{ Sympathy } \\
\hline & $B$ & $S E$ & $L L$ & $U L$ & $B$ & $S E$ & $L L$ & $U L$ & $B$ & $S E$ & $L L$ & $U L$ & $B$ & $S E$ & $L L$ & $U L$ \\
\hline Gender & $0.19^{*}$ & 0.09 & 0.01 & 0.38 & 0.06 & 0.06 & -0.06 & 0.19 & -0.10 & 0.10 & -0.30 & 0.11 & -0.04 & 0.14 & -0.31 & 0.23 \\
\hline Supervisor & 0.12 & 0.09 & -0.06 & 0.30 & -0.01 & 0.06 & -0.13 & 0.11 & -0.08 & 0.10 & -0.27 & 0.12 & -0.08 & 0.13 & -0.34 & 0.18 \\
\hline Unfairness (M) & & & & & $0.09^{*}$ & 0.05 & 0.01 & 0.19 & $0.24^{* *}$ & 0.08 & 0.09 & 0.39 & $-0.39^{* * *}$ & 0.10 & -0.59 & -0.19 \\
\hline Ability (X) & $\begin{array}{r}-0.44^{* * *} \\
F(3\end{array}$ & $\begin{array}{c}0.06 \\
R^{2}= \\
202)=\end{array}$ & $\begin{array}{l}-0.56 \\
.21 \\
17.86 \\
\end{array}$ & -0.31 & -0.05 & $\begin{array}{c}0.05 \\
R^{2}= \\
4,201)\end{array}$ & $\begin{array}{l}-0.14 \\
.05 \\
=2.45^{*}\end{array}$ & 0.05 & 0.05 & $\begin{array}{r}0.08 \\
R^{2}= \\
+, 201) \\
\end{array}$ & $\begin{array}{l}-0.10 \\
.05 \\
=2.79^{*}\end{array}$ & 0.20 & $\begin{array}{r}0.36^{\text {*** }} \\
F(4,\end{array}$ & $\begin{array}{c}0.10 \\
R^{2}= \\
201)=\end{array}$ & $\begin{array}{l}0.16 \\
27 \\
18.32^{*}\end{array}$ & 0.56 \\
\hline
\end{tabular}

$* p<.05 .{ }^{* *} p<.01 .{ }^{* * *} p<.001$ 
Table 20.

Mediation Analyses using Blameworthy as the Antecedent (Study 2)

\begin{tabular}{|c|c|c|c|c|c|c|c|c|c|c|c|c|c|c|c|c|}
\hline \multirow[b]{3}{*}{ Antecedent } & \multicolumn{16}{|c|}{ Consequent } \\
\hline & \multicolumn{4}{|c|}{ Unfairness } & \multicolumn{4}{|c|}{ Anger } & \multicolumn{4}{|c|}{ Fear } & \multicolumn{4}{|c|}{ Sympathy } \\
\hline & $B$ & $S E$ & $L L$ & $U L$ & $B$ & $S E$ & $L L$ & $U L$ & $B$ & $S E$ & $L L$ & $U L$ & $B$ & $S E$ & $L L$ & $\overline{U L}$ \\
\hline Gender & $0.19^{*}$ & 0.09 & -0.01 & 0.37 & 0.06 & 0.06 & -0.06 & 0.19 & -0.10 & 0.10 & -0.30 & 0.11 & -0.04 & 0.13 & -0.31 & 0.22 \\
\hline Supervisor & $0.16^{\dagger}$ & 0.09 & -0.02 & 0.33 & -0.01 & 0.06 & -0.12 & 0.12 & -0.08 & 0.10 & -0.28 & 0.11 & -0.12 & 0.13 & -0.37 & 0.13 \\
\hline Unfairness (M) & & & & & $0.08^{\dagger}$ & 0.05 & -0.01 & 0.17 & $0.26^{* * *}$ & 0.08 & 0.11 & 0.41 & $-0.34^{* *}$ & 0.10 & -0.54 & -0.15 \\
\hline \multirow[t]{2}{*}{ Blameworthy (X) } & $0.45^{* * *}$ & 0.06 & 0.32 & 0.57 & 0.08 & 0.05 & -0.02 & 0.17 & -0.09 & 0.08 & -0.24 & 0.06 & $-0.47^{* * *}$ & 0.10 & -0.66 & -0.27 \\
\hline & \multicolumn{4}{|c|}{$\begin{array}{c}R^{2}=.22 \\
F(3,202)=18.69^{*}\end{array}$} & \multicolumn{4}{|c|}{$R^{2}=.05$} & \multicolumn{4}{|c|}{$\begin{array}{c}R^{2}=.06 \\
F(4,201)=3.01\end{array}$} & \multicolumn{4}{|c|}{$\begin{array}{c}R^{2}=.24 \\
201)=15.55^{* * *}\end{array}$} \\
\hline
\end{tabular}

$* p<.05 . * * p<.01 . * * * p<.001$.

Table 21.

Mediation Analyses using Dangerous as the Antecedent (Study 2)

\begin{tabular}{|c|c|c|c|c|c|c|c|c|c|c|c|c|c|c|c|c|}
\hline \multirow[b]{3}{*}{ Antecedent } & \multicolumn{16}{|c|}{ Consequent } \\
\hline & \multicolumn{4}{|c|}{ Unfairness } & \multicolumn{4}{|c|}{ Anger } & \multicolumn{4}{|c|}{ Fear } & \multicolumn{4}{|c|}{ Sympathy } \\
\hline & $B$ & $S E$ & $L L$ & $U L$ & $B$ & $S E$ & $L L$ & $U L$ & $B$ & $S E$ & $L L$ & $U L$ & $B$ & $S E$ & $L L$ & $U L$ \\
\hline Gender & 0.22 & 0.09 & 0.03 & 0.42 & 0.07 & 0.06 & -0.06 & 0.19 & -0.07 & 0.10 & -0.27 & 0.14 & -0.05 & 0.14 & -0.32 & 0.22 \\
\hline Supervisor & 0.13 & 0.09 & -0.06 & 0.32 & -0.01 & 0.06 & -0.13 & 0.11 & -0.08 & 0.10 & -0.27 & 0.12 & -0.08 & 0.13 & -0.34 & 0.18 \\
\hline Unfairness (M) & & & & & $0.10^{*}$ & 0.05 & 0.01 & 0.19 & $0.18^{*}$ & 0.07 & 0.04 & 0.33 & $-0.45^{* * *}$ & 0.10 & -0.65 & -0.26 \\
\hline Dangerous (X) & $\begin{array}{r}0.35^{* * *} \\
F(3\end{array}$ & $\begin{array}{c}0.07 \\
R^{2}= \\
202)=\end{array}$ & $\begin{array}{l}0.22 \\
.14 \\
10.96^{*}\end{array}$ & 0.48 & 0.05 & $\begin{array}{r}0.05 \\
R^{2}= \\
, 201) \\
\end{array}$ & $\begin{array}{l}-0.04 \\
.05 \\
=2.46^{*}\end{array}$ & 0.14 & 0.11 & $\begin{array}{c}0.07 \\
R^{2}= \\
+201) \\
\end{array}$ & $\begin{array}{l}-0.03 \\
.06 \\
=3.28^{*}\end{array}$ & 0.26 & $\begin{array}{r}-0.27^{* *} \\
F(4\end{array}$ & $\begin{array}{c}0.10 \\
R^{2}= \\
201)=\end{array}$ & $\begin{array}{l}-0.47 \\
18 \\
11.34^{*}\end{array}$ & -0.08 \\
\hline
\end{tabular}

$* p<.05 .{ }^{* *} p<.01 . * * * p<.001$ 
Table 22.

Indirect Effects of Stereotypes on Anger, Fear, and Sympathy (Study 2)

\begin{tabular}{|c|c|c|c|c|}
\hline \multirow[b]{2}{*}{ Path of Indirect Effect } & \multicolumn{4}{|c|}{ Indirect Effect } \\
\hline & $B$ & $\begin{array}{c}\text { Boot } \\
\text { SE }\end{array}$ & $\begin{array}{c}\text { Boot } \\
L L\end{array}$ & $\begin{array}{c}\text { Boot } \\
U L\end{array}$ \\
\hline \multicolumn{5}{|l|}{ Anger } \\
\hline Malingering — Unfair — Anger & 0.06 & 0.04 & -0.01 & 0.13 \\
\hline Ability - Unfair - Anger & -0.04 & 0.02 & -0.08 & 0.01 \\
\hline Blameworthy — Unfair — Anger & 0.04 & 0.02 & -0.01 & 0.08 \\
\hline Dangerous - Unfair - Anger & 0.03 & 0.02 & 0.01 & 0.07 \\
\hline \multicolumn{5}{|l|}{ Fear } \\
\hline Malingering — Unfair — Fear & 0.17 & 0.06 & 0.07 & 0.29 \\
\hline Ability — Unfair — Fear & -0.11 & 0.08 & -0.10 & 0.20 \\
\hline Blameworthy — Unfair — Fear & 0.12 & 0.04 & 0.04 & 0.20 \\
\hline Dangerous - Unfair - Fear & 0.06 & 0.03 & 0.01 & 0.13 \\
\hline \multicolumn{5}{|l|}{ Sympathy } \\
\hline Malingering - Unfair — Sympathy & -0.19 & 0.07 & -0.33 & -0.06 \\
\hline Ability — Unfair — Sympathy & 0.17 & 0.05 & 0.08 & 0.28 \\
\hline Blameworthy — Unfair — Sympathy & -0.15 & 0.05 & -0.26 & -0.06 \\
\hline Dangerous - Unfair - Sympathy & -0.16 & 0.05 & -0.26 & -0.07 \\
\hline
\end{tabular}

Notes. Boot SE = bootstrap standard error, Boot LL = bootstrap lower limit of 95\% confidence interval, Boot UL = bootstrap upper limit of $95 \%$ confidence interval. Confidence intervals not including zero represent a significant indirect effect. Bootstrap estimates for standard errors and confidence intervals were generated using 5000 bootstrap samples.

\section{Impact of Emotions on Behavioural Outcomes}

The third set of research questions represented by the model in Figure 3 examined whether emotional responses to the vignettes were associated with behavioural outcomes. As for Study 1, these questions addressed whether anger, fear, and sympathy predicted willingness to socialize with or give a job recommendation for the colleague described in the vignettes. Although the correlation between anger and fear, $r=.42$, was not large 
enough to expect issues of multicollinearity, the behavioural outcomes were first regressed separately on anger, fear, and sympathy in order to examine the unique impact of each emotion and then again with anger, fear, and sympathy entered simultaneously to examine the total variance explained by all three emotions together. This also allows for comparisons with the results of Study 1. Results for willingness to socialize and willingness to give a job recommendation are shown in Table 23 and Table 24, respectively.

Willingness to socialize. Examining the separate regressions of willingness to socialize on anger, fear, and sympathy, willingness to socialize was negatively associated with anger and positively associated with sympathy, separately explaining $7 \%$ and $11 \%$ of the total variance, respectively. Surprisingly, fear was not significantly associated with willingness to socialize and the model including only fear was also not significant. These results held when all three emotions were simultaneously entered as predictors of willingness to socialize. Anger and sympathy but not fear were significantly associated with willingness to socialize, and all three emotions combined explained $15 \%$ of the total variance.

Willingness to recommend. Examining the separate regressions of willingness to give a job recommendation on anger, fear, and sympathy, willingness to recommend was negatively associated with anger and fear and positively associated with sympathy. The models for these three emotions explained $8 \%, 5 \%$, and $10 \%$, respectively, of the total variance in willingness to recommend. When anger, fear, and sympathy were simultaneously included in one regression, however, the pattern of significance changed. Although sympathy remained significant, anger was only marginally significant, and fear 
was no longer significant. The total variance explained by all three emotions combined was $14 \%$.

In sum, Study 2 provided moderate evidence to support the model proposed in Figure 3. Separately, sympathy explained more of the variance in willingness to socialize followed by anger; however, fear was not significant. When all three emotions were entered into the regression simultaneously, this pattern of significance held and there was a small increase in explained variance over sympathy alone. All three emotions were associated with willingness to give a job recommendation when entered into the regression individually, with sympathy again explaining the most variance followed by anger and then fear. Entered simultaneously, only sympathy remained significant but there was again a small increase in explained variance over sympathy alone. Hence, although anger and fear both played a role, feeling less sympathetic appeared to be more important for behavioural intentions. 
Table 23.

Regression Results for Willingness to Socialize (Study 2)

\begin{tabular}{|c|c|c|c|c|c|c|c|c|c|c|c|c|c|c|c|c|}
\hline \multirow[b]{2}{*}{ Antecedent } & \multicolumn{16}{|c|}{ Willingness to Socialize } \\
\hline & $B$ & $S E$ & $L L$ & $U L$ & $B$ & $S E$ & $L L$ & $U L$ & $B$ & $S E$ & $L L$ & $U L$ & $B$ & $S E$ & $L L$ & $U L$ \\
\hline Gender & 0.17 & 0.09 & -0.01 & 0.35 & 0.15 & 0.10 & -0.04 & 0.34 & 0.14 & 0.09 & -0.04 & 0.33 & $0.16^{\dagger}$ & 0.09 & -0.02 & 0.34 \\
\hline Supervisor & 0.05 & 0.08 & -0.12 & 0.22 & -0.01 & 0.09 & -0.19 & 0.18 & 0.03 & 0.09 & -0.15 & 0.21 & 0.03 & 0.09 & -0.15 & 0.20 \\
\hline Anger & $-0.38^{* * *}$ & 0.10 & -0.59 & -0.17 & & & & & & & & & $-0.29^{*}$ & 0.11 & -0.51 & -0.07 \\
\hline Fear & & & & & -0.10 & 0.07 & -0.23 & 0.04 & & & & & -0.01 & 0.07 & -0.14 & 0.13 \\
\hline \multirow[t]{2}{*}{ Sympathy } & \multirow{2}{*}{\multicolumn{4}{|c|}{$\begin{array}{c}R^{2}=.07 \\
F(3,202)=4.93^{* *}\end{array}$}} & & & & & $0.21^{* * *}$ & 0.04 & 0.13 & 0.30 & $0.19^{* * *}$ & 0.04 & 0.10 & 0.28 \\
\hline & & & & & & $\begin{array}{r}R^{2}= \\
(3,202\end{array}$ & $\begin{array}{l}=.02 \\
2)=1.12\end{array}$ & & \multicolumn{4}{|c|}{$\begin{array}{c}R^{2}=.11 \\
F(3,202)=8.32^{* * *}\end{array}$} & \multicolumn{4}{|c|}{$\begin{array}{c}R^{2}=.15 \\
F(5,200)=6.84^{* * *}\end{array}$} \\
\hline
\end{tabular}

$* p<.05 .{ }^{* *} p<.01 .{ }^{* * *} p<.001$.

Table 24

Regression Results for Willingness to Give a Recommendation (Study 2)

\begin{tabular}{|c|c|c|c|c|c|c|c|c|c|c|c|c|c|c|c|c|}
\hline \multirow[b]{2}{*}{ Antecedent } & \multicolumn{16}{|c|}{ Willingness to Recommend } \\
\hline & $B$ & $S E$ & $L L$ & $U L$ & $B$ & $S E$ & $L L$ & $U L$ & $B$ & $S E$ & $L L$ & $U L$ & $B$ & $S E$ & $L L$ & $U L$ \\
\hline Gender & $0.29^{*}$ & 0.13 & 0.02 & 0.55 & 0.24 & 0.14 & -0.03 & 0.50 & $0.27^{*}$ & 0.13 & 0.01 & 0.53 & $0.29^{*}$ & 0.13 & 0.03 & 0.54 \\
\hline Supervisor & -0.15 & 0.13 & -0.40 & 0.11 & -0.16 & 0.13 & -0.42 & 0.10 & -0.11 & 0.13 & -0.36 & 0.14 & -0.11 & 0.12 & -0.36 & 0.13 \\
\hline Anger & $-0.48^{* * *}$ & 0.14 & -0.77 & -0.20 & & & & & & & & & $-0.30^{\dagger}$ & 0.16 & -0.61 & 0.01 \\
\hline Fear & & & & & $-0.22^{*}$ & 0.09 & -0.39 & -0.04 & & & & & -0.13 & 0.10 & -0.31 & 0.06 \\
\hline \multirow[t]{2}{*}{ Sympathy } & \multirow{2}{*}{\multicolumn{4}{|c|}{$\begin{array}{c}R^{2}=.08 \\
F(3,202)=5.47^{* * *}\end{array}$}} & & & & & & 0.06 & 0.13 & 0.38 & $0.23^{* * *}$ & 0.06 & 0.11 & 0.35 \\
\hline & & & & & & $\begin{array}{r}R^{2}= \\
3,202\end{array}$ & $\begin{array}{l}.05 \\
=3.6\end{array}$ & & \multicolumn{4}{|c|}{$\begin{array}{c}R^{2}=.10 \\
F(3,202)=7.55^{* * *}\end{array}$} & \multicolumn{4}{|c|}{$\begin{array}{c}R^{2}=.14 \\
F(5,200)=6.48^{* * *}\end{array}$} \\
\hline
\end{tabular}

$* p<.05 .{ }^{* *} p<.01 .{ }^{* * *} p<.001$. 


\section{Qualitative Analysis}

One open-ended item was included at the end of both Study 1 and Study 2 asking participants to describe their experiences with colleagues or other people outside of work who have returned to work following a leave of absence for mental or physical health problems. The goal of including this item was to better understand thoughts and feelings associated with stigma and to explore any differences between reactions to individuals who take leaves of absences for mental and physical health problems. The breakdown of responses to this item are shown in Table 25.

Table 25.

Frequency of Responses (Qualitative Analysis)

\begin{tabular}{lccccc}
\hline & \multicolumn{2}{c}{$\begin{array}{l}\text { Study 1 } \\
\text { (MTurk) }\end{array}$} & \multicolumn{2}{c}{$\begin{array}{l}\text { Study 2 } \\
\text { (PSPC) }\end{array}$} & Total \\
\hline Non-response & 97 & $14.5 \%$ & 149 & $45.3 \%$ & 246 \\
Indicated no experience & 41 & $6.1 \%$ & 4 & $1.2 \%$ & 45 \\
Irrelevant response & 67 & $9.9 \%$ & 0 & $0.0 \%$ & 66 \\
Included in analysis & 464 & $69.5 \%$ & 176 & $54.5 \%$ & 641 \\
\hline
\end{tabular}

ancluded responses that did not comment on how the participant reacted to their experience or nonsense answers.

To analyze responses to this item, I conducted a thematic analysis using the methodology proposed by Braun and Clarke (2006). I began by familiarizing myself with the content of participants' comments by reading all comments from both studies. Next, I systematically generated and assigned codes to each response in the data set. Some codes represented phrases or one or more sentences from a response. Other codes represented entire responses. Each part of the data was given equal attention to ensure all data was 
given equal consideration in the analysis. At this stage, colours were assigned to codes associated with problems due to 1) physical health 2) mental health and 3) both physical and mental health in order to facilitate comparisons of experiences with mental and physical health problems. Next, all codes were printed, cut into individual strips of paper, and sorted into piles representing possible themes, which also helped to increase familiarity and deepen understanding of the data set. This step ended with eight labeled sets of codes, which corresponded to possible themes, and 1 set of codes that did not seem to fit anywhere.

In the next step of the analysis, I reviewed the participant responses corresponding to the codes for each of the eight possible themes. Reflecting on the meaning and scope of the possible themes, it became apparent that three potential themes were actually a part of the same overarching theme, and three potential themes were actually emotional responses that fit into other themes. At this point, codes that had not

previously fit into a theme were reviewed and the majority were determined to actually fit into these broader themes. This phase ended with a thematic map (see Figure 5) containing five overarching themes. Finally, all the comments were read again to determine if the five identified themes were representative of the data set, and quotes that best demonstrated each theme were selected from the data and used to report findings.

\section{Description of themes}

The thematic analysis resulted in five main themes: benevolence, limits of personal responsibility, picking up the slack, uncertainty, and mistreatment. The benevolence theme encompasses the goodwill and social conscience that many individuals possess with regard to helping others. It concerns whether or not the 
individual has a positive reaction to helping a coworker in difficult times. The limits of personal responsibility theme refers to the idea that benevolence is not unlimited. There is a point at which an individual believes they have done enough or cannot do more without negative consequences for themselves. The theme of picking up the slack includes the negative reactions that individuals have towards increased work as a result of a coworker with a health problem. It concerns how attributions to factors like low performance or poor management result in negative emotional reactions. The theme of uncertainty involves how individuals experience doubt and insecurity about how coworkers with health problems will behave and perform, particularly in the case of mental health problems. Finally, the theme of mistreatment encompasses behaviours that may be misinterpreted as negative, as well as overt behaviours that are clearly hostile.

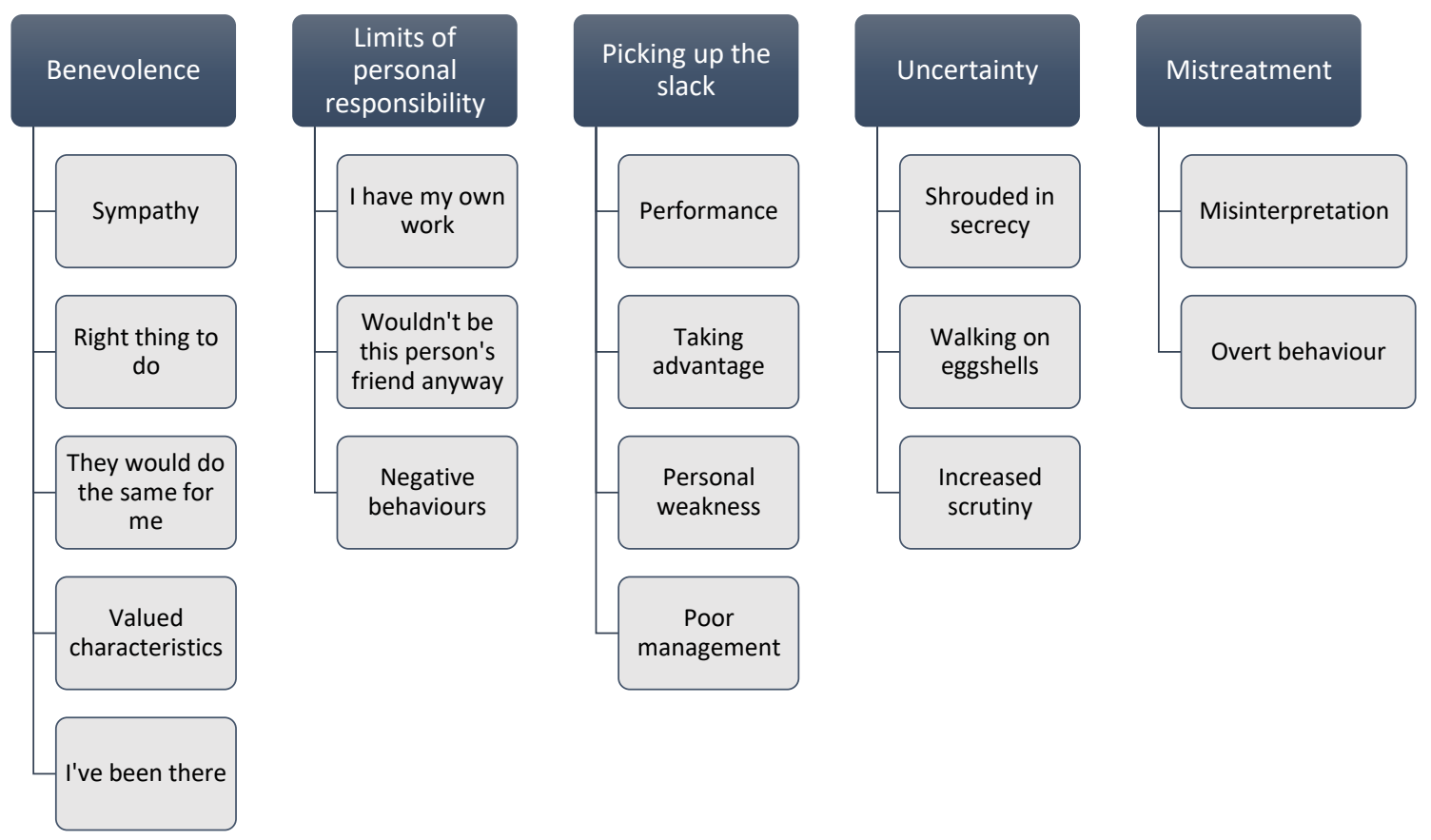

Figure 3. Thematic map for qualitative analysis 


\section{Benevolence}

The vast majority of comments expressed goodwill towards colleagues who had taken leave and returned to work for health reasons. Although some participants explained their goodwill simply in terms of sympathy, other participants gave rationales for their benevolence, which included believing that helping was the right thing to do, others would do the same for them, the individual had value to them in some way, and because they themselves understood how difficult the situation was.

Sympathy. Many participants indicated they felt sympathy and concern for the coworker who was experiencing health problems. In their comments about how they felt towards coworkers returning to work following depression-, anxiety-, or stress-related leave, participants often responded with comments such as "I felt sympathy and concern for them" (participant \#824, female, age 30), "I felt a lot of sympathy for them" (participant \#872, female, age 28), or "I didn't think much of it at all, but felt sympathy" (participant \#396, male, age 26).

These feelings of sympathy were frequently associated with desires to help. One participant commented: "I felt sympathy for them and wanted to help them get back on their feet" (participant \#23, male, age 29), and another wrote: "I wanted to help as much as I could" (participant \#511, female, age 27). Describing her experience with a coworker who had returned to work following stress-related leave, another participant explained: "I felt sympathy and concern for them, I took the time to listen to the stories they chose to share with me and offer support. I also offered help to them with catching up on their outstanding workload" (participant \#824, female, age 30). 
The right thing to do. Participants clearly expressed that helping people with get back to work was morally the right thing to do for both physical and mental health problems. One participant wrote: "I am always happy to provide help and support when someone returns to work. I believe it is the right thing to do" (participant \#431, male, age 59), and another commented: "I think it's great and the right thing to make sure jobs are there for people who come back to work" (participant \#256, female, age 41), in reference to multiple reasons for leave including surgery, sickness, and maternity leave. This sentiment that helping is the right thing to do was also expressed in terms of everyone deserving help. As one person described: "I have known many people who have experienced setbacks both physically and mentally. What I think is that they deserve all the help they can get to get back on their feet" (participant \#214, female, age 59).

Participants also believed that helping people get back to work is the right thing to do even at the expense of increased workload for themselves or their team. For example, regarding his experience with an employee who had a back injury, one supervisor wrote: "It did put extra work on the team, but covering was the right thing to do" (participant \#, 380, male, age 45). However, reactions to extra work was not always met positively despite believing that helping was the right thing to do. According to one participant: "It was frustrating to deal with his issues but we made accommodations because it is the right thing to do" (participant \#126, female, age 46).

They would do the same for me. The idea that benevolence is reciprocal between individuals and amongst team members was also present in the data. For example, one participant wrote: "I had a coworker who had limited range of motion so I had to help with the heavy lifting. It was okay because I knew they would do the same for 
me" (participant \#155, female, age 42). Describing a situation when a coworker was on leave for surgery, another participant wrote: "Her work would have piled up so we all chipped in to help. I do not remember feeling any resentment or anything. I enjoy helping and know that people would do the same for me" (participant \#161, male, age 27). Another participant described how their goodwill was conditional on feeling the other person would reciprocate: "Like any colleague, I'm happy to pitch in when I feel it would be reciprocated if the roles were reversed" (participant \#848, female, 39).

Other participants pointed out that they helped out their coworkers simply because they would want others to do the same for them. For example, describing a situation when she helped a coworker who had returned to work after depression, a participant wrote: "I would want someone to do the same for me" (participant \#68, male, age 47). Similarly, another participant responded that she hoped coworkers would help her just as she helped them:

It doesn't bother me at all to pitch in when they return. I know that the same situation could happen to me in the future, and I would hope that my coworkers would be just as helpful and empathetic as I have been to them (participant \#406, female, age 45).

Still others expressed the view that team members help each other out in a similar manner that family members help each other. One participant described how the team divided up another coworker's work during a leave of absence for mental health reasons and then helped when she returned: "She needed plenty of help when she came back but we willingly put in the effort. We were family after all" (participant \#673, male, age 57). 
Valued characteristics. The analysis revealed that a coworker's work ethic, level of knowledge, and degree of effort contributed to benevolent attitudes towards supporting that coworker during difficult times. Describing his experience with a coworker who returned to work after a leave of absence for anxiety, one participant wrote: "I knew they were very capable of doing their job, so just helped them in any way I could" (participant \#68, male, age 47). Similarly, another respondent indicated a positive attitude towards a returning coworker who was known to try hard: "When my coworker came back to work everyone knew that they would try to do their best at their job and we would try to help out as much as we could" (participant \#457, female, age 61). Likewise, one respondent also indicated she had no issues helping hard-working coworkers who get sick: "I have worked with people who do this and end up breaking down or getting sick. Most people I have worked with don't have an issue with these types of people needing a little help sometimes" (participant \#752, female, age 56). This goodwill towards people known to work hard was also expressed towards coworkers who received accommodations:

The 3 people sitting next to me at work have all been on a leave of absence for either mental or physical reasons. One is back at work full-time but still gets accommodations and the other 2 are still gradually increasing their hours and are not performing all their regular duties. They are all hard workers and doing the best they can. I have no problems helping them (participant \# 928, female, age 44).

Admiration and pride were frequent reactions to coworkers who were trying hard to recover and get back to work. For example, one younger male participant described his admiration for a coworker who had returned to work after being on leave for mental 
health problems: "He worked twice as hard to meet up to standard of other workers and maintain a peaceful work attitude with other co-workers. It has been such a great experience working with him" (participant \#128, male, age 26). Similarly, another woman described the pride she felt seeing her coworker face the difficulties of getting back to work after a severe depression:

Nous l'avons accueilli les bras ouvert, avec une petite carte et un cadeau. J'ai ressenti de la fierté de la voir revenir à son rythme. De prendre le temps d'analyser comment elle se sentait jour après jour avec ce retour progressif [We welcomed her back with open arms, with a card and a small gift. I felt proud to see her get back into her work. Thinking about how she must feel day after day dealing with this gradual return] (participant \#713, female, age 45).

As a consequence of these feelings of admiration and pride, one participant described her desire to help a colleague who had been on stress leave following a period of harassment at work: "I felt compassion and pride for this person and the desire to help her" (participant \#984, female, age 58).

I've been there. Many participants described feeling empathy and compassion because they knew from personal experience how difficult it can be to stay at work or return to work when not feeling well. A number of respondents who had experienced their own health problems described how they try to help coworkers having difficulties. For example, one participant described trying to be supportive: "I've personally had to leave work for mental health reasons as have some of my friends. I worry for them and do my best to be supportive" (participant \#342, female, age 28), and another participant described trying to be encouraging: 
J'encourage mes collègues qui reviennent au travail suite à un problème de santé mentale ou physique. Je les comprends puisque j'ai vécu cette expérience moimême donc je sais comment ça peut être difficile [I encourage my colleagues who return to work after a mental or physical health problem. I understand because I've lived through this kind of experience myself and so I know how difficult it can be] (participant \#929, female, age 49).

Writing of the difficulties that individuals can have when returning to work, another participant explained how her own experience with mental health problems influenced her response:

When she returned to work, I felt bad for her because many people did not want to help her and even judged her behind her back. I have struggled with similar issues in the past and I had a lot of compassion for her when she returned (participant \#515, female, age 27).

Some participants who had experienced problems with their own mental health expressed a willingness to help even at their own expense. One participant spoke of having no ill-will towards taking on the workload of another colleague on leave for mental health reasons:

Sure, it sucked for those three months having to work extra hours, and extra hard, however they could not be the best version of themselves if not for the break. As someone who suffers from Anxiety, Depression, and PTSD, I have an intimate awareness of mental health issues, and am happy to accommodate anyone who has decided to put their health first (participant \#784, female, age 35).

The different levels of support offered by those with and without experience with 
mental health problems was described by a participant:

Those who had the most empathy had experienced similar situations, and that they would spend more time "coaching" individuals to a point where they could function normally. Those who did not have similar exposures tended to remain nonchalant towards the individuals neither offering support or encouragement. Ignorance does tend to direct attitudes (participant \#724, male, age 38).

\section{Limits of responsibility}

The second theme derived from the analysis was that some individuals feel there are limits to how much they are willing to help a coworker with health problems. In some cases, willingness to help was limited by participants' own work responsibilities or ability to help with certain issues. In other cases, help was limited because participants did not feel they were close enough to the individual to warrant personal sacrifice. An important part of this theme, however, are the conflicting beliefs regarding what is morally right and what is fair.

I have my own work. This aspect of limited responsibility was prominent when participants felt that helping a coworker interfered with their own work role or workload. As stated by one participant: "We still have deadlines so I would like to help and complete my tasks on time" (participant \#67, male, age 49). Another respondent who had experienced depression themselves explained that she was supportive as long as her workload didn't increase: "I didn't think anything of it, as I too struggle with depression. I felt as long as she was capable of doing her job, and I wasn't doing her work too, I was okay with it" (participant \#213, female, age 43).

Participants expressed conflicting feelings about wanting to help coworkers with 
health problems but also not wanting more work. Their comments also conveyed how helping a coworker is not always voluntary and cannot necessarily be declined. One participant commented about a coworker who was returning to work for unspecified reasons: "I felt concern for them and frustration that I could not do more to help" but then continued on to explain that he felt conflicted: "There is no right answer. At the same time, I didn't want to do more work--I didn't love that job--so it was a bit of a battle between my morality and my sanity" (participant \#11, male, age 23). Another participant described conflicting feelings of worry and frustration while their coworker was on leave and then relief that they could get back to work they preferred:

I felt so worried about him, but at the same time all of his work fell on me. It was really hard to pick up all the slack on the weeks that he was gone. I felt so relieved when he returned back to work not only because he was feeling better, but now I can go back to my role at work (participant \#436, female, age 31). Participants also described difficulties balancing concern for their sick coworker with pressures of the contemporary workplace. There was a general feeling of wanting to help others but also feeling stress to meet commitments. One participant explained the frustrations of being overloaded with work:

Je suis une personne qui aime aidé de nature, mais quand il s'agit d'une prendre des tâches supplémentaires en plus de nos tâches déjà surchargées, ceci peut causer des frustrations lorsque le retour à la normale est trop long [I'm a person who likes to help by nature, but when it means taking on more tasks on top of my already heavy workload, this could be frustrating if returning to normal takes too long] (participant \#705, female, age 42). 
Likewise, another participant explained their conflicting concerns for their coworker and a lack of resources:

I didn't want to overload them. At the same time, unfortunately, these days, we have fewer and fewer people working in the office, so every time that we all have to pick up the slack because people are off, it puts more strain on the rest of us. There are no extra people anymore (participant \#888, female, age 44).

The idea that other coworker's stress levels increase as a result of accommodations was also a source of conflicting emotions. One supervisor described the conflict she felt between helping one of her employees who required accommodation and increasing the workload of other team members:

I felt badly for him, because he was not in a good place, and I knew him to be very capable, but at the same time I felt that I needed to protect the rest of the team. I felt annoyed that he wasn't able to pull his weight, and that I couldn't replace him. I felt that implementing the accommodations was also not being fair to others (i.e. he can't have stress, so your and my stress will have to go up by doing his job) (participant \#882, female, age 33).

Wouldn't be this person's friend. Despite continuing to be helpful to a degree, participants believed that it was okay to set limits with coworkers who they did not particularly like. One participant explains trying to encourage a coworker with a foot injury but setting boundaries: "I tried to encourage her to take the time she needed, but she wasn't receptive. Truthfully, I didn't like this women [sic] very much personally, so tried to set boundaries with her to avoid getting overly involved" (participant \#956, female, age 34). Similarly, another participant described a situation at work when she 
didn't initiate helping a coworker with mental health problems because it was not someone she would normally socialize with: "I was open to helping her but didn't seek her out as it made me feel anxious/uncomfortable to interact with this person. I would not pick to socialize with this person before or after however" (participant \#855, female, age 45).

Negative behaviours. There are also certain behaviours that individuals feel cross the line of what they are either responsible or capable of helping with at work. For example, although many coworkers likely feel it is ok to talk about health problems to an extent, there is a limit to how much talking is considered acceptable. One participant described an experience with a coworker who was having difficulty coping with his brother's suicide:

I was glad he returned and have been doing everything I could to help him get caught up and back in the swing of things. However, I am trying to convince him to see a counselor because he is somewhat using coworkers as counselors by continually talking about what he is going through (participant \#499, male, age 42).

Unpredictability was also viewed negatively, particularly when day-to-day operations were affected. Describing a situation with a supervisor who frequently called in sick on short notice, one participant wrote:

I had a supervisor who would call off work the day of due to mental health reasons (which we were understanding about); however, she didn't set up additional staffing and our department would be left short-handed. I am completely fine with people taking mental health days (I take some), but you need 
to make sure that staff is aware and can make accommodations (participant \#551, female, age 22).

Similarly, another participant described how the unpredictable nature of a coworker's presence at work was difficult for both management and other colleagues:

Co-worker came back from a physical health condition, however their return was sporadic in the sense that, they would come back for a day or two and then be gone again for weeks. Then come back again for a day or two and be gone again for weeks. I was not privy to the specific reasons of their absence but I could tell management was getting annoyed and I can sympathize with that. The unpredictability of an employee is difficult for management and colleagues alike (participant \#808, male, age 31).

Disruptive behaviour of employees seemed to affect supervisors in particular because of their perceived responsibility for both the coworker with health problems and the other team members. One supervisor described a situation with an employee struggling with addiction whose team members accepted him back after one period of leave but whose behaviour (e.g., theft, asking for money) restricted the team's ability to trust him after subsequent leaves:

As the supervisor, I had to ensure that the work environment was as safe and comfortable as possible so I talked to my manager and we had a conversation with the employee about his behaviour. He ended up going on leave for a second time to get sober. The second time he came back, we did a graduated return to work and while the team was glad to have him back, no one trusted him like they used to (participant \#791, male, age 39). 
Similarly, another supervisor explained how he felt conflicted about helping one of his employees with mental health problems who could sometimes be abusive to other team members. The supervisor described the period after the employee returned to work after taking a leave of absence:

His return after a few months was progressive and tumultuous. Relationships within the team were damaged and as the manager I felt torn between supporting the aggressor and supporting the other team members, understanding that the aggressor was behaving that way due to his mental health struggles, not that he was inherently a bully... I felt badly for him, because he was not in a good place, and I knew him to be very capable, but at the same time I felt that I needed to protect the rest of the team (participant \#882, female, age 41).

\section{Picking Up the Slack}

The theme "picking up the slack" encompasses the negative and sometimes hostile reactions that individuals have towards having more work as a result of a coworker with a mental or physical health problem. Although some participants used this phrase in a neutral tone when describing the work that was not being completed by the sick coworker, "picking up the slack" primarily had a negative connotation that participants attributed to perceived performance difficulties, coworkers who were taking advantage, character weaknesses, or poor management.

Perceived performance. Participants frequently described increased workload as a consequence of having a coworker return to work after a leave of absence. Describing their experience with a coworker who was accommodated with a part-time schedule following a leave of absence for an anxiety disorder, one participant explained: "When he 
returned he was allowed to work part time until he felt up to speed. People took on a certain amount of his workload for him" (participant \#364, female, age 51). Another participant described a coworker who had returned to work after an unspecified health problem: "He was very slow and he looked very lost. He knew what to do but very slow doing and couldn't really talk to you. I had to direct him like a kid" (participant \#49, male, age 30).

For some respondents, increases in workload as a result of a coworker who had not completely recovered after a leave of absence for a mental health problem resulted in feelings or annoyance and irritation. One participant wrote: "She has anxiety and can only work so much. It is extremely annoying because the rest of us have to pick up her slack" (participant \#164, female, age 21), and another commented: "One worker had to take time off for a mental break down. When he came back he was very slow and didn't do well. It was irritating" (participant \#119, male, age 55).

These negative feelings towards poor perceived performance were also evident, however, for coworkers who had difficulties adjusting to work following other types of leave (e.g., surgery, maternity leave). For example, one participant commented on a situation with a coworker who was out for several weeks with a virus and was slower than usual when he returned: "I remember feeling a bit resentful at the co-worker who was out. I didn't like that I did his work and wasn't paid for it" (participant \#574, female, age 34). Another participant described their annoyance with a coworker who had returned after surgery: "I also had to accommodate her coming and going a lot with appointments. That was kind of annoying but I tried to as patient and understanding as I could" (participant \#66, female, age 51). 
From the perspective of one participant, negative emotional responses to coworkers who take leave or are underperforming are unavoidable if other team members experience more stress. She explained:

As much as I don't think the person with mental health issues is at fault for going on leave, it does make work life more difficult for the rest of the team as we have to take on more work and responsibilities which creates more stress. It also creates feelings of animosities towards the person with mental health issues which is totally wrong morally but as long as the rest of the team has to suffer the consequences of having someone with a mental health issues on the team, it will create negative feelings (participant \#702, female, age 38).

Taking advantage. This sub-theme reflects how the perception that an individual is taking advantage of a situation or getting unfair special treatment can lead to negative attitudes towards that individual. For example, one participant commented about feeling taken advantage of by a colleague who had returned to work: "I felt like I was being used. I was doing most of the work, while my colleague spent time on phone chatting with friends and family or read $[s i c]$ a magazine. The person should not have returned to work yet" (participant \#381, female, age 66). Another participant described her perception that a coworker was taking advantage by claiming to have migraines:

A co worker [sic] took time off for a migraine issues and would come and go as she pleased. she took advantage of how nice the employers were. It is often a lot of people will experience a headache at work but calling it a migraine shouldn't give you more privileges. I felt that it was unfair they were getting to hold there 
$[$ sic] higher position and get paid more than me when I did all the work (participant \#96, female, age 25).

Participants also made comments that accommodations are special privileges rather than rights, implying that those who receive accommodations are taking advantage. For example, one participant commented: "I have several mental health conditions and have never request any special privileges or accommodations" (participant \#24, male, age 23), and another participant wrote: "I have had others that have come back to work with light duty status. It is fine to work with those people as long as they don't flaunt it and take advantage" (participant \#451, male, age 37).

Malingering is another form of taking advantage that was present in the data. Although not mentioned frequently, some participants believed that individuals sometimes pretended to have health problems to get out of work. For example, commenting on a coworker who had taken stress leave, a participant wrote: "I just felt he wanted a vacation and it imposed a workload on us" (participant \#115, male, age 58). Another participant wrote about her belief that people malinger in order to get vacation: I work with a handful of people that fake injuries to get out of work for months at a time. Some of them feign injury to get surgeries they needed well before they started work. The ones who leave for mental health reasons often post vacations on social media (participant \#21, female, age 27).

Judging a coworker with health problems to be legitimately sick versus malingering resulted in very different reactions. For example, one participant commented how judging someone to be honest resulted in a positive reaction: "I was more than happy to help him because I knew he was telling the truth" (participant \#503, male, age 37). 
Another participant describes questioning accommodation requirements: "Some you question the extent of their identified limitations because they are known to take advantage of situations, others you empathize with completely because you know they are not (taking advantage)" (participant \#848, female, age 39). Similarly, the following quote shows the contrast between reactions to individuals who are perceived to be malingering compared to individuals who are perceived to honestly need a leave of absence:

In some situations, it is evident that the person has convinced a medical professional to provide a note for stress leave that is not warranted. You know that they are abusing the system and feel resentful and not at all sympathetic to their situation. In other situations, you are aware that the leave is legitimate and you willingly accommodate even if it means extra work on your part (participant \#690, male, age 55).

Personal weakness. One of the fundamental stereotypes underlying mental health stigma is that individuals with mental health problems are weak or at fault. This was reflected in comments such as: "I knew a person who went out of work due to stress. I felt the person was weak minded because the work wasn't that stressful" (participant \#115, male, age 58). Another participant's comments portrays individuals with mental health problems as unable to cope: "Some people do seem to have a "dark cloud" follow them and they don't appear to have coping mechanisms that are effective and tend to play a victim role often" (participant \#848, female, age 39). Similarly, another individual who was admitted to hospital for mental health reasons was described as unable to handle pressure: "Pressure was too much for him, although everyone else was under the same 
conditions" (participant \#429, male, age 60).

Taking leave for depression or anxiety was considered to be a sign of weakness and in some cases viewed as unnecessary. For example, one participant with anxiety used the fact that she had not taken leave as an indicator that she was stronger than those who did take leave: "I have not had this happen at my work but I would feel annoyed that this person's work slack has to be picked up by everyone else including me. It is irritating because I also have anxiety but I just power through and do my work like everyone else" (participant \#3, female, 29). Describing her experience with coworkers who had taken a leave of absence, another participant's comments illustrated how leave for depression or anxiety is sometimes perceived as weakness because it is not serious like other mental health disorders: "Generally it's been things like being bipolar or schitzophrenic [sic] . Millions of people deal with depression and/or anxiety and don't have the luxury of taking off from work" (participant \#534, male, age 34). In contrast, another participant who had taken leave for burnout viewed taking leave as beneficial; however, she felt other coworkers with mental health problems were at fault because she believed they were not putting in the effort to recover:

We are well supported at our jobs, there should be nothing stopping someone from taking the time they need to go take care of themselves and learn how to come back to work and be full participating members of the team (participant \#897, female, age 44).

Likewise, another participant expressed how coworkers sometimes judge others who take leave as unable to handle stress:

I have worked with many individuals who have been off work for stress leave and 
it seems that many co-workers judge them when they return. They seem to think that we don't work in an environment that "could be that stressful" to go off work (participant \#774, male, age 35).

Lack of sympathy as a result of blaming the individual was evident. For example, one participant described how her reactions differed when coworkers with health problems take care of themselves compared to coworkers who do not make lifestyle changes: "Those who were mentally and physically able to return, I felt great for. Those who could not return due to not committing to lifestyle changes I do not feel the slightest empathy for" (participant \#306, female, age 49).

The negativity of reactions by coworkers who believe individuals are weak or at fault for their mental or physical health problems is evident from the contrast with reactions by coworkers who believe anyone can have health problems. For example, one participant wrote "'"There's no reason to shame somebody for addressing or falling victim to a disability, either physical, emotional, mental, or otherwise" (participant \#478, male, age 25), and another commented:

ANYONE can have a mental illness, and ANYONE can get seriously, and unexpectedly injured. NO STIGMA should be attached to these folks - we need to help them reintegrate, and be patient with them when they struggle or face setbacks (participant \#879, female, age 33).

Poor management. Participants also believed that management has an important role in determining how employees react to having a team member with health problems. As one participant stated: "Colleagues are entitled to leave as much as anyone else including myself. As long as management tries to fill the gap with temporary employees 
or additional team members while the person is absent, I feel that that is ok" (participant \#903, female, age 37). Another participant expressed their belief that managers need to understand what the returning coworker is capable of in order to assign workload: "I think the most important work-aspect is that the manager understands the returning employee's capabilities and does not "dump" extra work onto another team member, or pass off the returning employee to another team member to manage" (participant \#936, female, age 29). Similarly, another person explained their opinion on management's role: In general I am all for having a person return to their duties. I would like to see more people hired to do the work if the person is not capable of returning to full capacity. Over a long term it should not be the responsibility of co-workers to do more work. It is management responsibility to make sure they have the capacity to do the work without additional burdens on staff (participant \#842, gender unspecified, age 42).

Despite believing that management has an important role in managing workload, participants indicated that this does not always happen and expressed their dissatisfaction when management did not provide resources, lacked understanding, or overloaded team members. Describing her experience with management after a coworker went on a leave of absence, one participant expressed anger at how the organization did not adjust their performace objectives when a coworker went on leave:

Une colère face à l'employeur car mon entente de performance ne prévoit pas un ajustement de mes objectifs pour de telles raisons. Lorsque je veux renégocier mes objectifs de rendement, le gestionnaire me dit: tu es supposé gérer cela [Anger towards the employer because my performance agreement isn't adjusted 
for these reasons. When I want to renegociate my performance objectives, the manager says: you're supposed to manage that] (participant \#989, male, age 56). Similarly, another participant explained her frustration at management for shuffling a heavy workload from one employee to another:

In one case, an assistant had gone on leave of absence for her mental health due to her heavy workload and lack of direction (among other things), and they simply reallocated her workload to the other assistants for the duration of her absence. When she returned, they shuffled portfolios and gave her a different client group. This to me made no sense; it's just displacing the problem, not resolving it. Any frustration I felt was not towards the employee, but towards management (participant \#876, female, age 23).

In addition to frustration and stress, lack of support from management resulted in other negative reactions such as distrust. One participant expressed their distrust of management after no replacements were found to cover for another coworker taking a leave of absence: "I find this hard as a colleague, as it has left our department short staffed and left me with little faith in our management team to be empathetic or trusted if I ever have a need for an accommodation" (participant \#692, female, age 35). Likewise, the following excerpt illustrates how a participant felt suspicious that upper management really didn't care about preventing leaves of absences caused by burnout:

Cependant, malgré une attitude semblant ouverte de la part des supérieurs, je n'ai pas eu l'impression que la gestion et tous les patrons en haut ont vraiment voulu prendre les mesures pour éviter que cela se reproduise [However, despite a seemingly open attitude on the part of my superiors, I didn't get the impression 
that management and all the higher up bosses really wanted to take measures to avoid this happening in the future] (participant \#919, female, age 57).

\section{Uncertainty}

The theme of uncertainty encompasses feelings that participants expressed about how to talk to and behave around participants who were returning to work following a leave of absence. Much of this uncertainty resulted from the lack of information when health problems were mental health-related; however, there was also concern about not acting in a way that would cause the returning coworker to relapse.

Shrouded in secrecy. Because of the sensitive nature and stigma of mental health problems, individuals may not want to talk about their mental health problems with coworkers. When combined with considerable concerns for privacy, there is often secrecy and mystery. For example, one participant wrote: "I had a coworker try to kill himself several years ago. It was not really addressed within the organization and was a bit awkward when he returned to work" (participant \#417, female, age 64), and another commented: "We also were not told that he was off for mental health reasons, so we didn't necessarily know why he was gone for so long" (participant \#882, female, age 41).

As a result of secrecy, coworkers of individuals with mental health problems often have very little information about what to expect when that individual returns to work. This lack of information contributes to uncertainty about how to react. Speaking of a coworker who later openly talked about being on leave for two years for mental health reasons, a participant explained:

Because the whole thing was shrouded in secrecy (rightly so due to confidentiality), it made it awkward to know how to react to his return. He is now 
very open about his situation which makes it much easier to talk about (participant \#882, female, age 41).

Secrecy was also perceived to be different for mental and physical illnesses.

Respondents felt that coworkers returning for physical health reasons were more open and as a result there was more information provided from supervisors and other coworkers. Hence, privacy was less of a concern for physical health problems. One participant explained his view that physical health problems are also talked about more openly because they are usually more visible:

Managers/supervisors are more likely to speak about a colleague's physical health condition when discussing their return to work. When a colleague has taken time off for physical health conditions, it is often easier to tell and in my experience there has been a greater show of support on the part of colleagues and management. With mental health conditions, even if people are aware of the condition, people tend to not speak about it as much (participant \#907, female, age 31$)$.

Secrecy about mental health problems may also contribute to perceptions that an individual is malingering. One participant explained how lack of visibility and openness about mental health problems leads to suspicion:

Overall, I think physical health conditions are much easier to manage. People are more open about it, they are often very obvious (so less "she's faking it"), and often don't affect the performance of knowledge-based workers/jobs to the same degree. Mental health conditions are less obvious (more potential for "she's faking it"), people are more secretive about them (participant \#882, female, age 41). 
With respect to accommodations, one participant explained that she understood that accommodations are documented and legitimate but that when the reason for accommodation is unknown, it's natural to think of the accommodations as privileges:

...si je ne sais pas pourquoi il est accommodé, je suis naturellement tenté de percevoir ces accommodements comme des "privilèges" mais je sais que cela n'est pas le cas car les demandes d'accommodations doivent être justifiées... [...if I don't know why he's accommodated, I'm naturally likely to perceive these accommodations as "privileges" but I know that isn't the case because requests for accommodations have to be justified....] (participant \#117, female, age 55). Another participant described resentment from team members who were assigned particular tasks because of an accommodation for another team member and explained this could be avoided with more information: "It showed that Management needed to have a conversation with the team so that everyone understood the reasons for the change" (participant \#93, female, age 45).

Finally, secrecy leads to a lack of information, which leads to talk and speculation between coworkers about why a person may have been on leave. Describing their experiences with coworkers who had taken leave for suspected or known mental health reasons, one participant stated: "When first returning to work, it was a bit awkward. It's a subject everyone is whispering about and all are afraid to ask, what happened?" (participant \#512, female, age 48), and continued: "There were rumors and unanswered questions flying around" (participant \#512, female, age 48). As a consequence, coworkers of the individual returning to work react cautiously, which is represented in the next subtheme. 
Walking on eggshells. The analysis also showed that reactions to coworkers returning to work following a leave of absence for health problems were sometimes cautious, ranging from a little cautious to extremely cautious depending on the situation. As one participant stated regarding his experience with a coworker who had returned to work after "an emotional breakdown": "When this person came back to work everyone treat this person so different they walked on egg shells around s/he [sic]" (participant \#226, male, age 62).

One reason for these cautious reactions resulted from having very little information about the situation and as a consequence not knowing how to act or what to talk about. For example, regarding coworkers who had been on leave because of burnout, one participant made commented:

I was happy to have her back and to see her getting her life back on track, but when I was having lunch with her I was also nervous at first about how to talk openly with her about how she was feeling/what she experienced. I was careful in my statements that I made until they were ready to engage in the type of conversations we held prior to their absence (participant \#524, male, age 44).

Likewise, another participant described feeling nervous about talking to a coworker who had returned to work following a two year leave of absence for a "mental breakdown":

When he returned, I did not know how to treat him. He looked and acted completely differently, not like the person I knew. I wanted to talk to him, but also did not want him to feel pressure (as though something I said could somehow send him back into that dark hole) (participant \#213, female, age 41).

This previous quote also demonstrated another reason for cautious behaviours: 
concern that pressure from the work environment would cause the individual to relapse.

Concerning a coworker who had taken leave caused by burnout, one participant commented: "I felt a bit like I was walking on eggshells. I felt that it was our work environment that caused the issues, and now in her returning, I didn't want that to occur again" (participant \#701, female, age 44). Another participant describes how he felt about a coworker with depression and anxiety returning to work: "I was nervous about this person returning to work because the nature of the work is stressful and I wasn't sure if the person would relapse" (participant \#213, female, age 41).

Although there were instances of nervousness concerning interactions with coworkers who had physical health problems (e.g., chemotherapy treatment), there was more uncertainty concerning mental health problems because symptoms are less visible. As one participant stated regarding coworkers returning to work after a mental health problem: "If it's mental, then you don't really know how to act because there's no obvious way to see how the person is being affected by your actions" (participant \#213, female, age 41).

Finally, some participants felt awkward, nervous, or scared in response to what they perceived to be weird behaviour. One participant commented: "I used to work with a girl who I believe was out due to mental issues. She started acting really weird and it was uncomfortable for everyone when she finally returned to work" (participant \#106, female, age 43), and another stated: "there was one guy who made everybody feel weird. he only lasted a few day $[$ sic $]$, but it was scary the few days that he was there" (participant \#253, male, age 63). 
Increased scrutiny. The theme of uncertainty was also expressed in the form of increased scrutiny with other coworkers observing the individual returning to work to see how they would perform, if they could handle pressure, and in some cases whether they were trustworthy. One participant described how her worry about the coworker led to increased scrutiny: "She is a very capable and knowledgeable worker and I was glad she had returned. Now, I am always looking out for how she reacts under work pressures and I am concerned she might leave again" (participant \#699, female, age 44). Similarly, another participant described a situation with a coworker who worked irregular hours who she suspected had an accommodation for a health problem. The participant describes the reaction of a third coworker: "On the other hand it did bother another co-worker, and she started to keep tabs on him. I'm not sure if she reported to the manager or not, but I felt that she was getting irritated" (participant \#976, female, age 47).

In some cases, past behaviours led to increased scrutiny of individuals with mental health problems because colleagues were uncertain if those individuals were now trustworthy. This appeared particularly relevant for supervisors who felt responsible for both the individual experiencing health problems and other team members. One supervisor described how he watched an employee with addiction issues who had previously made team members feel uncomfortable by asking for money: "I had to keep a closer eye on him to make sure (he) stuck to his schedule and make sure his interactions with other team members was appropriate" (participant \#791, male, age 39). The same supervisor continued on to describe how he felt about the employee eventually leaving the team: "I do feel guilty if my increased awareness of his actions contributed to his feeling alienated from the team, but I don't know how else I could have handled it." 


\section{Mistreatment}

The final theme derived from the data was mistreatment, which encompasses negative treatment of individuals with health problems. Although not frequently commented on by participants, there were instances when employees were bullied, ostracized, and treated unfairly. The lack of openness regarding mental health problems and resulting uncertainty demonstrated by coworkers of individuals with mental health problems also suggested opportunities for misinterpretation.

Misinterpretation. Analyzing responses from the perspective of participants with mental health problems, as well as from the perspective of participants who were coworkers of individuals with mental health problems, it became apparent that there are many opportunities for miscommunication. For example, a supervisor who is worrying about pressuring an employee who is returning to work may misinterpret the amount of work an employee is capable of and either not immediately assign work or not assign enough work. From the perspective of the returning employee, however, this may confirm their fears that colleagues will believe they're no longer competent and be interpreted as mistreatment. This situation was described by one participant:

Work is inherently stressful, so it's harder to give work to someone coming back from mental health-related leave because you don't want to overburden them. While you think you are protecting them, they can feel like you are "dumbingdown" the work and being treated unfairly due to their condition (participant \#882, female, age 33).

Similarly, sometimes when coworkers are uncertain how to act around an individual with a mental health problem, they can behave nervously. From the 
perspective of the individual with the mental health problem, however, coworkers behaving in this awkward manner could likely be misinterpreted as rejection.

Overt behaviour. In other cases, mistreatment appeared more clear-cut.

Describing a situation with a coworker with anxiety who was new to the team, one participant explained how the new coworker was treated even though her work seemed on par with previous new team members: "Quickly rumors were spreading about how she was lazy and not doing her job, people were talking about how she kept screwing up and treated her poorly" (participant \#971, female, age 31). Similarly, a supervisor who had now moved to a new group shared his experience with a former employer who he felt was treated poorly by senior staff:

I have heard from former colleagues that the employee, when bringing up concerns regarding strenuous workload, processes, or the behavior of some of the senior staff, has been advised that "maybe [they] weren't cut out for this work". As the person's supervisor, I had no concerns about their ability or aptitude for the position, however, in my opinion, the person's history with mental health may have been used to diminish or trivialize their very valid concerns with regards to workload, poor management decisions and behaviour (participant \#840, female, age 36).

Likewise, another participate described witnessing uncivil behaviour and lack of sympathy towards a coworker who he thought may have been depressed after losing his wife: "I hear things on a daily basis like "if he can't handle his wife dying he should stay home until he can" and "he hasn't done anything right, NOTHING, since his wife died 3 months ago"" (participant \#858, female, age 56). 
There were also examples of coworkers being ostracized because of their mental health problems. For example, one participant commented about having a coworker return to work after a leave of absence for a mental health problem: "At this one job but the person still acted really weird. Mostly everyone stayed out of her way. We didn't talk to her or interact with never" (participant \#552, male, age 50), and another stated that she felt: "de la tristesse car ces collègues sont par expérience écartées, classées comme inférieurs, et dénudées de dignité [sadness because from her experience these coworkers are set apart, categorized as inferior, and stripped of dignity]" (participant \#989, male, age 56).

Employees with physical health problems also experienced mistreatment. One participant commented: "I had a few colleagues return to work after surgery, and was appalled at how unfair the supervisor was toward them, even though they were capable of getting job done!" (participant \#283, female, age 41), and another described witnessing what they perceived to be cruel treatment of an older coworker:

Our supervisor was cruel to the woman, demanding that she work harder and complete data entry faster than the woman was able to do. I heard the supervisor tell the woman that there would be NO ACCOMMODATIONS made for her recovery period. The woman was wearing a cumbersome neck brace, and it was clear that she was having trouble typing at speed (participant \#610, male, age 35). A participant with mental health problems who was currently not working stated: "I was able to complete all tasks in my last position. However, no additional work was given to me even though I was available and asking for more work. The union did not help me and basically told me to be thankful I was back at work" (participant \#807, 
female, age 39). In addition, another participant with depression stated:

Étant moi-même en retour pour dépression majeur, je qualifierais mon expérience de très difficile. Jugement, peur, rejet et le manque de ressource au travail font en sorte que l'adaptation est plutôt insurmontable [Having returned myself after major depressive disorder, I would describe my experience as very difficult. Judgment, fear, rejection, and a lack of resources at work make accommodation rather hopeless] (participant \#818, female, age 52).

Finally, participants commented on mistreatment from insurance companies that want continuing proof of disability. As stated by one participant regarding his experience with a coworker with anxiety:

She went 3 months without money from anyone because no one would help her figure out the insurance portion, and then as soon as she was on disability the insurance was trying to force her back to work almost from the start. If you're mentally ill, they constantly want you to prove you're still too sick to work, so you spend your whole time off stressing about whether or not they're going to force you back to work (participant \#971, female, age 34).

\section{Summary of Findings}

To summarize, there were a range of reactions to coworkers returning to work following a leave of absence for health problems. Most participants expressed goodwill and benevolence towards accommodating a coworker with health problems, mental or physical, but there were also limits to helping if it had a negative impact on their own work or stress levels. This concern regarding workload was also central to the less frequent expressions of hostility regarding what participants referred to as picking up the 
slack for coworkers who were perceived as working too slowly, taking advantage of team members or the organization, or weak.

The analysis also showed that participants believed mental and physical health problems in the workplace differed in several key ways. First, there was secrecy around leaves of absence for mental health problems. In the absence of information, speculation about why a coworker had taken leave was implicated in rumours and gossip, as well as uncertainty about how to interact with the returning coworker. Second, there was concern about stress and pressure from work causing relapses of mental health problems. As a result, coworkers described behaving cautiously and observing the coworker for signs that they weren't coping. Finally, coworkers thought to have mental health problems were sometimes perceived as behaving oddly or were not trusted because of past behaviours. Importantly, although there were relatively few reports of individuals being mistreated, overt hostility and rejection were clearly distressing. Those who experienced mistreatment described strong feelings of fear, sadness, or anger. Witnesses described feeling upset and shocked when this behaviour was tolerated by the organization. Moreover, they believed that mistreatment caused victims to take further leaves of absence and, in some cases, decided to leave the team themselves. In short, even though mistreatment is infrequent, the consequences are far-reaching and can seriously impact the individuals who experience mistreatment, their team members, and the organization. 


\section{Discussion}

The overall aim of this research was to examine whether work-related accommodations increase mental-health stigma in the workplace beyond the level experienced as a result of disclosing depression or anxiety. The results of both studies, however, provided no evidence that accommodations increased endorsement of negative stereotypes or perceptions of unfairness towards having a coworker with depression or anxiety. Moreover, because negative stereotypes and perceived unfairness were proposed to precede emotional and behavioural responses, there was also no evidence that accommodations had an impact on either of these outcomes. Rather, the results suggested that knowing a coworker has depression or anxiety casts some doubt on their ability and increases perceptions of dangerousness compared to physical injury. In addition, there was solid evidence that those participants who endorsed stereotypes were more likely to believe that making changes for coworkers with health problems is unfair to themselves and others in the workplace and, consequently, to respond negatively. Hence, stigma that interferes with implementation of accommodations (Kensbock et al., 2017; Schultz et al., 2011) may be the result of disclosing depression or anxiety rather than the accommodation itself.

Given that accommodations are sometimes viewed as special privileges, it is surprising that the accommodation condition had no impact in either study, particularly considering the close association that is proposed to exist between perceptions that a coworker is getting special treatment and judgements that the situation is unfair to other coworkers (Colella, 2001). One possibility for these unexpected results is that the accommodation manipulation (i.e., extra time for tasks and time off for medical 
appointments) had no effect because employees expect coworkers with health problems to take more time to complete tasks and to have medical appointments. Participants in the no accommodation condition (i.e., return to regular schedule and duties) may, therefore, have responded similarly to the accommodation condition because they assumed that, even though the colleague was described as returning to their regular schedule and duties, there would still be informal adjustments made to help the colleague return to work.

The possibility that the accommodation condition described expected adjustments for a coworker experiencing health problems is supported by the qualitative analysis. Whether participants' comments expressed benevolence or hostility, their prior experiences with coworkers returning to work following a leave of absence for health problems clearly involved at least a period of adjustment during which the returning coworker needed extra help and support. Therefore, although the no-accommodation condition specified that the colleague would be returning to a normal schedule and duties, participants may have responded in a similar manner as participants in the accommodation condition. It is conceivable that a larger proportion of participants might have reacted more negatively to an accommodation that is viewed more as a perk (e.g., private office, parking next to the entrance) or to an accommodation that was described as longer term.

Also surprisingly, overall endorsement of negative stereotypes was somewhat low, suggesting that participants in these two samples had relatively positive attitudes towards coworkers with depression or anxiety. While this may have been true at the group level, this does not mean that stigma towards depression and anxiety or stigma towards accommodations does not exist or that it has no impact. On the contrary, the 
qualitative analysis showed that believing an individual was malingering or otherwise taking advantage of coworkers and employers had a considerable negative impact on the reactions of a small number of participants. Moreover, judging an individual to be at fault or weak for taking a leave of absence for certain mental health problems like depression and anxiety was also implicated in unsympathetic reactions, and the secrecy surrounding mental health problems was considered central to feelings of uncertainty and cautious behaviours.

Individuals with mental health problems are often already worried about the impact of disclosure on their work lives (MacDonald-Wilson et al., 2011) and experiencing rejection or hostility even on a small scale are likely to have a large impact (Fisher, Overholser, Ridley, Braden, \& Rosoff, 2015; Steger \& Kashdan, 2009), particularly if the source of that mistreatment is in a position of power (Tepper, 2000). Hence, even a small proportion of the workforce with negative attitudes towards accommodating a coworker for depression or anxiety could have important practical significance.

Importantly, the results of both studies point to the central role that perceived unfairness plays in emotional reactions and, therefore, behaviours in a work environment. Stigma research has not typically studied perceived unfairness as a possible explanation for negative reactions to individuals with mental health problems. Perceived unfairness from the stigmatizer's perspective may not be as important a concern for stigma research outside of the work context where there is less direct competition for resources and more choice regarding social interactions. In a work context, colleagues can have a large impact on day-to-day life and team members are expected to interact and work together 
despite differences. Moreover, there are frequent opportunities to compare one's own situation with other colleagues (e.g., workload, pay, promotions). The present research provides evidence that, once a negative stereotype such as perceived malingering, reduced work ability, blame, or dangerousness is activated, coworkers are likely to have negative emotional responses because they perceive the situation to be unfair. Consequently, it would be beneficial for future research examining stigma in the workplace to further study the role of perceived unfairness.

\section{Limitations}

Pattern of results by sample. It is important to acknowledge that generalizability of this research may be limited because of the different pattern of results obtained for Study 1 and Study 2. One possible explanation is that the two samples represent different subsets of the working population whose attitudes differ towards coworkers with depression and anxiety. The MTurk sample used in Study 1 had a balanced gender composition with more male than female supervisors and was primarily American and well-educated. According to a recent meta-analysis (Walter, Seibert, Goering, \& O'Boyle, 2019), findings based on this sample are reasonably comparable to those found using conventional population-level data collection methods.

In comparison, the organizational sample used in Study 2 was Canadian, close to $75 \%$ female with more female than male supervisors, older, and even more well-educated than the MTurk sample. Moreover, the sample was from a public sector organization with unionized employees. Unlike the MTurk sample who were compensated a small amount for participation, participants in Study 2 first had to be engaged enough to read the weekly organization-wide e-newsletter containing the recruitment notice and then have 
enough interest to motivate them to continue to the online survey. In short, results of Study 1 are likely a closer approximation of attitudes held by the general working population than results of Study 2, and Study 2 results may not be representative of the public service.

Initial reactions vs longer-term responses. The experimental vignette surgery is an excellent methodology for better understanding initial responses to a situation that employees are likely to face in real life (Aguinis \& Bradley, 2014). These initial responses are important; however, the qualitative analysis demonstrated that stigma is complex and that, following the initial news that an individual with health problems will be returning to work, there are many factors that can shape longer term responses. Moreover, because the results of the present research suggest that only a small proportion of the population continues to hold stigmatizing attitudes towards depression and anxiety, future research should consider further qualitative analyses based on semi-structured interviews. This methodology would allow researchers to probe further into both nonstigma- and stigma-related factors underlying negative reactions to accommodations for depression or anxiety. As stated by participants in the present research, sometimes negative reactions to coworkers returning to work following a leave of absence for health reasons factors are the result of factors such as excessive workloads and time pressure, which have nothing to do with stigma.

\section{Research Implications}

Important role of appraisal theory. The current research highlights the potential value of integrating Frijda's (1986) appraisal theory of emotions into organizational research on mental health-related stigma and job accommodations. Frijda proposed that 
appraisals of an event depend on factors such as situational meaning, importance for the self or valued others, and expected change in circumstances. Moreover, appraisals determine emotional responses, which include not only the subjective feeling of an emotion (e.g., feeling angry) but also tendencies toward action (e.g., approach, avoid, uncertainty) (Frijda et al., 1989). The results of the current research provide strong evidence to support this theory by demonstrating that appraisals involving negative stereotypes and perceptions of unfairness can lead to negative emotional and behavioural responses. This implies that emotions are central to explaining stigmatizing behaviours and that it would be valuable for future research to consider other factors contributing to negative appraisals of coworkers with mental health problems.

In addition to explaining stigmatizing attitudes and behaviours, Frijda's (1986) theory also has potential to explain negative responses to coworkers with mental health problems that are not based on the stigma. The qualitative analysis suggests that the primary concern for most employees is likely to be whether or not they will be expected to take on more work. Moreover, in work environments with heavy workloads, employees are likely to feel uneasiness about not being able to manage additional work and anger if the organization does not provide adequate resources or implement an accommodation fairly. Affect-based research on organizational justice suggests that emotional responses can mediate the association between perceived injustice and negative organizational outcomes such counterproductive work behaviours (Colquitt et al., 2013). Hence, future research to examine dimensions of appraisal (Frijda et al, 1989) most relevant to an organizational setting would be helpful to understand responses to coworkers with health problems. 
Additional behavioural outcomes. This research examined willingness to socialize and willingness to give a job recommendation as behavioural outcomes of stigma. Although these are important outcomes, there are other workplace-specific behaviours that would be beneficial to study. In particular, it would be useful to study how willing employees are to voluntarily help coworkers as opposed to helping because they are required to help. It would also be beneficial to study workplace incivility, which includes low intensity behaviours such as disrespectful or condescending conduct with ambiguous intent (Cortina, Magley, Williams, \& Langhout, 2001). Cortina (2008) proposed that, because incivility is low-level and ambiguous, uncivil behaviour can be selectively used as a form of discrimination in social contexts where blatant discrimination is unacceptable. The result of the qualitative analysis for the present research suggests that this may indeed be the case for employees who have little choice about working with coworkers who have health problems. Hence, future research should consider workplace incivility as an additional potential behavioural outcome of stigma.

\section{Practical Implications}

Accommodation beyond the individual. Accommodations are typically individual-level interventions intended to help individuals overcome functional limitations and successfully carry out their work; however, there are several reasons that approaching both informal and formal accommodations at the team-level would likely result in more successful outcomes for both the accommodated individual and their team members. First, although accommodations typically involve modifications for an individual, there is likely to be at least some impact on the work of coworkers and supervisors. If an accommodation results in long-term increases in stress for other team 
members or supervisors because of increases in workload or time pressure, they are likely to perceive the accommodation negatively (Colella, 2001). This was confirmed by qualitative findings from the present research even for those who believed that helping people return to work is the right thing to do. To prevent these negative reactions, either the overall workload for the team must be adjusted or more resources in the form of extra time or personnel must be allocated.

Second, although stigma can lead to unfounded negative judgments and perceived unfairness, it is also likely that lack of information regarding accommodations and the secrecy around mental health problems leads to uncertain, awkward behaviour even from well-intentioned coworkers. Although privacy is an important consideration, team members need some information about the situation in order to prevent speculation and rumours. Participants in the present research commented that they felt awkward and sometimes avoided interactions with the returning coworker simply because they did not know if their coworker wanted to talk about their leave or to pretend nothing had happened. Hence, an analysis of which information is suitable and can be provided to team members would be a helpful component of the accommodation process.

Finally, allowing team members to have input regarding changes that are likely to affect them could improve their perceptions of the accommodation process. Although privacy can obviously limit how much information can be given to team members if the returning coworker does not wish the reason for accommodation to be disclosed, team members may still have ideas about how to fairly implement changes that impact them without necessarily having detailed information. For example, for an individual with depression or anxiety who is accommodated with a flexible schedule, team members can 
have input about which hours of the days are most important to have all team members present without knowing why the accommodation is necessary. Providing team members with an opportunity to have input could increase perceptions of procedural justice (Leventhal, 1980) and, therefore, result in more positive reactions to accommodations.

Targets for education. There are multiple targets for education to increase understanding of the accommodation process. First, it is important for individuals returning to work following a leave of absence for depression or anxiety to understand the impact of secrecy. Although they may be worried about stigma, the results of the present research suggest that overall attitudes towards depression and anxiety are positive, with most participants expressing benevolence and goodwill towards helping coworkers return to work. In the case that the individual decides to keep the reason for leave private, they should understand that some coworkers may act awkwardly not because they are judging or reacting negatively but because they are uncertain how to act. This is not to say that none of their coworkers will hold stigmatizing attitudes and act negatively. Rather, it is important to understand that misinterpretation by all parties is possible in the absence of information.

It is also important to educate supervisors regarding which information can be shared with team members without violating privacy. Because employees are typically less comfortable sharing information about mental health problems as compared to physical health problems (MacDonald-Wilson et al., 2011), supervisors may provide no information at all out of concern that they may be breaching employee privacy. In reality, however, supervisors can inform other team members about what to expect from the 
accommodation process and how changes might impact team members without revealing private health-related details.

The results of the present research also imply that it is important for coworkers to be educated about the organization's responsibility to accommodate employees with disabilities in a manner that does not compromise the mental or physical health of other coworkers. Although an individual who is perhaps working more slowly than others or who has an accommodation for health problems is a tempting target for blame when other team members are overloaded, the organization is ultimately responsible for managing resources and workload. Although management may not respond when informed that employees are overworked, blaming the individual is unlikely to improve the situation.

One last target for education are individuals within organizations who are in a position to influence the accommodation process. Although it is important to continue to work on improving attitudes of front-line employees and supervisors, organizational decision-makers need to understand the value of well-defined policies and processes that help employees return to work and, if necessary, receive accommodations. In particular, organizational decision-makers should be aware of the prevalence of depression and anxiety in the workforce and the likelihood of future disability leaves for employees with depression or anxiety if accommodations are unsuccessful. Moreover, organizations should be aware that, in addition to potentially losing the employee with health problems, other employees who perceive that the organization does not care about the health of its employees can also form negative attitudes towards the organization. 


\section{Conclusion}

Depression and anxiety are common mental health problems in the working population (Dewa et al., 2004), resulting in substantial emotional and financial distress for both individuals and organizations (Dewa \& McDaid, 2011; Mental Health Commission of Canada, 2017). Job accommodations are intended to help individuals with mental or physical disabilities overcome functional limitations so that they can perform their essential job functions (Chow et al, 2014); however, employees who receive accommodations report experiencing mistreatment as a consequence of stigma (Kensbock et al., 2017, Schultz et al., 2011). The present research found that accommodations had no impact on endorsement of negative stereotypes; however, participants who did endorse negative stereotypes were more likely to react negatively because they perceived that having a coworker with health problems was unfair to themselves and other coworkers. Hence, the experiences of stigma experienced by those who receive accommodations may be a result of disclosing a mental health problem in order to receive accommodation. 


\section{References}

Adler, D.A., McLaughlin, T.J., Rogers, W.H., Chang, H., Lapitsky, L., \& Lerner, D. (2006). Job performance deficits due to depression. American Journal of Psychiatry, 163(9), 1569-1576. doi: 10.1176/appi.ajp.163.9.1569

American Psychiatric Association. (2013). Diagnostic and statistical manual of mental disorders (5th ed.). Arlington, VA: American Psychiatric Publishing.

Americans with Disabilities Act (ADA) (1990) Public Law No. 101-336; 42 USC Section 12211

Anderson, K.N., Jeon, A.B., Blenner, J.A., Wiener, R.L., \& Hope, D.A. (2015). How people evaluate others with social anxiety disorder: A comparison to depression and general mental illness stigma. American Journal of Orthopsychiatry, 85(2), 131-138.

Angermeyer, M.C., Holzinger, A., \& Matschinger, H. (2010). Emotional reactions to people with mental illness. Epidemiologia e Psichiatria Sociale, 19(1), 26-32.

Angermeyer, M.C., \& Matschinger, H. (1996). The effect of personal experience with mental illness on the attitude towards individuals suffering from mental disorders. Social Psychiatry and Psychiatric Epidemiological, 31(6), 321-326.

Angermeyer, M.C., \& Matschinger, H. (1997). Social distance towards the mentally ill: Results of representative surveys in the Federal Republic of Germany. Pscyhological Medicine. 27. 131-141.

Angermeyer, M.C., \& Matschinger, H. (2003). The stigma of mental illness: Effects of labelling on public attitudes towards people with mental disorders. Acta Psyciatrica Scandinavica, 108, 304-309. 
Angermeyer, M.C., Matschinger, H., Carta, M.G., \& Schomerus, G. (2014). Changes in the perception of mental illness stigma in Germany over the last two decades. European Psychiatry, 29(6), 390-395. doi: 10.1016/j.eurpsy.2013.10.004

Aguinis, H., \& Bradley, K.J. (2014). Best practice recommendations for designing and implementing experimental vignette methodology studies. Organizational Research Methods, 17(4), 351-371. doi: 10.1177/1094428114547952

Atzmuller, C., \& Steiner, P.M. (2010). Experimental vignette studies in survey research. Methodology, 6(3), 128-138. doi: 10.1027/1614-2241/a000014

Augsberger, A., Yeung, A., Dougher, M., \& Hahm, H. (2015). Factors influencing the underutilization of mental health services among Asian American women with a history of depression and suicide. BMC Health Services Research, 15, 1-11.

Barclay, L.J., Skarlicki, D.P., \& Pugh, D.S. (2005). Exploring the role of emotions in injustice perceptions and retaliation. Journal of Applied Psychology, 90(4), 629643.

Bender, A., \& Farvolden, P. (2008). Depression and the workplace: A progress report. Current Psychiatry Reports, 10(1), 73-79.

Blank, L., Peters, J., Pickvance, S., Wilford, J., \& MacDonald, E. (2008). A systematic review of the factors which predict return to work for people suffering episodes of poor mental health. Journal of Occupational Rehabilitation, 18, 27-34. doi: $10.1007 / \mathrm{s} 10926-008-9121-8$

Blonk, R.W.B., Brenninkmeijer, V., Lagerveld, S.E., Houtman, I.L.D. (2006). Return to work: A comparison of two cognitive behavioural interventions in cases of work- 
related psychological complaints among the self-employed. Work \& Stress 20(2), 129-144, doi: 10.1080/02678370600856615

Bogardus, E.S. (1925). Social distance and its origins. Journal of Applied Sociology, 9, 216-226.

Braun, V., \& Clarke, V. (2006). Using thematic analysis in psychology. Qualitative Research in Psychology, 3(2), 77-101. doi: 10.1191/1478088706qp063oa

Canadian Humans Right Act, Revised Statutes of Canada (1985, c. H-6). Retrieved from the Justice Laws website: https://laws-lois.justice.gc.ca/PDF/H-6.pdf

Canadian Medical Association. (2008). 8th Annual National Report Card on Health Care. Retrieved from http://www.bc-psychologist.com/downloads/other/ National_Report_Card_EN.pdf

Center, C. (2011). Law and job accommodation in mental health disability. In I.Z. Schultz \& E.S. Rogers (Eds.), Work Accommodation and Retention in Mental Health (pp. 3-32). New York, NY: Springer

Center for Behavioral Health Statistics and Quality (2017). 2016 National Survey on Drug Use and Health: Detailed Tables. Retrieved from https://www.samhsa.gov/data/sites/default/ files/NSDUH-DetTabs2016/NSDUH-DetTabs-2016.pdf

Chow, C.M., Cichocki, B., \& Croft, B. (2014). The impact of job accommodations on employment outcomes among individuals with psychiatric disabilities. Psychiaric Services, 65(9), doi: 10.1176/appi.ps.201300267 
Colella, A. (2001). Coworker distributive fairness judgments of the workplace accommodations of employees with disabilities. Academy of Management Review, 26(1), 100-116.

Colella, A., Paetzold, R.L., \& Belliveau, M.A. (2004). Factors affecting coworkers' procedural justice inferences of the workplace accommodations of employees with disabilities. Personnel Psychology, 57, 1-23. doi: 10.1111/j.17446570.2004.tb02482.x

Colquitt, J.A., Conlon, D.E., Wesson, M.J., Porter, C.O.L., \& Ng, K.Y. (2001). Justice at the millennium: A meta-analytic review of 25 years of organizational justice research. Journal of Applied Psychology, 86(3), 425-445. doi: 10.1037/00219010.86 .3 .425

Colquitt, J.A., Rodell, J.B., Zapata, C.P., Scott, B.A., Long, D.M, Conlon, D.E., Wesson, M.J. (2013). Justice at the millennium, a decade later: A meta-analytic test of social exchange and affect-based perspectives. Journal of Applied Psychology, 98(2), 199-236. doi: 10.1037/a0031757

Cook, T.M., \& Wang, J. (2010). Descriptive epidemiology of stigma against depression in a general population sample in Alberta. BMC Psychiatry, 10(29), 1-11.

Corrigan, P.W., Morris, S.B., Michaels, P.J., Rafacz, J.D., \& Rusch, N. (2012).

Challenging the public stigma of mental illness: A meta-analysis of outcome studies. Psychiatric Services, 63(10), 963-973. doi: 10.1176/appi.ps.201100529

Corrigan, P.W., \& Fong, M.W. (2014). Competing perspective on erasing the stigma of illness: What says the dodo bird? Social Science and Medicine, 103, 110-117. 
Corrigan, P.W., Larson, J.E., Michaels, P.J., Buchholz, B.A., Del Rossi, R., Fontecchio, M.J., Castro, D., Gause, M., Kryzanowshi, R, \& Rusch, N. (2015). Diminishing the self-stigma of mental illness by coming out proud. Psychiatry Research, 229, 148-154

Cortina, L.M. (2008). Unseen injustice: Incivility as modern discrimination in organizations. The Academy of Management Review, 33(1), 55-75.

Cortina, L.M., Magley, V.J., Williams, J.H., \& Langhout, R. (2001). Incivility in the workplace: Incidence and impact. Journal of Occupational Health Psychology, $6(1), 64-80$.

Crocker, J., Major, B., \& Steele, C. (1998). Social stigma. In S. Fiske, D. Gilber, \& G. Lindzey (Eds.), Handbook of Social Psychology (pp. 504-553). Boston, MA: McGraw-Hill

Curcio, C., \& Corboy, D. (2019). Stigma and anxiety disorders. A systematic review. Stigma and Health. Advance online publication. doi: 10.1037/sah0000183

Davidson, J. (2005). Contesting stigma and contested emotions: Personal experience and public perception of specific phobias. Social Science \& Medicine, 61, 2155-2164.

Dewa, C.S, Goering, P., Lin, E., \& Paterson, M. (2002). Depression-related short-term disability in an employed population. Journal of Occupational and Environmental Health, 44(7), 628-633.

Dewa., C.S, Lesage, A., Goering, P., \& Caveen, M. (2004). Nature and prevalence of mental illness in the workplace. HealthcarePapers, 5(2), 12-25.

Dewa, C.S., Lin, E., (2000). Chronic physical illness, psychiatric disorder and disability in the workplace. Social Science \& Medicine, 51, 41-50. 
Dewa, C.S., \& McDaid, D. (2011). Investing in the mental health of the labor force: Epidemiological and economic impact of mental health disabilities in the workplace. In I.Z. Schultz \& E.S. Rogers (Eds.), Work Accommodation and Retention in Mental Health (pp. 33-51). New York, NY: Springer

Dooley, D., Prause, J., \& Ham-Rowbottom, K.A. (2000). Underemployment and depression: Longitudinal relationships. Journal of Health and Social Behavior, $41,421-436$.

Erickson, S.R., Guthrie, S., VanEtten-Lee, M., Himle, J., Hoffman, J., Santos, S.F., Janeck, A.S., Zivin, K., \& Abelson, J.L. (2009). Severity of anxiety and workrelated outcomes of patients with anxiety disorders. Depression and Anxiety, 26, 1165-1171.

Everett, B. (2004). Best practices in workplace mental health: An area for expanded research. HealthcarePapers, 5(2), 114-116.

Fisher, L.B., Overholser, J.C., Ridley, J., Braden, A., \& Rosoff, C. (2015) From the Outside Looking In: Sense of Belonging, Depression, and Suicide Risk, Psychiatry, 78(1), 29-41. doi: 10.1080/00332747.2015.1015867

Frijda, N.H. (1988). The laws of emotion. American Psychologist, 43(5), 349-358.

Frijda, N.H., Kuipers, P., \& ter Schure, E. (1989). Relations among emotion, appraisal, and emotional action readiness. Journal of Personality and Social Psychology, 57(2). 212-228.

Gates, L.B. (2000). Workplace accommodation as a social process. Journal of Occupational Rehabilitation, 10(1), 85-98. 
Gates, L.B., \& Akabas, S.H. (2011). Inclusion of people with mental health disabilities into the workplace: Accommodation as a social process. In I.Z. Schultz \& E.S. Rogers (Eds.), Work Accommodation and Retention in Mental Health (pp. 375391). New York, NY: Springer

Goffman, E. (1963). Stigma: Notes on the management of spoiled identity. Englewood Cliffs, NJ: Prentice-Hall

Grant, J.B., Bruce, C.P., \& Batterham, P.J. (2016). Predictors of personal, perceived and self-stigmatowards anxiety and depression. Epidemiology and Psychiatric Sciences, 25, 247-254.

Griffiths, K.M., Christensen, H., Jorm, A.F., Evans, K., \& Groves, C. (2004). Effect of web-based depression literacy and cognitive-behavioural therapy interventions on stigmatising attitudes to depression. British Journal of Psychiatry, 185, 342-349.

Griffiths, K.M., Batterham, P.J., Barney, L., \& Parsons, A. (2011). The generalised anxiety stigma scale (GASS): Psychometric properties in a community sample. BMC Psychiatry, 11, 1-9.

Harvey, S.B., \& Henderson, M. (2009). Occupational Psychiatry. Psychiatry, 8(5), 174178. doi: 10.1016/j.mppsy.2009.03.011

Hayes, A.F. (2013). Introduction to mediation, moderation, and conditional process analysis: A regression-based approach. New York, NY: The Guildford Press. doi: $10.1111 /$ jedm. 12050

Ipsos Reid (2007). Mental health in the workplace: Largest study ever conducted of Canadian workplace mental health and depression [News release]. Retrieved from https://www.ipsos.com/en-ca/mental-health-workplace 
Job Accommodations Network. (2017). Workplace accommodations: Low cost, high impact. Morgantown, WV. Electronic version retrieved by email from the Job Accommodations Network

Jorm, A.F., Christensen, H., \& Griffiths, K.M. (2004). Changes in depression awareness and attitudes in Australia: The impact of beyondblue: The national depression initiative. Australian and New Zealand Journal of Psychiatry, 40, 42-46.

Jorm, A.F., Reavley, N.J., \& Ross, A.M. (2012). Belief in the dangerousness of people with mental disorders: A review. Australian \& New Zealand Journal of Psychiatry, 46(11), 1029-1045. doi: 10.1177/0004867412442406

Jorm, A.F., \& Wright, A. (2008). Influences on young people's stigmatising attitudes towards peers with mental disorders. The British Journal of Psychiatry, 192(2)

Kelloway, E.K. (2017). Mental health in the workplace: Towards evidence-based practice. Canadian Psychology, 58(1). 1-6. doi: 10.1037/cap0000084

Kensbock, J.M., Boehm, S.A., \& Bourovoi, K. (2017). Is there a downside of job accommodations? An employee perspective on individual change processes. Frontiers in Psychology: Organizational Psychology Section. 8. Article 1536. doi: 10.3389/fpsyg. 2017.01536

King, M., Dinos, S., Shaw, J., Watson, R., Stevens, S., Passetti, F., Weich, S., \& Serfaty, M. (2007). The stigma scale: Development of a standardised measure of stigma of mental illness. British Journal of Psychiatry, 190(3), 248-254. doi:

10.1192/bjp.bp.106.024638 
Knoll, J.L., \& Annas, G.D., (2016). Mass shootings and mental illness. In L.H. Gold \& R.S. Simon (Eds.), Gun Violence and Mental Illness (pp. 81-104). Washington, DC: American Psychological Association

Krupa, T., Kirsh, B., Cockburn, L., \& Gewurtz, R. (2009). Understanding the stigma of mental illness in employment. Work, 33(4), 413-425. doi: 10.3233/WOR-20090890

Lerner, D., Adler, D., Hermann, R.C., Rogers, W.H., Chang, H., Thomas, P., Greenhill, A., \& Perch, K. (2011). Depression and work performance: The work and health initiative study. In I.Z. Schultz \& E.S. Rogers (Eds.), Work Accommodation and Retention in Mental Health (pp. 103-120). New York, NY: Springer

Lerner, D., \& Henke, R.M. (2008). What does research tell us about depression, job performance, and work productivity? Journal of Occupational and Environmental Medicine, 50(4), 401-410. doi: 10.1097/JOM.0b013e31816bae50

Leventhal, G.S. (1980). What should be done with equity theory? New approaches to the study of fairness in social relationships. In K.J. Gergen, M.S. Greenberg, \& R.H. Willis (Eds.) Social Exchange: Advances in Theory and Research (pp. 27-55). New York, NY: Springer

Lim, D., Sanderson, K., \& Andrews, G. (2000). Lost productivity among full-time workers with mental disorders. The Journal of Mental Health Policy and Economics, 3, 139-146. doi: 10.1002/mhp.93

Link, B.G. (1987). Understanding labelling effects in the area of mental disorders: An assessment of the effects of expectations of rejection. American Sociological Review, 52, 96-112. 
Link, B.G, \& Phelan, J.C. (2001). Conceptualizing Stigma. Annual Review of Sociology, 27, 363-385.

Link, B.G., Yang, L.H., Phelan, J.C., \& Collins, P.Y. (2004). Measuring mental illness stigma. Schizophrenia Bulletin, 30(3), 511-541.

MacDonald-Wilson, K.L., Russinova, Z., Rogers, E.S., Lin, C., Ferguson, T., Dong, S., \& MacDonald, M.K. (2011). Disclosure of mental health disabilities in the workplace. In I.Z. Schultz \& E.S. Rogers (Eds.), Work Accommodation and Retention in Mental Health (pp. 191-217). New York, NY: Springer

Major, B. \& Eccleston, C.P. (2005). Stigma and social exclusion. In D. Abrams, M.A. Hogg, \& J.M. Marques (Eds.), The Social Psychology of Inclusion and Exclusion (pp. 63-87). New York: Psychology Press

Major, B., \& O'Brien, L.T. (2005). The social psychology of stigma. Annual Review of Psychology, 56, 393-421. doi: 10.1146/annurev.psych.56.091103.070137

McGurk, S.R., \& Wykes, T. (2008). Cognitive remediation and vocational rehabilitation. Psychiatric Rehabiliation Journal, 31(4), 350-359. doi:

$10.2975 / 31.4 .2008 .350 .359$

Mental Health Commission of Canada. (2017). Strengthening the case for investing in Canada's mental health system: Economic Considerations. Ottawa: Mental Health Commission of Canada. Retrieved from https://www.mentalhealthcommission.ca/sites/default/files/201703/case_for_investment_eng.pdf 
Norman, R., Sorrentino, R., Windell, D., \& Manchanda, R. (2008). Are personal values of importance in the stigmatization of people with mental illness? Canadian Journal of Psychiatry, 53(12), 848-856. doi: 10.1177/070674370805301210

Paetzold, R.L., Garcia, M., Colella, A., Ren, L., Triana, M., \& Ziebro, M. (2008). Perceptions of people with disabilities: When is accommodation fair? Basic and Applied Social Psychology, 30(1), 27-35.

Parliament of Canada. (2006). Out of the Shadows at Last: Transforming mental health, mental illness, and addiction services in Canada. 38th Parl., 1st sess. Rept 1. Retrieved from http://publications.gc.ca/collections/collection_2011/sen/yc170/YC17-0-391-2-1-eng.pdf

Peer, J., \& Tenhula, W. (2011). Employment interventions for persons with mood and anxiety disorders. In I.Z. Schultz \& E.S. Rogers (Eds.), Work Accommodation and Retention in Mental Health (pp. 233-262). New York, NY: Springer

Pescosolido, B.A. (2013). The public stigma of mental illness: What do we think; What do we know; What can we prove? Journal of Health and Social Behavior, 54(1), 1-21. doi: $10.1177 / 0022146512471197$

Public Service Alliance of Canada. (n.d.). Human rights. Retrieved from http://psacunion.ca/human-rights

Robbins, J.M., Ford, M.T., \& Tetrick, L.E. (2012). Perceived unfairness and employee health: A meta-analytic integration. Journal of Applied Psychology, 97(2), 235272.

Rogers, E.S., \& MacDonald-Wilson, K.L. (2011). Vocational capacity among individuals with mental health disabilities. In I.Z. Schultz \& E.S. Rogers (Eds.), Work 
Accommodation and Retention in Mental Health (pp. 73-89). New York, NY:

Springer

Romer, D., \& Bock, M. (2008). Reducing the stigma of mental illness among adolescents and young adults: The effects of treatment information. Journal of Health Communication, 13(8), 742-758. doi: 10.1080/10810730802487406

Schomerus, G., Van der Auwera, S., Matschinger, H., Baumeister, S.E., \& Angermeyer, M.C. (2015). Do attitudes towards persons with mental illness worsen during the course of life? An age-period-cohort analysis. Acta Psychiatrica Scandinavica, 132(5), 357-364. doi: 10.1111/acps.12401

Schultze, B., \& Angermeyer, M.C. (2003). Subjective experiences of stigma. Social Science \& Medicine, 56, 299-312.

Schultz, I.Z., Duplassie, D., Hanson, D.B., \& Winter, A. (2011). Systemic barriers to job accommodations in mental health: Experts' consensus. In I.Z. Schultz \& E.S. Rogers (Eds.), Work Accommodation and Retention in Mental Health (pp. 353372). New York, NY: Springer

Statistics Canada (2003). Canadian Community Health Survey, 2002 [public-use microdata file]. Retrieved from https://www150.statcan.gc.ca/n1/dailyquotidien/030903/dq030903a-eng.htm

Statistics Canada (2013). Canadian Community Health Survey, 2012 - Mental Health [public-use microdata file]. Retrieved from https://www.statcan.gc.ca/dailyquotidien/140403/dq140403f-eng.pdf 
Steger, M.F., \& Kashdan, T.B. (2009). Depression and everyday social activity, belonging, and well-being. Journal of Counselling Psychology, 56(2), 289-300. doi: $10.1037 / \mathrm{a} 0015416$.

Stuart, H. (2004). Stigma and work. HealthcarePapers, 5(2), 100-111.

Tepper, B.J. (2000). The consequences of abusive supervision. The Academy of Management Journal, 43(2), 178-190.

van der Klink, J.J., Blonk, R.W., Schene, A.H., van Dijk, F.J. (2001). The benefits of interventions for work-related stress. American Journal of Public Health, 91(2), 270-276.

Wahl, O.F. (1999). Mental health consumers' experience of stigma. Schizophrenia Bulletin, 25(3), 467-478.

Wald, J. (2011). Anxiety disorders and work performance. In I.Z. Schultz \& E.S. Rogers (Eds.), Work Accommodation and Retention in Mental Health (pp. 121-140). New York, NY: Springer

Walter, S.L., Seibert, S.E., Goering, D., \& O'Boyle, E.H. (2019). A tale of two samples: Do results from online panel data and conventional data coverge? Journal of Business and Psychology, 34, 425-452.

Wang, P.S., Beck, A.L., Berglund, P., McKenas, D.K., Pronk, N.P., Simon, G.E., \& Kessler, R.C. (2004). Effects of major depression on moment-in-time work performance. The American Journal of Psychiatry, 161(10), 1885-1891. doi: 10.1176/ajp.161.10.1885 
Wood, L., Birtel, M., Alsawy, S., Pyle, M., \& Morrison, A. (2014). Public perceptions of stigma towards people with schizophrenia, depression, and anxiety. Psychiatry Research, 220, 604-608.

World Health Organization. (2001). The World Health Report 2001: Mental health: New understanding, new hope. Geneva: World Health Organization

World Health Organization (2016). Global Health Estimates 2015: Burden of disease by cause, age, sex, by country and by region, 2000-2015. Geneva: World Health Organization 


\section{Appendix A. Study 1 Recruitment Notice}

Study Name: Workplace Health and Accommodations Research Study

Description: In this study, we want to learn more about attitudes and responses you might have towards individuals who return to work following a leave of absence for mental or physical health reasons. The period of time after an employee returns to work can be difficult with changes and adjustments for everyone involved. The results of this research will help us better understand how to improve this transition period.

Task Requirements: After reading a short scenario about a fictitious coworker who will soon be returning to work following a leave of absence, you will be asked to answer survey items regarding your attitudes and emotional responses towards the coworker and situation described in the scenario. Additionally, you will be asked about some of your individual characteristics and demographics.

Eligibility Requirements: Individuals with work experience living in the United States and Canada.

Duration and Locale: 10 minute questionnaire online

Researchers: Christine Tulk (Master's student); Dr. Janet Mantler (Faculty Supervisor, Department of Psychology, Carleton University)

Email: ChristineTulk@cmail.carleton.ca

This study has received clearance by the Carleton University Research Ethics Board-B (Protocol \# 110147). 


\section{Appendix B. Study 1 Consent Information}

\section{Workplace Health and Accommodations Research Study}

Thank you for taking the time to consider participating in this research study! The intent of this consent information is to ensure that you understand the purpose of the study in order for you to determine whether you wish to participate.

Purpose: In this study, we want to learn more about attitudes you may have towards coworkers who return to work following a leave of absence for mental or physical health reasons.

Task Requirements: After reading a short scenario about a fictitious coworker who will soon be returning to work following a leave of absence, you will be asked to answer survey items regarding your attitudes and emotional responses towards the coworker and situation described in the scenario. Additionally, you will be asked about some of your individual characteristics and demographics. The survey will take 10-12 minutes to complete.

Possible Benefits and Risks: We do not anticipate any direct benefit from your participation in this study. However, your participation may allow researchers to better understand what factors influence attitudes towards individuals returning to work after a leave of absence. We also do not anticipate any risks from taking this survey. If you feel any discomfort at any point, you may choose to skip any questions you are not comfortable answering.

No waiver of your rights: By agreeing to this research, you are not waiving any rights or releasing the researchers from any liability.

Right to withdraw: Your participation is voluntary, and you have the right to end your participation at any point during the survey. If you choose to withdraw, you may skip to the end of the survey to read more information on the study or you may close the survey window. Incomplete survey responses will be deleted. You can also withdraw your data after completing the survey by contacting the researchers through the Amazon Mechanical Turk web platform. Withdrawal will no longer be possible once the study is complete because data will be anonymized by deleting Worker IDs.

Anonymity/Confidentiality: Participation in this survey is confidential. No personal identifiers such as names or IP addresses will be collected by Qualtrics. Once the study is complete, data will be anonymized by deleting Amazon Mechanical Turk Worker IDs. All data will be stored on Toronto-based servers and in password-protected files. Research records may be accessed by the Carleton University Research Ethics Board in order to ensure continuing ethics compliance. After the study is completed, research data will be retained for future use and may be used for academic presentations, publications, and teaching. If requested, the anonymous data may be shared in online data repositories. 
REB Review and Contact Information: This project was reviewed and cleared by the Carleton University Research Ethics Board-B (Clearance \# 110147). If you have any ethical concerns with the study, please contact Dr. Bernadette Campbell, Chair by phone at 613-520-2600 ext. 4085 or by email at ethics@carleton.ca.

Researcher contact information:

Name: Christine Tulk

Position: Master's Student

Department: Psychology

Carleton University

Email: christine.tulk@carleton.ca
Supervisor contact information:

Name: Dr. Janet Mantler

Position: Associate Professor

Department: Psychology

Carleton University

Email: janet.mantler@carleton.ca

I voluntarily agree to participate in this study.

$\square$ Yes

No 


\section{Appendix C. Study 1 and Study 2 Questionnaire}

\section{Negative Stereotypes (Work Ability and Malingering)}

Items for the malingering and work ability sub-scales were created for the present research. WA = work ability, $\mathrm{M}=$ malingering,

Thinking about the situation in the paragraph you just read, please indicate the extent to which you agree or disagree with the following statements.

Response options: 1 = Strongly disagree to $5=$ Strongly agree

1. People often pretend to have health problems like this to get special treatment at work. (M)

2. This person would be a capable employee. (WA)

3. This person would be a reliable co-worker (WA)

4. This person is probably using illness as an excuse to get out of doing their work. (M)

\section{Unfairness}

Items for perceived unfairness were created for the present research.

1. Making changes at work for this person would be unfair. (F)

2. This situation would be unfair to other people at work. (F)

\section{Emotional Reactions (Angermeyer \& Matschinger, 1996)}

Items marked with * were added to the original set of items.

The original article specifies a 5-point Likert scale but does not specify the anchors.

No Cronbach's alpha was specified in the original research.

Please indicate the extent you felt the following emotions as you imagined yourself in the scenario:

Response options: 1 (Not at all), 2 (A little bit), 3 (Moderately), 4 (Quite a bit), 5

(Extremely)

1. desire to help

2. anger

3. sympathy

4. uneasiness

5. fear

6. inspiration*

7. irritation

8. disgust

9. enthusiasm*

10. anxiety

Social Distance (Norman, Sorrentino, Windell, Manchanda, 2008; Schomerus, Angermeyer, Baumeister, Stolzenburg, Link, \& Phelan, 2016)

Scales for social distance vary slightly depending on the measurement context but are generally derived (e.g., Normal et al., 2008; Schomerus et al., 2016) from seminal work by Bogardus (1925).

Cronbach's alpha $=0.82$ for the 5 items taken from Schomerus et al. (2016). 
Items 1, 3, and 7 were created for the present research. Items 5 and 8 taken from Schomerus et al. (2016). Items 2, 4, 9, and 10 were modified from Schomerus et al. (2106) by adding the words in italics. Item 10 was modified from "marry" "meet". Item 6 was taken from Norman et al. (2008).

Please indicate how willing you would be to:

Response options: 1 (Definitely not willing) to 5 (Definitely willing)

1. work in the area next to this person.

2. spend an evening socializing with this person at a work event.

3. take a coffee break with this person.

4. make friends with this person at work.

5. to have this person start working closely with you.

6. recommend this person for a job.

7. have this person become your supervisor.

8. move next door to this person.

9. make friends with this person outside of work.

10. have this person meet your family.

\section{Negative Stereotypes (Dangerousness and Blame Sub-scales)}

Dangerousness and blame sub-scales items were taken from an established scale by

Schomerus, Angermeyer, Baumeister, Stolzenburg, Link, and Phelan (2016).

Cronbach's alpha for dangerousness $=.85$ and for blame $=.70$.

$\mathrm{DP}=$ dangerousness/predictability, $\mathrm{B}=$ blame

Again imagining the person you just read about as if this was a real person returning to work, please indicate the extent you agree or disagree with the following statements.

Response options: $1=$ Strongly disagree to $5=$ Strongly agree

1. This person is to blame for their problems. (B)

2. To some extent, it is this person's fault that they got into this situation. (B)

3. This person is a danger to other people. (DP)

4. This person is unpredictable. (DP)

5. This person only has to pull themselves together to get well. (B)

6. This person is a danger to themselves. (DP)

7. This person's problems likely results from their weak character. (B)

Please answer the following questions about the paragraph you read at the beginning. These questions will help us to understand whether the scenario was clearly written.

1. The colleague who is returning to work was:

$\square$ on leave for depression

$\square$ on leave for anxiety

on leave for surgery

Not sure

2. The colleague who is returning to work will be:

$\square$ returning to normal duties and work schedule

getting extra time for detailed tasks and time off for appointments 


\section{Not sure}

\section{Experience with mental health problems}

Open-ended item created for the present research.

Could you describe any experiences you have had with colleagues who have returned to work after taking leave for a mental health problem? What did you think and feel when that colleague returned to work? Please remember not to identify any individual coworkers or yourself in your answer.

\section{Demographics}

This final section asks a few more demographic questions to help us describe our research participants. Please skip any items you are uncomfortable answering.

1. What age are you?

2. What is your gender?

$\square$ Man

Woman

Non-binary / I prefer not to specify

3. What is your highest level of education?

High school

College diploma

Bachelor's degree

Graduate degree (e.g. Master's, PhD)

$\square$ Professional Designation (e.g. Engineering, Law, Medicine)

Other (please specify) [Text box provided]

4. What area of work are you employed in?

$\square$ Client contact centre
$\square$ Health care practitioners
$\square$ Federal regulators
$\square$ Compliance, inspection and
enforcement
$\square$ Communications or public affairs
$\square$ Access to information and privacy
$\square$ Security
$\square$ Science and technology
$\square$ Library services
$\square$ Legal services
$\square$ Administration and operations
$\square$ Human resources
$\square$ Financial management

$\square$ Procurement
$\square$ Real property
$\square$ Materiel management
$\square$ Information management
$\square$ Information technology
$\square$ Internal audit
$\square$ Evaluation
$\square$ Data sciences
$\square$ Policy
$\square$ Project management
$\square$ Software Development
$\square$ Computer System
$\quad$ Administration
$\square$ Other services to the public
$\square$ Other

5. How many years have you been in the paid workforce? 
6. What is your current work status?

$\square$ Full-time (37.5 hours or more per week)

$\square$ Part-time (less than 37.5 hours per week)

7. Do you currently supervise others?

$\square$ Yes

$\square$ No 


\section{Appendix D. Study 1 Follow-up Information}

More information on accommodations: Job accommodations are intended to help individuals return to work following a leave of absence or remain at work during periods of symptom exacerbation. The period of time after an employee returns to work can be difficult with changes and adjustments for everyone involved. Research suggests that supportive coworkers can be important to the success of job accommodations. Less is known, however, about the factors that influence attitudes and emotional responses of coworkers towards mental health problems such as depression or anxiety. Because depression and anxiety are leadings contributor to disability, it is important to understand how to implement accommodations in a manner that is constructive for both individuals with these conditions and the coworkers who support them.

What are we trying to learn in this study? In this study, you were asked to read a scenario about a fictitious colleague who was returning to work after a leave of absence for health reasons. Each participant randomly received one of six scenarios, which varied the reason for the leave of absence (depression vs anxiety vs surgery) and whether the colleague received a job accommodation or not. All participants were then asked to answer the same survey items on attitudes, emotional responses, and willingness to spend time with the colleague described in the scenario. By comparing responses across these conditions, we can see if participants responded differently to the different scenarios.

Where can I learn more? There are several online resources to learn more about mental health in the workplace and job accommodations.

For American participants, please visit: https://askjan.org/

For Canadian participants, please visit: https://www.chrc-ccdp.gc.ca/eng/content/what-duty-accommodate

https://www.workplacestrategiesformentalhealth.com

What if I have questions later? If you have any remaining concerns, questions, or comments about the experiment, please feel free to contact Christine Tulk (Principal Investigator) at christine.tulk@carleton.ca or Dr. Janet Mantler (Faculty Sponsor) at janet.mantler@carleton.ca. If you have any ethical concerns with the study (Clearance \# 110147), please contact Dr. Bernadette Campbell, Chair, Carleton University Research Ethics Board-B (by phone at 613-520-2600 ext. 4085 or via email at ethics@carleton.ca). 


\section{Appendix E. Supplementary Tables}

Table E1. Means and Standard Deviations by Accommodation for Surgery (Study 1)

\begin{tabular}{lccccc}
\hline & \multicolumn{2}{c}{$\begin{array}{c}\text { No Accommodation } \\
(\mathrm{n}=55)\end{array}$} & & \multicolumn{2}{c}{$\begin{array}{c}\text { Accommodation } \\
(\mathrm{n}=75)\end{array}$} \\
\cline { 2 - 3 } \cline { 5 - 6 } \cline { 5 - 6 } Malingering & $\mathrm{M}$ & $\mathrm{SD}$ & & $\mathrm{M}$ & $\mathrm{SD}$ \\
Ability & 2.05 & 0.94 & & 2.06 & 0.78 \\
Blameworthy & 3.76 & 0.76 & & 3.81 & 0.73 \\
Dangerous & 2.08 & 0.81 & & 2.02 & 0.78 \\
Unfairness & 1.80 & 0.78 & & 1.79 & 0.72 \\
Anger & 2.25 & 0.92 & & 2.22 & 0.94 \\
Fear & 1.38 & 0.60 & & 1.33 & 0.69 \\
Sympathy & 1.49 & 0.60 & & 1.58 & 0.82 \\
Recommend & 3.82 & 1.11 & & 3.76 & 1.06 \\
Socialize & 3.47 & 1.03 & & 3.60 & 0.97 \\
\hline
\end{tabular}

Table E2. Means and Standard Deviations by Accommodation for Depression (Study 1)

\begin{tabular}{lccccc}
\hline & \multicolumn{2}{c}{$\begin{array}{c}\text { No Accommodation } \\
(\mathrm{n}=60)\end{array}$} & & \multicolumn{2}{c}{$\begin{array}{c}\text { Accommodation } \\
(\mathrm{n}=57)\end{array}$} \\
\cline { 2 - 3 } \cline { 5 - 6 } \cline { 5 - 6 } Malingering & $\mathrm{M}$ & $\mathrm{SD}$ & & $\mathrm{M}$ & $\mathrm{SD}$ \\
Ability & 2.03 & 0.95 & & 2.25 & 0.98 \\
Blameworthy & 3.64 & 0.68 & & 3.58 & 0.77 \\
Dangerous & 2.20 & 0.94 & & 2.13 & 1.01 \\
Unfairness & 2.27 & 0.86 & & 2.26 & 0.85 \\
Anger & 2.37 & 0.90 & & 2.36 & 0.98 \\
Fear & 1.42 & 0.83 & & 1.33 & 0.64 \\
Sympathy & 1.60 & 0.87 & & 1.58 & 0.72 \\
Recommend & 3.82 & 1.13 & & 3.89 & 1.10 \\
Socialize & 3.63 & 0.98 & & 3.53 & 0.98 \\
\cline { 1 - 2 } & 3.99 & 0.71 & & 3.98 & 0.73 \\
\hline
\end{tabular}

Table E3. 
Means and Standard Deviations by Accommodation for Anxiety (Study 1)

\begin{tabular}{lccccc}
\hline & \multicolumn{2}{c}{$\begin{array}{c}\text { No Acommodation } \\
(\mathrm{n}=55)\end{array}$} & & \multicolumn{2}{c}{$\begin{array}{c}\text { Accommodation } \\
(\mathrm{n}=60)\end{array}$} \\
\cline { 2 - 3 } \cline { 5 - 6 } & $\mathrm{M}$ & $\mathrm{SD}$ & & $\mathrm{M}$ & $\mathrm{SD}$ \\
\hline Malingering & 1.99 & 1.00 & & 2.00 & 0.82 \\
Ability & 3.50 & 0.76 & & 3.53 & 0.89 \\
Blameworthy & 2.42 & 1.17 & & 2.13 & 0.81 \\
Dangerous & 2.27 & 0.86 & & 2.17 & 0.78 \\
Unfairness & 2.48 & 0.86 & & 2.23 & 0.92 \\
Anger & 1.47 & 0.92 & & 1.29 & 0.46 \\
Fear & 1.58 & 0.70 & & 1.52 & 0.55 \\
Sympathy & 3.64 & 1.11 & & 3.55 & 1.19 \\
Recommend & 3.23 & 1.09 & & 3.32 & 0.87 \\
Socialize & 3.72 & 0.89 & & 3.83 & 0.76 \\
\hline
\end{tabular}

Table E4.

Hierarchical Regression Analysis for Unfair (Study 1)

\begin{tabular}{lcccc}
\hline & \multicolumn{4}{c}{ Unfair } \\
\cline { 2 - 5 } & $\Delta R^{2}$ & $B$ & $S E$ & $\beta$ \\
\hline Step 1 & $.04^{*}$ & & & \\
Gender & & -0.16 & 0.10 & -0.09 \\
Supervisor & & $0.25^{*}$ & 0.10 & 0.13 \\
Depression & & 0.13 & 0.12 & 0.07 \\
Anxiety & & 0.14 & 0.12 & 0.07 \\
Accommodation & & -0.07 & 0.10 & -0.04 \\
Step 2 & .003 & & & \\
$\quad$ Depression x & & 0.03 & 0.23 & 0.01 \\
$\quad$ Accommodation & & & & \\
Anxiety x & & -0.19 & 0.24 & -0.08 \\
$\quad$ Accommodation & & & & \\
\hline
\end{tabular}

Notes. Gender coded $0=$ male, $1=$ female. Supervisor coded $0=$ no, $1=$ yes. Depression and anxiety dummy-coded with surgery as reference. Accommodation coded $0=$ no, $1=$ yes. $* p<.05 . * * p<.01 . * * * p<.001$.

Table E5. 
Means and Standard Deviations for Surgery (Study 2)

\begin{tabular}{|c|c|c|c|c|c|c|c|c|}
\hline & \multicolumn{4}{|c|}{ No Accommodation } & \multicolumn{4}{|c|}{ Accommodation } \\
\hline & \multicolumn{2}{|c|}{$\begin{array}{l}\text { No Info } \\
(\mathrm{n}=15)\end{array}$} & \multicolumn{2}{|c|}{$\begin{array}{c}\text { Info } \\
(\mathrm{n}=14)\end{array}$} & \multicolumn{2}{|c|}{$\begin{array}{l}\text { No Info } \\
(\mathrm{n}=19)\end{array}$} & \multicolumn{2}{|c|}{$\begin{array}{c}\text { Info } \\
(n=20)\end{array}$} \\
\hline & $M$ & SD & $\mathrm{M}$ & SD & M & $\mathrm{SD}$ & $\mathrm{M}$ & SD \\
\hline Malingering & 1.77 & 0.59 & 1.57 & 0.51 & 1.71 & 0.58 & 1.53 & 0.60 \\
\hline Ability & 3.53 & 0.48 & 3.68 & 0.85 & 3.95 & 0.52 & 3.95 & 0.63 \\
\hline Blameworthy & 1.55 & 0.60 & 1.52 & 0.54 & 1.47 & 0.64 & 1.55 & 0.57 \\
\hline Dangerous & 1.40 & 0.54 & 1.43 & 0.56 & 1.44 & 0.61 & 1.57 & 0.70 \\
\hline Unfairness & 1.97 & 0.64 & 1.82 & 0.72 & 1.74 & 0.63 & 1.78 & 0.66 \\
\hline Anger & 1.31 & 0.37 & 1.07 & 0.14 & 1.16 & 0.28 & 1.42 & 0.67 \\
\hline Fear & 1.82 & 0.60 & 1.31 & 0.38 & 1.69 & 0.75 & 1.82 & 0.91 \\
\hline Sympathy & 3.60 & 0.63 & 3.57 & 1.02 & 4.05 & 0.62 & 3.84 & 1.01 \\
\hline Recommend & 3.67 & 0.72 & 3.93 & 0.83 & 3.58 & 1.07 & 3.75 & 0.79 \\
\hline Socialize & 3.94 & 0.45 & 4.02 & 0.46 & 3.87 & 0.75 & 3.94 & 0.57 \\
\hline
\end{tabular}

Table E6.

Means and Standard Deviations for Depression (Study 2)

\begin{tabular}{|c|c|c|c|c|c|c|c|c|}
\hline & \multicolumn{4}{|c|}{ No Accommodation } & \multicolumn{4}{|c|}{ Accommodation } \\
\hline & \multicolumn{2}{|c|}{$\begin{array}{l}\text { No Info } \\
(\mathrm{n}=18) \\
\end{array}$} & \multicolumn{2}{|c|}{$\begin{array}{c}\text { Info } \\
(\mathrm{n}=15)\end{array}$} & \multicolumn{2}{|c|}{$\begin{array}{l}\text { No Info } \\
(\mathrm{n}=20)\end{array}$} & \multicolumn{2}{|c|}{$\begin{array}{c}\text { Info } \\
(\mathrm{n}=18)\end{array}$} \\
\hline & M & SD & M & $\mathrm{SD}$ & M & SD & M & $\mathrm{SD}$ \\
\hline Malingering & 1.53 & 0.67 & 1.50 & 0.76 & 1.52 & 0.55 & 1.61 & 0.63 \\
\hline Ability & 3.69 & 0.71 & 3.97 & 0.79 & 3.70 & 0.66 & 3.75 & 0.65 \\
\hline Blameworthy & 1.47 & 0.69 & 1.30 & 0.63 & 1.36 & 0.53 & 1.71 & 0.74 \\
\hline Dangerous & 1.87 & 0.63 & 1.71 & 0.73 & 1.68 & 0.63 & 1.93 & 0.67 \\
\hline Unfairness & 2.03 & 0.85 & 1.77 & 0.65 & 1.65 & 0.61 & 1.94 & 0.70 \\
\hline Anger & 1.28 & 0.37 & 1.49 & 0.82 & 1.15 & 0.20 & 1.19 & 0.23 \\
\hline Fear & 1.80 & 0.78 & 1.78 & 0.74 & 1.50 & 0.50 & 1.67 & 0.67 \\
\hline Sympathy & 3.67 & 0.91 & 4.07 & 0.80 & 3.70 & 1.17 & 3.67 & 1.08 \\
\hline Recommend & 3.61 & 0.78 & 3.93 & 1.16 & 3.55 & 0.76 & 3.44 & 0.86 \\
\hline Socialize & 4.04 & 0.74 & 4.25 & 0.66 & 4.17 & 0.59 & 3.97 & 0.60 \\
\hline
\end{tabular}

Table E7. 
Means and Standard Deviations for Anxiety (Study 2)

\begin{tabular}{|c|c|c|c|c|c|c|c|c|}
\hline & \multicolumn{4}{|c|}{ No Accommodation } & \multicolumn{4}{|c|}{ Accommodation } \\
\hline & \multicolumn{2}{|c|}{$\begin{array}{l}\text { No Info } \\
(\mathrm{n}=16) \\
\end{array}$} & \multicolumn{2}{|c|}{$\begin{array}{c}\text { Info } \\
(\mathrm{n}=15)\end{array}$} & \multicolumn{2}{|c|}{$\begin{array}{l}\text { No Info } \\
(\mathrm{n}=19) \\
\end{array}$} & \multicolumn{2}{|c|}{$\begin{array}{c}\text { Info } \\
(\mathrm{n}=18)\end{array}$} \\
\hline & M & $\mathrm{SD}$ & M & $\mathrm{SD}$ & M & $\mathrm{SD}$ & M & $\mathrm{SD}$ \\
\hline Malingering & 1.47 & 0.64 & 1.77 & 0.59 & 1.61 & 0.70 & 1.69 & 0.71 \\
\hline Ability & 3.88 & 0.67 & 3.70 & 0.62 & 3.92 & 0.75 & 3.53 & 0.55 \\
\hline Blameworthy & 1.38 & 0.57 & 1.68 & 0.75 & 1.63 & 0.82 & 1.43 & 0.70 \\
\hline Dangerous & 1.87 & 0.48 & 2.07 & 0.77 & 1.84 & 0.69 & 1.70 & 0.55 \\
\hline Unfairness & 1.72 & 0.36 & 1.67 & 0.59 & 1.76 & 0.67 & 1.86 & 0.78 \\
\hline Anger & 1.10 & 0.20 & 1.13 & 0.28 & 1.12 & 0.23 & 1.22 & 0.40 \\
\hline Fear & 1.79 & 0.65 & 1.56 & 0.39 & 1.37 & 0.46 & 1.63 & 0.60 \\
\hline Sympathy & 4.31 & 0.48 & 3.93 & 0.96 & 3.79 & 1.13 & 4.17 & 0.99 \\
\hline Recommend & 4.06 & 0.85 & 3.53 & 0.64 & 3.58 & 0.84 & 3.94 & 0.87 \\
\hline Socialize & 4.37 & 0.49 & 4.05 & 0.44 & 4.05 & 0.73 & 4.12 & 0.71 \\
\hline
\end{tabular}


Table E8.

Hierarchical Regression Analysis for Unfairness (Study 2)

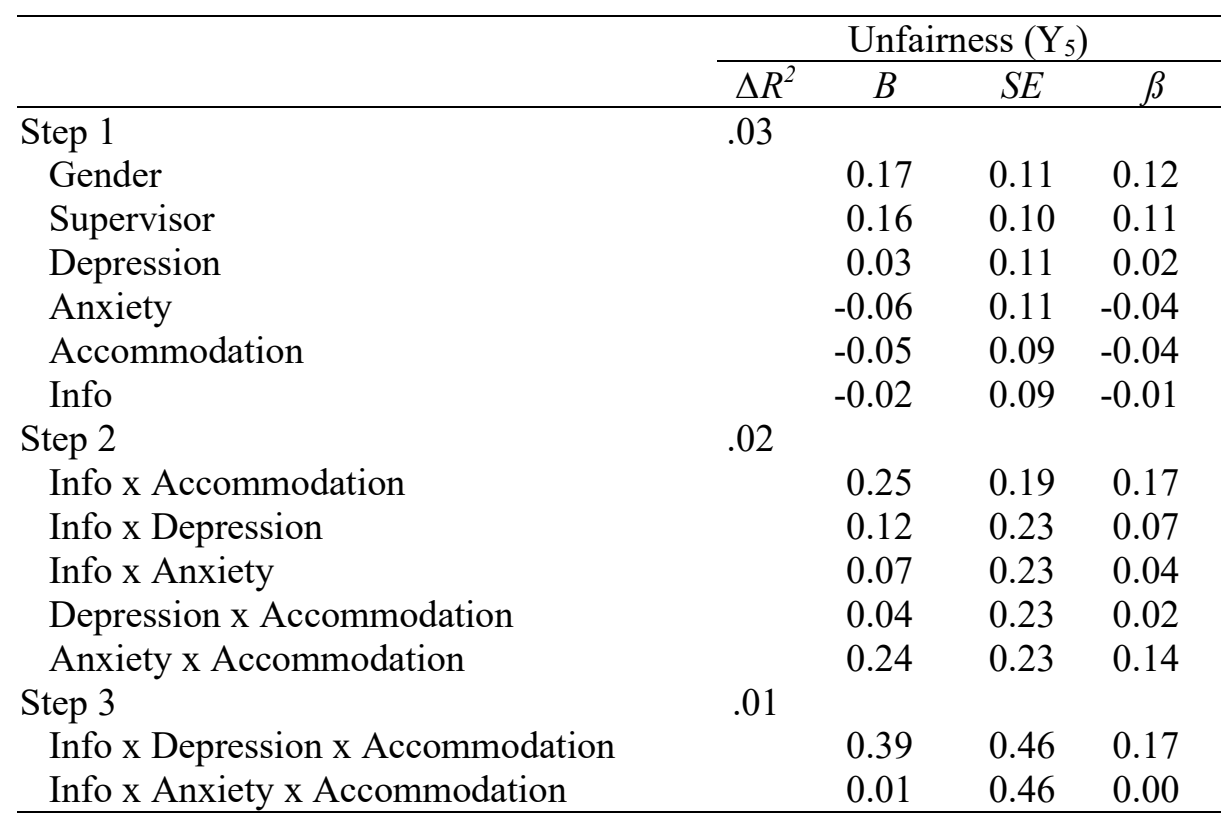

Notes. Gender coded $0=$ male, $1=$ female. Supervisor $\operatorname{coded} 0=$ no, $1=$ yes.

Depression and anxiety dummy-coded with surgery as reference.

Accommodation coded $0=$ no, $1=$ yes. Info coded $0=$ no, $1=$ yes.

$* p<.05 . * * p<.01 . * * * p<.001$. 


\section{Appendix F. Study 2 Recruitment Notice}

\section{Workplace Health and Accommodations Research Study}

You are invited to participate in an online research study being conducted by Christine Tulk as part of her Master of Arts thesis in Psychology at Carleton University. After reading a short scenario about a fictitious colleague who will soon be returning to work following a leave of absence, you will be asked to answer survey items regarding your attitudes and emotional responses towards the colleague and situation described in the scenario. You will also be asked some demographics. Participation is completely anonymous and will take 10-12 minutes.

The period of time after an employee returns to work after a leave of absence for mental or physical health reasons can be difficult with changes and adjustments for everyone involved. The results of this research will help us to better understand how to improve this transition period. For more information, you can email Christine.Tulk@carleton.ca (Master's student) or Janet.Mantler@carleton.ca (Faculty Supervisor, Department of Psychology, Carleton University)

Clicking on the link below will take you to the Qualtrics online survey platform. You can choose to participate in English or French by selecting the language in the dropdown box in the upper right corner.

\section{https://carletonpsych.co1.qualtrics.com/jfe/form/SV 9S0V59uXmgJYhvf}

This study has received clearance by the Carleton University Research Ethics Board-B (Protocol \# 110147). 


\section{Appendix G. Study 2 Consent Information}

Thank you for taking the time to consider participating in this research study! The intent of this consent information is to ensure that you understand the purpose of the study in order for you to determine whether you wish to participate.

Purpose: In this study, we want to learn more about attitudes you may have towards coworkers who return to work following a leave of absence for mental or physical health reasons.

Task Requirements: After reading a short scenario about a fictitious coworker who will soon be returning to work following a leave of absence, you will be asked to answer survey items regarding your attitudes and emotional responses towards the coworker and situation described in the scenario. Additionally, you will be asked about some of your individual characteristics and demographics. The survey will take 10-12 minutes to complete.

Possible Benefits and Risks: We do not anticipate any direct benefit from your participation in this study. However, your participation may allow researchers to better understand what factors influence attitudes towards individuals returning to work after a leave of absence. We also do not anticipate any risks from taking this survey. If you feel any discomfort or distress at any point, you may choose to skip any questions you are not comfortable answering.

No waiver of your rights: By agreeing to this research, you are not waiving any rights or releasing the researchers from any liability.

Right to withdraw: Your participation is voluntary, and you have the right to end your participation at any point during the survey. If you choose to withdraw, you may skip to the end of the survey to read more information on the study or you may close the survey window. Incomplete survey responses will be deleted. You will not be able to withdraw your data after completing the survey because there are no personal identifiers collected in the survey.

Anonymity/Confidentiality: Participation in this survey is anonymous. No personal identifiers such as names or IP addresses will be collected by Qualtrics. All data will be stored on Toronto-based servers and in password-protected files. Research records may be accessed by the Carleton University Research Ethics Board in order to ensure continuing ethics compliance. After the study is completed, research data will be retained for future use and may be used for academic presentations, publications, and teaching. If requested, the anonymous data may be shared in online data repositories.

REB Review and Contact Information: This project was reviewed and cleared by the Carleton University Research Ethics Board-B (Clearance \# 110147). If you have any ethical concerns with the study, please contact Dr. Bernadette Campbell, Chair by phone 
at $613-520-2600$ ext. 4085 or by email at ethics@carleton.ca.

Researcher contact information:

Name: Christine Tulk

Position: Master's Student

Department: Psychology

Carleton University

Email: christine.tulk@carleton.ca
Supervisor contact information:

Name: Dr. Janet Mantler

Position: Associate Professor

Department: Psychology

Carleton University

Email: janet.mantler@carleton.ca

I voluntarily agree to participate in this study.

$\square$ Yes

No 


\section{Appendix H. Study 2 Follow-up Information}

More information on accommodations: Job accommodations are intended to help individuals return to work following a leave of absence or remain at work during periods of symptom exacerbation. The period of time after an employee returns to work can be difficult with changes and adjustments for everyone involved. Research suggests that supportive coworkers can be important to the success of job accommodations. Less is known, however, about the factors that influence attitudes and emotional responses of coworkers towards mental health problems such as depression or anxiety. Because depression and anxiety are leadings contributor to disability, it is important to understand how to implement accommodations in a manner that is constructive for both individuals with these conditions and the coworkers who support them.

What are we trying to learn in this study? In this study, you were asked to read a scenario about a fictitious colleague who was returning to work after a leave of absence for health reasons. Each participant randomly received one of six scenarios, which varied the reason for the leave of absence (depression vs anxiety vs surgery) and whether the colleague received a job accommodation or not. Half of all participants also received information on the duty to accommodate. All participants were then asked to answer the same survey items on attitudes, emotional responses, and willingness to spend time with the colleague described in the scenario. By comparing responses across these conditions, we can see if participants responded differently to the different scenarios.

Because only half of participants were asked to read information on the duty to accommodate, we are providing the information here: Employees with mental and physical disabilities are protected from discrimination under the Canadian Human Rights Act and the Employment Equity Act. When an employee has a mental or physical health condition that results in a limitation of skills or abilities, employers have a duty to accommodate. This can mean changes to rules or practices that prevent these employees from fully participating in the workplace. This does not mean that an employer is obligated to employ a person who cannot perform essential job functions. This also does not mean lowering standards for job qualifications, which are the skills or attributes that one has to meet for a particular job.

Where can I learn more? To learn more about mental health and job accommodations in the Canadian workplace, please visit: https://www.chrc-ccdp.gc.ca/eng/content/what-duty-accommodate https://www.workplacestrategiesformentalhealth.com

What if I have questions later? If you have any remaining concerns, questions, or comments about the experiment, please feel free to contact Christine Tulk (Principal Investigator) at christine.tulk@carleton.ca or Dr. Janet Mantler (Faculty Sponsor) at janet.mantler@carleton.ca. If you have any ethical concerns with the study (Clearance \# 110147), please contact Dr. Bernadette Campbell, Chair, Carleton University Research Ethics Board-B (by phone at 613-520-2600 ext. 4085 or via email at ethics@,carleton.ca). 